\title{
WHEN THE STATE TAKES OVER A LIFE: THE PUBLIC GUARDIAN AS PUBLIC ADMINISTRATOR
}

\author{
By \\ Pamela B. Teaster \\ Dissertation submitted to the Faculty of the \\ Virginia Polytechnic Institute and State University \\ in partial fulfillment of the requirements \\ for the degree of \\ DOCTOR OF PHILOSOPHY \\ in \\ Public Administration and Public Affairs \\ Charles T. Goodsell, Ph.D. \\ Committee Chairman \\ Committee \\ Larkin S. Dudley, Ph.D. \\ William J. McAuley, Ph.D. \\ Gary L. Wamsley, Ph.D. \\ Doris T. Zallen, Ph.D.
}

February 17, 1997

Blacksburg, Virginia

Keywords: Guardianship, Public Administration, Autonomy, Democratic Governance 


\title{
WHEN THE STATE TAKES OVER A LIFE: THE PUBLIC GUARDIAN AS PUBLIC ADMINISTRATOR
}

\author{
by \\ Pamela Booth Teaster \\ Committee Chairman: Charles T. Goodsell, Ph.D. \\ Public Administration and Public Affairs
}

\begin{abstract}
(ABSTRACT)
Public guardians are individuals appointed by the state to care for the interests of incapacitated citizens. The nature and quality of their care is examined at sites in Maryland, Delaware, Tennessee, and Virginia. In the first three states public guardianship programs have been running for at least ten years; in Virginia two pilot projects are currently underway. All sites use different service delivery models. In addition to studying case file notes, public guardians, program supervisors, and wards were observed and interviewed with regard to their background, their views on public guardianship, accountability and effectiveness, and services provided.

The aim of this study is to contribute to a better qualitative understanding of how well state public guardian programs intersect intimately with individuals for whom no other responsible decision maker exists. The study concludes with recommendations regarding the roles of the public guardian in improving wards' quality of life through substitute decision making and in enhancing democratic governance to give voice to wards through their own participation in decision making and relationships with their public guardian.
\end{abstract}




\section{ACKNOWLEDGMENTS}

On a typical day that I did not pack lunch, my husband went to the Lunchbox Restaurant, which has now become a landmark on my personal historic register. It was on that day when John Molumphy, a soon-to-be good friend posed the question, "And what does your wife do?" From that question came an invitation to meet with him on what became numerous occasions, and thus my dissertation topic was ignominiously born.

Writing the dissertation has confirmed my belief that no endeavor is ever accomplished without the support of many caring persons. I know that I could never have completed it without the help of the persons I fondly refer to as dissertation monitors, shepherds, and angels. I have needed them at different times and sometimes all at once.

Monitors are persons with whom I have a formal academic relationship. These persons have guided me by their example and by reading text and listening to ideas. They include public administrators, gerontologists, and in particular, my dissertation committee, without whose thoughtful help I would never be able to complete this project.

Shepherds are special persons who have completed dissertations or like projects themselves. All of these people have unfailingly assisted me in piecing together the ideas that have become this study. Winsor Schmidt helped me grow from a person who knew nothing about guardianship whatsoever to a person who is willing to discuss guardianship with anyone who will listen. I have been privileged to work with him on the state evaluation project during the entire course of the dissertation. Jim McAuley encouraged me and never stopped his encouragement. He has been my mentor in every conceivable way, and because of him I call myself a gerontologist. Charles Goodsell, my chair, helped me discover my life's research path and find my own voice in public administration. He has tirelessly edited drafts and made insightful, thought-provoking comments; I am forever indebted to him.

My angels have hovered around with comfort and words of encouragement. They have helped me when the going was tough and showed up when I needed them, edited, and listened. They are a heavenly host: Phyllis Greenberg, Michelle Hoffmann, Kathy Stadler, Harriette Shivers, John Molumphy, Kenneth Witt, Fred Campbell, Linda Barrett, Kevin McCullough, Olivia Dooley, Joyce and Pete Teaster, Hillel Abramson, Janet Neal, Carol Broadhurst, and Bob Copenhaver. My parents, John and Doris Booth, unfailingly gave me love and support; they persisted through early mornings, late nights, expensive telephone bills, and rearranged schedules. Wiser than I can ever hope to be, they know that parenting never ends.

To my guardian angel I must give the most credit, and he is my husband, Gerald. My attempt to list his ways of helping would denigrate all that he did and continues to do. From him I have learned the true meaning of soulmate, a scholarship that I will continue throughout the days of my life. 


\section{CONTENTS}

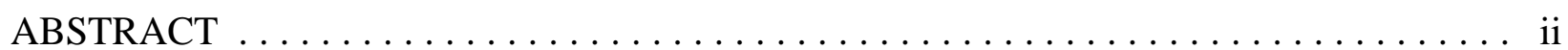

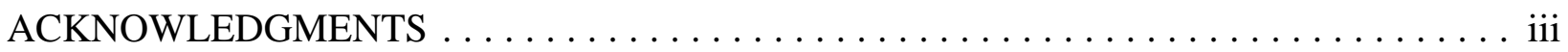

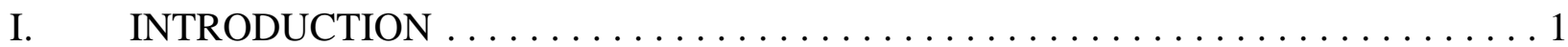

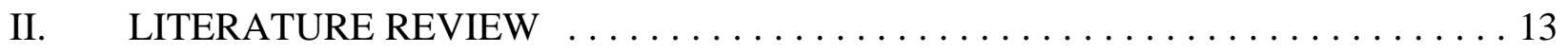

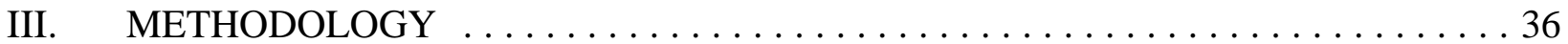

IV. BACKGROUND AND EFFORTS OF PUBLIC GUARDIANS $\ldots \ldots \ldots \ldots \ldots . . .49$

V. PROGRAM SUPERVISORS AND GUARDIANSHIP . . . . . . . . . . . . . . 79

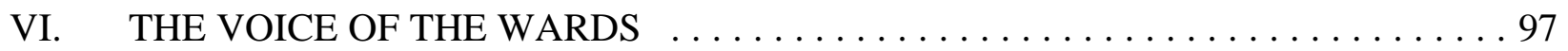

VII. CONCLUSIONS AND RECOMMENDATIONS $\ldots \ldots \ldots \ldots \ldots \ldots \ldots \ldots \ldots$

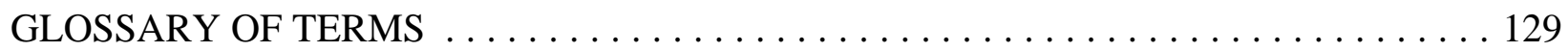

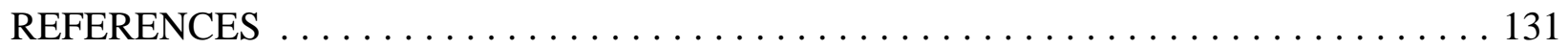

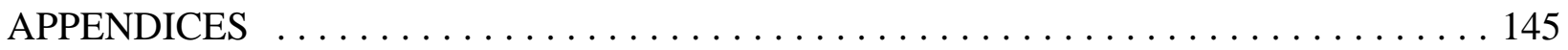

A. RESEARCH PROTOCOLS AND INFORMED CONSENT DOCUMENTS $\ldots \ldots 145$

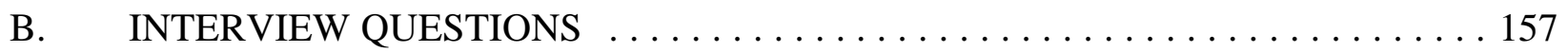

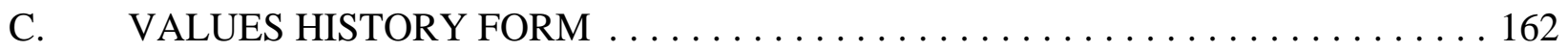

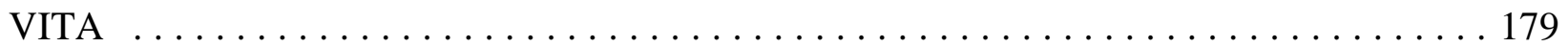




\section{TABLES}

1. BACKGROUND OF PUBLIC GUARDIANS $\ldots \ldots \ldots \ldots \ldots \ldots \ldots \ldots \ldots \ldots$

2. BACKGROUND OF PROGRAM SUPERVISORS $\ldots \ldots \ldots \ldots \ldots \ldots$

3. CHARACTERISTICS OF WARDS WHO WERE INTERVIEWED AND

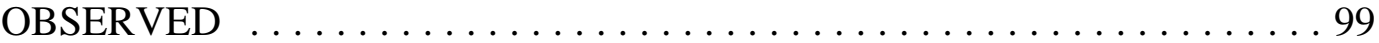

4. CHARACTERISTICS OF WARDS WHO WERE UNABLE TO

COMMUNICATE CLEARLY . . . . . . . . . . . . . . . . . . . . 100 


\section{CHAPTER I}

\section{INTRODUCTION}

This is the way we were: in our growing up and in our marrying and in our living and in our dying.

Thornton Wilder

The imposition of guardianship is an extremely intrusive act by the state. When an adjudication of plenary (total) guardianship based on incompetency or incapacity ${ }^{1}$ is made, an individual loses virtually all his or her rights, including the right to vote, to change locations, to marry, to control financial decisions, to transfer property, and to make health care decisions. The legal authority of a guardian resembles that of a parent over a child and is just as binding. Although legislation that restricts guardianship powers has been refined in many states, partial or limited guardianships are rarely employed by the courts. Advocates for the rights of persons have pressed for revisions in guardianship laws, procedures, and standards since the 1960s.

Guardianship has undergone general statutory changes, particularly in this century, attributable largely to three factors. First, older persons, as they live longer, tend to be candidates for guardianship due to chronic mental and/or physical impairments, especially prevalent in the 85 plus population. Second, medical technologies are extending the lifespan significantly. However, because medical technologies have advanced, quality of life issues arise. Although an individual is able to live longer, does he or she want to live longer if to do so is merely to exist? What complexities accompany increasing the life span, and are individuals, families, or society ready to reach a consensus regarding them? Third, because of the focus on civil rights issues in the 1960s, the rights of such groups as older persons, women, and the mentally ill have come to the forefront in policy debate (Barnes, 1992).

Though any adult may have a legally appointed guardian, guardianship disproportionately affects older persons (Alexander, 1990) and often operates on the concept that older persons as a group are in need of protection (Horstman, 1975). It also affects persons with mental illness, mental retardation, and developmental disabilities, as well as those who are homeless, or in the end stages of HIV. Generally, public guardians (who are of last resort) serve as guardians when family members are inappropriate or warring, for indigent persons, and for

${ }^{1}$ Great confusion exists in medical and legal practice regarding the terms incompetency and incapacity. Currently incapacity is the preferred term, as it avoids the yes or no distinction of incompetency, as well as its historical trappings (See Sabatino, 1996). The terms will be used interchangeably in this dissertation. 
clients who are labeled as social deviants and are in need of therapeutic intervention by the state (Kittrie, 1971).

Little wonder that such an intrusive act has come under intense scrutiny. Although many guardians function with the greatest of concern for the ward, many wards have suffered injustice at the hands of unscrupulous guardians. The state itself has denied to citizens due process rights in order to fulfill its role as parens patriae, or "father of his country" (Barnes, 1992). The duty of the state to protect persons from presenting a harm to themselves or to others exists in tension with the right of an individual to freedom from unnecessary government intervention, i.e., the right to self-determination to live life and make decisions regarding one's person and property.

Guardianship conflicts with the normative value of personal liberty; in public guardianship the government subsumes individual rights under its parens patriae power in order to protect persons who are unable to care for or make decisions for themselves. Literature concerning guardianship, particularly the legal literature, is heavily weighted toward the preservation of individual self-determination (Alexander, 1990; Barnes, 1992; Horstman, 1975; Regan, 1972), while the medical literature favors promotion of what is in an individual's best interest (Callahan, 1984; Buchanan \& Brock; 1986; Dickens, 1989; Veatch, 1984).

The concept of autonomy receives its definition from the 18th century moral philosopher Immanuel Kant, who interpreted it to mean the ability of an individual to be governed by selfauthored laws (Dubler, 1987). Autonomy or freedom in action and decision is regarded as an ultimate good, while beneficence or "doing good," often linked with paternalism, has a negative connotation. Ethical considerations of autonomy and beneficence have evolved with the advent of modern medicine, due to the increase in lifespan as well as new medical options for treatment. Once content to agree to whatever physicians recommended, patients are increasingly more knowledgeable than they were in the past about their own health and treatment options. Today patients are surviving diseases and living longer; they have fewer acute illnesses and more chronic illnesses. Thus, they have more time to learn about their medical problems and make more informed decisions. This view of decision making, together with the Nuremberg Code (1947) concerning human experimentation, has dramatically altered the physician/patient relationship. Physicians are bound, at least in most instances, to respect the wishes of competent patients regarding treatment decisions. Respect for the wishes of competent patients was extended, through a number of court cases, to include respect for the wishes of incapacitated patients (In re Quinlan, 1976; Cruzan vs. Director, Missouri Department of Health, 1990).

\section{THE GUARDIANSHIP PROCESS}

All states have statutory provisions concerning guardianship, which are grounded in Roman civil law and English common law (Horstman, 1975). These general provisions concern the capacity of individuals to make decisions regarding their property, their person, or both. The state intervenes when the ability of a person to make reasoned decisions comes into question. 
When a person is thought to lack the capacity to make certain decisions, a petitioner requests a court hearing. The court makes a determination regarding competency, defined as the ability of an individual to handle personal care and financial affairs, and whether this inability appears fairly permanent (Molumphy \& Shivers, 1994). The court petition is usually brought forward by a relative or friend of the alleged incapacitated person, but other actors may also bring forward a petition: departments of social services, hospitals, nursing facilities, adult protective services agencies, and some public guardianship agencies.

The court provides notice of the hearing to the alleged incapacitated person. However, court notices for hearings can be fraught with legalese and thus incomprehensible, even to competent persons. An example of a hearing notice follows:

At or before 10 A.M. of the Monday next after the expiration of 10 days after the date of service of this citation by filing a written answer to the application of (petitioner) filed in said court on the (date) alleging said ward has no guardian and praying for the appointment of the persons and estate of said ward. At said above mentioned time and place, said ward and all other persons may contest said application if they so desire. (Richmond Times-Dispatch, Sept. 21, 1987)

Proposed wards, or alleged incompetent persons, are not necessarily required to appear at the hearing, and many states do not provide legal representation for them, even if they are indigent. The presence of potential wards is waived if it is determined that they could be harmed by attendance at the hearing. Many wards never know that they may attend or contest their hearing, resulting in the uncomfortable position, from the standpoint of civil liberties, that wards do not know that they have lost their civil rights. Additional problems exist if the ward should return to competency at some future date, for guardianships are notoriously difficult to overturn. Further, a determination of incompetency carries with it a tremendous burden on wards--one of stigmatization, even if the court determines that a proposed ward is competent (Alexander, 1985; Horstman, 1975).

In this largely non-adversarial hearing (some take no more than five minutes to take citizenship rights away), a judge makes a determination of whether or not individuals are competent to make decisions regarding their finances, their person, or both. Evidentiary rules do not apply in many hearings. Determinations of incapacity often turn on the written statement of a medical expert or a petition stating that the ward seems confused. Still in some states, persons can be declared incapacitated merely because they are of advanced age. Although age-related statutes are changing across the nation, insidious examples of ageism may prevent the judiciary from implementing necessary statutory reforms (Hurme, 1994; Keith \& Wacker, 1994).

The petitioner is represented by legal counsel, and the person, also generally an attorney, who determines the best interests of the alleged incompetent person, is designated as the 
guardian ad litem ${ }^{2}$. A determination by the guardian ad litem includes who would be the best guardian of the alleged incompetent person and his or her types of limitations. However, the guardian ad litem does not advocate for the potential ward. The guardian ad litem may determine that it is in the potential ward's best interest to have a plenary guardianship (including guardianship of the person and of the estate), while the potential ward may strenuously object to having a particular guardian and be justified in doing so. The role of the guardian ad litem in the hearing to establish guardianship is not clearly defined, and some states do not use the concept at all (Morrisey, 1982).

\section{PROBLEM STATEMENT}

Reforms of guardianship laws and processes have been proposed through state code revision; however, in spite of attempts to make reforms in the guardianship process, little data exist on the implementation of changes to the system (Keith \& Wacker, 1994). Additionally, little information is available on the benefit to the wards of having a guardianship; research indicates that the majority of guardianships are instituted for the benefit of the guardian rather than for the ward (Alexander, 1985; Cohen, 1978; Horstman, 1975; Regan, 1981).

A number of attorneys or private citizens usually come forward to be guardians of persons with significant estates $(\$ 50,000$ or higher). However, many alleged incapacitated persons have no one who is willing to assume guardianship. Such persons are sometimes referred to as the unbefriended (Kapp, presentation, November 18, 1996). They are often indigent, difficult behaviorally, have no one who is willing to make decisions on their behalf, or have persons willing to assume guardianship for whom there is an obvious conflict of interest (i.e., preserving the estate to the detriment of the ward). To address this unmet need, public guardianship has arisen as a last resort.

\section{Public Guardianship}

A public guardian is defined as an official appointed by a state or local government or court whose duty it is to serve incompetent persons lacking relatives or friends appropriate to serve as guardian (Schmidt, Miller, Bell, \& New, 1981). Public guardianship occurs in a variety of models and statutorily exists in approximately 42 states (Schmidt, presentation, March 25, 1996). The four distinct models are (a) an independent state public guardianship agency, (b) a government agency also providing social service, (c) government employees (sheriff, administrator, or judge) not providing social services, who must assume guardianship when there is no one to do so, and (d) the private sector via volunteers or county or state contracts with nonprofit or for-profit institutions (Regan \& Springer, 1977; Schmidt, Miller, Bell, \& New, 1981;

${ }^{2}$ Guardian ad litem translates as guardian to or of the suit. 
Siemon, Hurme, \& Sabatino, 1993). Variations among and between systems and governmental codes make them difficult to identify and compare.

Though many courts regard public guardians as preferable to private guardians, public guardianship is not a panacea for resolving the abuses and dilemmas of private guardians. Public guardianship programs such as the Public Guardian of Los Angeles County and the public guardian in Chicago have been plagued by problems. The public guardian in California placed inordinate numbers of wards into institutions. The public guardian in Chicago was found guilty of embezzling money from the estates of several wards; she forged records to reflect client visits that were never made or were made to wards who were deceased (Schmidt, Miller, Bell, \& New, 1981).

Public guardians are often assigned enormous caseloads (as high as 1:341), compared to a suggested maximum ratio of one case worker to thirty-three wards (Schmidt, Miller, Bell, \& New, 1981). Unreasonably high caseloads make it difficult to address even minimal needs of the ward. Funding is generally inadequate for programs that are instituted. Conflict of interest problems exist when public guardians are housed in an agency that also provides direct services to wards. Finally, there is often little oversight of the public guardian, and few priorities are established for their complex mission (Dudovitz, 1985).

\section{Theoretical Grounding}

Because of its inherent problems, many states as well as countries abroad are wrestling with the complexities of guardianship issues. Demographic trends underscore the immediate need to evaluate and refine a system to which rising numbers of persons will need access in this century and the next. Population projections suggest that more guardians and more alternatives to guardianship will also be required to assist needful populations. The tension exists between the duty of the state to intervene in the lives of persons in order to prevent them from being a harm to themselves and the duty of the state to enhance their autonomy and allow them to live in the least restrict environment possible.

Public guardianship is on the horns of the dilemma between the tension. Guardianship should be avoided at all costs because of the unrelenting restrictions that it places on an individual but rarely ever cedes. Public guardianship is of last resort by its very nature, and public guardianship agencies must have as their goal to put themselves out of business. They must work to divert guardianship rather than encourage it. They must work to provide the least restrictive services possible, and, therefore, maximize a ward's autonomy in decision making regarding the course of his or her life.

Another important consideration is the highly personal and atypical nature of guardianship. Each case presents a unique set of circumstances that makes the decisions of the surrogate on behalf of a ward individualistic and ill-defined using rules of thumb. Guardianship 
is as unique as an individual life. Public guardianship must deal with problems and issues that do not fit a form, rule book, or a well-thought out definition. Public guardianship must address individuals with complex relationships and needs. Consequently, the state must tailor its services to the specific and contextual needs of individuals. As such, public guardianship compels public administration to develop a theory of the state that is empowering, sensitive to undeserved power, open to variation, enabling, and context specific (Wamsley et al., 1990).

Requirements of the public guardian make this agency unique among agencies. The tasks of the public guardian are frequently at loggerheads with bureaucratic organization. Bureaucracy, in many instances, seeks to control turf, define, promote sameness, and slot people and their problems into lines on a page or boxes to be checked on a form. As Fredrick Taylor (1915) did with his one best way, the state strives to divide a task into its component parts and develop a standard set of tools or operating procedures. The state attempts to be a neutral entity dispensing its even-handed and dispassionate services to its customers. Presently, the state is woefully unequipped to handle the complex issues of public guardianship, for in guardianship, unlike snow removal, education, and welfare, living the decisional life of another person demands attention to how he or she would have lived it, not conformity to the state's definitions and decisions. Therefore, the current structure of the state appears to break down when faced with such mammoth problems, created by the unique preciousness of just one citizen.

Government is geared to mass action, not individual action. No machine models, no three E's of efficiency, economy, and effectiveness, no scientific management principles will begin to address the dilemmas that public guardians must face on a daily and ongoing basis.

Hence, I argue that public guardianship provides an important example of why public administration must move from the current machine model. Instead, public administration must look to a more responsive, reflexive bureaucracy (Dennard, 1994; Evans \& Wamsley, 1996, under review; March \& Olsen, 1995; Stivers, 1993) in which the state addresses the complex needs of an individual. Stivers (1993) sees the potential in public administration for incorporating feminine aspects of leadership, expertise, virtue, and the administrative state. Public administrators can acknowledge their expertise as grounded in empathy and understanding of unique situations. Regarding leadership, this extension of public administration theory rejects hierarchy and promotes shared, democratic leadership. Such a new ontology recognizes that a role of public administrators is that of promoting virtuous citizens and citizen administrators (Cooper, 1991) who bring experience to bear on new situations and respect the values of clients and other actors who are involved. This view of the administrative state recognizes that administrative discretion must be a "power with" rather than a "power over" individuals (Follett, 1918/1965). Finally, this theory for public administration acknowledges phronesis (Aristotle, 1976), or the exercise of practical wisdom. Such wisdom is acquired only by experience with similar situations; it takes into account the decision maker and the effects of the decision on the polity. 
Public guardianship presents unique problems that require the state to be at once empowering and context specific. Applying the machine model of public administration makes a mockery of the goals of public guardianship. Public guardianship presents an avenue through which to expand a new theory for public administration by exploring and examining public administrators' roles in making decisions on behalf of another individual. In making these decisions, public guardians draw on concepts of virtue, leadership, and expertise in a form of public administration that demands responsivity to wards, reflexivity with ward's wishes and values, and representation of the best interests or expressed wishes of the ward. Public guardians must exercise phronesis in order to make the best decisions for their ward and to know which standard of decision making--best interests or substituted judgment--to apply in decision making. Additionally, public administrators as guardians who are as citizens with the rest of us (Cooper, 1991), must consider the lives of others, who are, after all, still citizens of the polity.

In public guardianship, the state intersects intimately with the life of another individual, to the point that the relationship of an administrator to an individual ward mirrors that of a mother to a child. Public guardianship resonates with a theory of public administration that compels the state to be reflexive, responsive, and representative of the citizens for whom it makes decisions. This study expands such a conception of the state by showing that it must practice principles of democratic governance when living the decisional life of another person.

\section{PURPOSE OF THE STUDY}

Because increasing numbers of persons need guardianship or guardianship services, and in spite of the potential for problems, public guardianship has arisen in many states to meet the needs of such individuals in order to fill the widening gap between the need for surrogate decision making and available, committed, and appropriate surrogate decision makers. Frustrated by the variation in public guardianship because of states' enabling legislation, studies are often localized and limited to data concerning one or two programs. Obtaining information and making conclusions are hampered by the diversity in populations and in service delivery models. Little information is available on the need for guardians, how people enter the system, how decisions are made for guardianship (Bulcroft, Kielkropf, \& Tripp, 1991; Iris, 1988), how guardians function, how many guardians are active, and the conditions of wards.

In response to these gaps in information and identified problems, and normatively grounded in a theory of public administration as democratic governance, this study addresses how public guardians meet the needs of wards: the nature of guardian/ward interactions, wards' perceptions of guardianship, public guardians' perceptions of their wards and of public guardianship, and comments and responsibilities of program supervisors. Sources for research 
included case file notes, interviews and participant observations of primary public guardians ${ }^{3}$, their wards, and program supervisors. This study examines the extent to which primary public guardians respect autonomy through surrogate decision making and the least restrictive alternative. Also, it expands on a theory for public administration in which the state is individuating, empowering, contextual, reflexive, responsive, and representative of its citizens and their needs. It explores, by examining public guardianship, why and how public administration should return to principles of democratic governance rather than principles of economy, efficiency, and effectiveness.

\section{RESEARCH METHODOLOGY}

Although studies of guardianship have dealt with such issues as guardian-to-ward ratio, models of guardianship delivery, and the problems and advantages of models of public guardianship, few studies have concerned themselves directly with the intersection of the state and the ward. Addressing this gap in the research literature, this research attempts to answer the primary question, "How do public guardians meet the needs of their wards?" Secondary questions stem from this question. Do public guardians respect the ward's autonomy when possible? Do public guardians provide for the least restrictive alternative? To what extent are the ethical values of autonomy and least restrictive alternative observed? How do public guardians interact with their wards? What is the nature of the interactions? Is the task of the public guardian an appropriate one for the state, given the extremely sensitive role that the state must assume in public guardianship? How are public guardians responsive to and representative of their clients?

\section{Qualitative Research}

Consistent with the research questions, I selected the qualitative method of analysis so that the lived experiences of the actors could be studied. Qualitative research permits each participant to reveal process, perspective, and knowledge as they affect the course of completed action (Rothe, 1994). This type of analysis allows the researcher to study specific issues in depth and detail (Patton, 1990). Analysis of this kind gives voice, at an intimate level, to the perceptions of the participants and the rich contextual fabric of public guardianship.

At each site, I interviewed the ward (if able to communicate), observed the interactions of the ward and the primary public guardian, and interviewed the primary public guardian and the program supervisor. Triangulation of data, or the combination of methodologies in the study

${ }^{3}$ The term primary public guardian or public guardian will be used interchangeably throughout the dissertation to indicate the street-level bureaucrat (Lipsky, 1980) who represents the nexus of the state and the individual. Where appropriate, paid guardians are distinguished from volunteer guardians. 
of the same phenomena or programs, was accomplished through participant observation, semistructured interview questions, and examination of written sources of information such as court petitions and psychological-social information in the ward's case file. Triangulation of data strengthens the study design because

no single method ever adequately solves the problem of rival causal factors. . .Because each method reveals different aspects of empirical reality, multiple methods of observation must be employed. This is termed triangulation. I now offer as a final methodological rule the principle that multiple methods should be used in every investigation (Denzin, 1978, p. 28).

\section{Research Sites in the Field}

I chose sites for data collection in four eastern states: Delaware, Tennessee, Maryland, and Virginia. They were selected for geographical proximity as well as different models of service delivery. The states of Maryland, Delaware, and Tennessee represent public guardianship programs that have been operating for at least ten years. The Commonwealth of Virginia has no statewide program for public guardianship; however, its demonstration projects represent two unique models of service delivery unlike those in the other states. In the states and sites chosen for analysis, the various service delivery models permit another layer for analysis. In Montgomery County, Maryland, the public guardian is located in a Department of Social Service; in Johnson City, Tennessee, the public guardian is a non-profit program associated with the Area Agency on Aging. In Delaware, the Office of the Public Guardian Office is the only state level court model of public guardianship in the country. The demonstration projects in Virginia include a private not-for-profit model, Personal Support Network (PSN), and a volunteer model, Chesapeake Volunteer Guardianship Program (CVGP), which is overseen by a lead agency, the Chesapeake Department of Social Services.

\section{Access to Research Sites}

I gathered preliminary information regarding this research design during a visit to the Maryland public guardian supervisor and a primary public guardian in October 1995; the Maryland state supervisor was also contacted for permission to conduct the initial probe. With Winsor C. Schmidt and Hillel Abramson, both of the University of Memphis, I am evaluating the Virginia demonstration projects for the Virginia Guardianship Association in cooperation with the Virginia Department on Aging. Permission to conduct research was approved by the Virginia Guardianship Association and the Commissioner on Aging for the Commonwealth of Virginia during an initial contact in March 1995. Later, I contacted the coordinators of the Virginia pilots, PSN and CVGP. Additionally, I communicated with the Executive Director and the public guardian of the First Tennessee Area Agency on Aging in Johnson City, Tennessee, and the Director of the Office of the Public Guardian in Wilmington, Delaware, for permission to conduct research. Research protocols were approved by the Institutional Review Board of 
Virginia Polytechnic Institute and State University for research involving human subjects in February 1996 (see Appendix A).

\section{Sources of Data}

The sources of the data were three-fold. The first source of data included open-ended interviews of wards, public guardians, and program supervisors. I interviewed all persons privately, took notes during the interviews, and audio taped the persons who were interviewed. I purposefully selected four wards with assigned public guardians from each research site. The persons most often selected for participation in this study included older adults, who comprise the majority of persons who are wards, and the chronically mentally ill. These two populations represent persons who are most likely to become wards (J.T. Molumphy, personal communication, October 17, 1995).

I selected the ward participants prior to interview and observation from information provided by the program supervisor or the primary public guardian. Information on potential interview candidates included the ward's name or other identifier, sex, age, willingness to be interviewed, ability to communicate, length of time the individual had been a ward, presenting conditions, and comments on lucidity. Relative lucidity was determined according to the ward's orientation to person, time, and place; ability to understand questions and reason; ability to know consequences of actions; ability to recognize the public guardian; ability to recognize persons generally (able to understand the purposes of the researcher); and ability to contextually associate information.

Where possible, participants included one adult male and one adult female. Among the four wards selected, two were lucid wards and two were wards who were unable to communicate or who could do so minimally. The purpose for selecting wards who differed in their ability to communicate was to permit the observation of any differences in meeting the needs of wards who could communicate with the primary public guardian versus wards who could not. Wards who could not communicate their wishes were observed only.

I interviewed wards only with their consent and at the discretion of the primary public guardian and the program supervisor. Wards were not interviewed in the presence of the public guardian. Prior to the interview, the ward was asked if he or she would be willing to participate in order to respect individual autonomy. As a condition of the informed consent document, the paid public guardians and program supervisors knew what questions would be asked of the ward prior to the interviews. I asked wards open-ended interview questions regarding their background, their needs, how the public guardian met their needs, how well the public guardian knew them, and how they felt about being a ward (see Appendix B).

The ward's primary public guardian was interviewed through semi-structured interviews. The interview questions asked of the primary public guardian explored what a primary public guardian does for a ward, the nature of the services provided, how the needs of wards are 
addressed, the relationship of the guardian with the ward, and the primary public guardian's reflections on being a public guardian. The primary public guardian was also questioned about the nature of being a public guardian, the time spent in care provision, the adequacy of service provision, and decision making.

The program supervisor of the primary public guardian was interviewed in order to elicit the supervisor's perceptions regarding the ward, the primary public guardian and the guardianship process. The program supervisor was also asked questioned regarding funding, administrative support, accountability, client advocacy, and public guardianship in general.

The second source of data included notes that I took from participant observations of guardian/ward interactions. I accompanied the primary public guardian while meeting the needs of the ward in order to observe guardian/ward interactions, services provided, duration and tone of visit, respect for ethical principles of autonomy and least restrictive alternatives, environmental factors associated with the ward, and ability of the ward to communicate with the primary public guardian. These observations were conducted during the visit of the primary public guardian with the ward, and my purpose and presence was made known to the ward. Primary public guardians and wards were observed for a duration of approximately one-half hour each.

The third source of data derived from court petitions and psychological-social information contained in case files on the ward. I analyzed and examined records in order to answer questions about the needs of the ward, when and why guardianship was initiated, the functioning level of the ward prior to guardianship and the present functioning level of the ward, services recommended and provided, and other pertinent information.

\section{ANALYSIS OF THE DATA}

The data are analyzed phenomonologically. An analysis conducted in this manner facilitates an examination of the data using "naturalistic approaches to inductively and holistically understand human experience in context-specific settings" (Patton, 1990, p. 37). In essence, the phenomonological paradigm is counter to the logical positivist paradigm that defines reality as finite and calculable. Rather, data analyzed in accordance with this paradigm answers why a specific phenomenon is occurring, stresses the content or intent of communication, focuses on persons' orientation to the world, examines the content of meaning as practiced and intended by participants, and discovers the world as shared and given (Rothe, 1994).

The primary research tool used was Microsoft Access, a relational database program, which helped me code the data according to themes. The data were analyzed according to protocols for qualitative analysis that include developing a sense of the landscape of issues surrounding the supervisor, primary guardians, and their wards (getting a sense of the whole); 
identification of topics; comparison and organization of the general topics; establishing relations between the topics; coding the data by categories; and summarizing the content for each category (Tesch, 1992). Analysis of the data was concurrent with initial data gathering and continued after all data were gathered.

Making overbroad comparisons between and among states is unwise. Even though delivery systems may appear to be similar, they are in fact quite different. The difficulty in making comparisons reflects the problem of earlier research in public guardianship. Ultimately, such an attempt proves futile because each state and its individual form of public guardianship is governed by unique statutes bounding service delivery parameters. Therefore, I do not compare the various systems according to their models of delivery, although I acknowledge noteworthy system differences as exploratory findings. This study does contribute to the body of knowledge by furthering an understanding of how public guardians uniquely meet the needs of their wards.

At the experiential and the perceptual level, this study examines what it means to be a ward under the care of a public guardian by providing a qualitative statement describing the nexus of the state and unbefriended citizens. It determines what it means to be a public guardian and a public guardian supervisor struggling to address the needs of persons for whom there exists no other person or entity to fulfill this role. Also, the study elaborates on a theory for public administration that requires that public guardians as public administrators be responsive, representative, and reflexive when meeting wards' needs. It evaluates the intersection of the state and the individual according to specific criteria established in the review of the literature and suggests operational norms for public guardians.

By observing, interviewing, and studying closely a small number of cases, my purpose is to add depth to the limited research studies of public guardianship, most of which have relied on little, if any, direct contact with the persons who are most intimately involved. This study illustrates how public guardianship, potentially bureaucracy's greatest challenge, attempts to meet the needs of wards by living the decisional life of another person. 


\title{
CHAPTER II
}

\section{LITERATURE REVIEW}

\begin{abstract}
Experience should teach us to be most on our guard to protect liberty when the government's purposes are beneficent. Men born to freedom are naturally alert to repel invasion of their liberty by evil-minded rulers. The greatest dangers to liberty lurk in insidious encroachment by men of zeal, well meaning but without understanding.
\end{abstract}

Louis Brandeis

Although a significant body of writing is drawn from legal commentary, fields such as social science, psychology, and ethics also have informed aspects of guardianship. Scholarship relevant to public guardianship is both included in and separate from literature on general issues of guardianship. Theoretical literature on guardianship has far exceeded actual research, with the majority of empirical studies on the subject having been done in confined localities. The following is a review of the literature as it pertains to the various and complex issues surrounding guardianship and the research questions.

\section{EARLY LITERATURE ON GUARDIANSHIP}

Early writing on guardianship addressed the flaws in guardianship and protective services. Lehmann and Mathiasen (1963) highlighted the dichotomy between the need for flexibility within the guardianship process and its generally plenary nature. They emphasized the importance of effective administration and stressed that "thought should be given, particularly when the ward does not have substantial assets, to the question whether this relationship might be structured more effectively through an administrative agency with judicial functions rather than through a court" (Lehmann \& Mathiasen, 1963, p. 85).

An early investigation, the Mental Competency Study, focused on guardianship as well as other issues (Allen, Ferster, Zinoff, \& Weihofen, 1968). Using court records and interviews with a wide variety of actors involved with civil competency, the authors evaluated proceedings leading to the appointment of a guardian or conservator, determinations of incompetency, and the effect of government agency determinations of persons' incapacity to manage benefit payments. The authors' recommendations for reform included changes in statutory terminology and definitions, creation of classes of persons for whom guardianship was suggested, attention to ward preferences, and considerations of public guardianship.

A highly significant empirical study of guardianship in Onondaga and Tompkins Counties in New York was conducted by Alexander and Lewin (1972). They hypothesized that guardianship serves third party interests. The authors studied existing American law, carried out a field study to ascertain the kinds of information supporting or opposing a legal determination 
of incapacity, and conducted an empirical study of interviews with various persons within the system. They concluded that "in almost every case examined, the aged incompetent was in a worse position after he was adjudicated incompetent than before. The study could identify no particular benefit which flowed to the incompetent that he could not have received without a finding of incompetency" (Alexander \& Lewin, 1972, p. 136).

Margaret Blenkner and associates (1971) conducted a landmark study that supported the findings of Alexander and Lewin and illustrated the inherent problems of state intervention in the lives of older adults perceived or adjudged incompetent. Their longitudinal study revealed that special, enhanced protective services afforded to clients actually worked to their detriment. The authors suggested that the higher rate of institutionalization of the experimental group receiving protective services resulted in its higher mortality rate. Re-analysis of the data used by Blenkner and associates suggested that it was skewed by covariates of survival (the experimental group was more debilitated than the control group) and by missing pretest data for control and experimental subjects (Berger \& Pilivan, 1976). However, re-analysis did not reveal that social casework services were beneficial; it simply ruled out that such services caused harm.

Concurring with the conclusions of Alexander and Lewin (1972) that persons' lives were not improved by guardianship, Horstman (1975) roundly condemned various aspects of the already plagued concept of guardianship by drawing upon its historical purposes. Distinguishing between police power predicated on confining individuals for the health and safety of others and parens patriae power based on state power to act to protect an individual's well-being, Horstman asserted that the state justifies guardianship by blurring the legal concepts of social defense and best interests. Consequently, persons may be adjudicated incompetent because of a mental abnormality or their deviation from normative values. He cited pivotal cases such as In re Josiah Oakes, 1845; Lake v. Cameron, 1966; and Lessard v. Schmidt, 1974 as representing the court's attempt to limit the state's power in this regard. Horstman sounded many themes of guardianship and guardianship reform, including the stigmatization of wards, the absence of due process protections in hearings, and the importance of functional abilities. These themes were elaborated upon and reiterated by Horstman's contemporaries as well as later scholars.

Mitchell (1978) echoed many of Horstman's suggestions and included the politics of guardianship in the discussion of guardianship reform. She contended that power is easily exercised over the poor and disenfranchised and argued that "protection" of incompetent persons could hide behind a veil of "best interests," potentially resulting in custodial care from an unfeeling bureaucracy that subjugates civil rights from the powerless. She emphasized "if [reform of guardianship laws] is to be more than cosmetic, [it] must face these political realities and address itself to altering deeply-rooted attitudes" (Mitchell, 1978, p. 466). 


\section{Alternatives to Guardianship}

A frequently addressed topic of writers on guardianship reform concerns provisions for the least restrictive alternative and its importance for protecting personal liberty. Alternatives to guardianship include durable and springing powers of attorney (activates when a particular condition, such as a coma, is met), advance directives, representative payeeship, and bill payers. Although it is impossible to employ alternatives to guardianship if persons cannot understand the implications of legal documentation that they sign, and service providers do not always recognize these documents when they are created, alternatives to guardianship are widely endorsed as mechanisms that carry the potential to avoid or allay guardianship (Alexander, 1990; Hommel \& Wood, 1990; Kapp, 1996; Maynard, 1990; Stiegel, 1992; Stiegel, 1996).

One such alternative to guardianship is that of financial assistance (Wilber, 1990). Wilber's study (1991) responded to the fact that one-third of persons referred to the public guardian in Los Angeles County were sent because of money problems; moreover, $80 \%$ of all referrals were inappropriate for guardianship (Steinberg, 1985). Dividing 63 communitydwelling elders into trial and control groups, the trial group of older persons was offered Daily Money Management (DMM) service agencies (Wilber \& Buturain, 1993), which consisted of assistance with "bill paying, budgeting, credit counseling, obtaining benefits, medical payment forms, and tax problems" (Wilber, 1991, p. 151). Although DMM services forestalled persons' evictions from homes and foreclosures, participation in a DMM intervention did not affect their appointment to conservatorship (Wilber, 1991, p. 154).

A second DMM study was conducted in 1995 involving participants from four existing DMM service agencies in Los Angeles County (Wilber, 1995). The DMM services were embedded in a case management agency so that comprehensive services could be provided to clients. The trial group consisted of 36 community-residing participants who were age sixty and older; the control group was the same control group as used in Wilber's earlier study. As with the previous study, findings at twelve months did not indicate a DMM/case management service diversion effect. Wilber concluded that, despite the fact that other alternatives are available, particularly as they relate to money management, sometimes guardianship is the only viable option for persons who lack capacity; interventions prior to guardianship include those that are supportive, shared, delegated, and surrogated (Wilber \& Reynolds, 1995). However, alternatives to guardianship "carry potential to significantly reduce the appropriate use of legal guardianship, particularly in cases involving cognitively impaired persons who are personally at risk, financially exploited, or both" (Wilber, 1996, p. 222).

Also significant to guardianship reform is literature addressing the development of another alternative to guardianship, that of health care decision making. One of the tools of medical treatment decision making is a "values inventory," which enhances ward autonomy and assists the guardians by helping them understand a ward's wishes (Gibson \& Nathanson, 1990). The values history, developed first at the University of New Mexico, documents preferences 
regarding another person or of the person being questioned (see Appendix C). In New York, a similar mechanism to that mentioned earlier maximizes ward autonomy through a panel, operating much like an ethics committee, "that makes health care decisions for persons with developmental disabilities”(Herr \& Hopkins, 1994, p. 1017), thus delaying or avoiding guardianship instituted for health reasons alone.

\section{RECENT LITERATURE ON GUARDIANSHIP}

Related to the least restrictive alternative, several empirical studies in the 1980s examined court proceedings and characteristics of persons who became wards. The Dade County, Florida, grand jury investigation (1982) of 200 random cases of guardianship opened between 1979 and 1981 revealed that $85 \%$ of wards were over the age of sixty, and six out of every ten wards were women. Eighty-seven percent of the mandated annual reports on wards' personal status were not up-to-date, with $75 \%$ incomplete in financial reporting and $91 \%$ tardy in physical examination reporting. A study conducted by Cohen (1983) of a sample of guardianship cases in three counties in Pennsylvania from 1978 to 1979 revealed that older, single females were more likely than other groups to become wards. He concurred with earlier research stating that guardianship predominately serves third party interests. Similar findings resulted from an empirical study of probate court records in Leon County, Florida, for the period 1977-1982 (Peters, Schmidt, \& Miller, 1985), with the additional finding that if estates were larger than $\$ 50,000$, relatives were likely to assume guardianships.

Friedman and Savage (1988) reviewed probate conservatorship court records of San Mateo County, California. They examined who was petitioned, the size of estates, and the gender of proposed wards. Consistent with previous empirical studies, $84 \%$ of wards were over sixty years of age, and two-thirds of them were women. Public guardians were petitioned in 45 of 178 total cases, with the primary reasons for guardianship petitions being inattention to financial affairs and inability to give informed consent.

An ethnographic study by Iris (1988) analyzed judicial decision making from the perspectives of family members, judges, attorneys, and physicians. The author concluded that in contested guardianship cases, "the contest frequently is focused on who would be the guardian rather than the need for protection itself'(Iris, 1988, p. 42). Vittoria (1992) also conducted an ethnographic study of guardianship hearings. Drawing upon Erving Goffman's work regarding participants who share a mutually sustained focus of action, she utilized a qualitative and interpretivist approach to examine guardianship hearings as a bounded system and found that the proposed ward should be heard not only in the pre-hearing phase of guardianship but also at the public hearing. She asserted that respondents could affirm themselves in this way and encourage the judge to fit guardianships more closely to their individual needs. 
Grossberg, Zimny, and Scallet (1989), from the Division of Geriatric Psychology at St. Louis University, studied the number of guardianship cases encountered and the nature of information used in depositions as evidence for guardianship determinations. The authors suggested that research should address the degree of impairment leading to agency or family petitions, the appropriateness and use of procedures for competency assessment, and factors influencing the acceptance of the assessment in court. Similarly, Bulcroft, Kielkopf, and Tripp (1991) examined data from probate records of guardianship petitions filed in Franklin County, Ohio, and Snohomish County, Washington, to develop a profile of who petitioned for and was granted private guardianship of elderly persons. The average age of wards was 76 , most of them were widowed, and they were not living in their own homes. "The factor most often reported under 'health problems' was 'failure to manage personal finances'"(Bulcroft, Kielkopf, \& Tripp, 1991, p. 160). Probate records and the courts generally failed to document incapacity; public guardians were often called upon to serve when family members disagreed about who should assume guardianship.

Keith and Wacker (1994) used court records and information taken directly from guardians in Iowa, Missouri, and Colorado. The authors studied older wards and their guardians at the social/psychological level, especially caregiver strain upon guardians and the effect of statutory changes on guardianship hearings. Role strain on guardians proved to be great, and the authors determined that guardians themselves were in need of support (Lehmann \& Mathiasen, 1963; Molumphy \& Shivers, 1994). The authors bolstered their findings with research on family caregiving (Cicirelli, 1992; Doty, 1986; Dwyer \& Coward, 1992). Additionally, they determined that legislation concerning reform of guardianship is symbolic; in practice, it is often not implemented.

Lisi and Hommel (1992) studied guardianship systems nationally. Data were gathered from 563 guardianship hearings, 726 files on guardianship, and 228 petitions for guardianship from 1989-1992 in thirty jurisdictions in ten states. The study, conducted at the National Center for Social Gerontology, produced information on characteristics of wards, characteristics of guardians, and outcomes of the guardianship process. The authors concluded that wards were generally white (83\%) and female (67\%) over the age of sixty with variable economic status. Most guardians were relatives, and persons were declared incompetent with as little information as a physician's written statement. They recommended further investigations of alternatives to guardianship, the development of judicial resource materials for state courts, ongoing training for attorneys regarding guardianship, an increase in court use of information on proposed wards' functional status, participation of the respondent to his or her fullest extent, use of limited guardianship whenever possible, and the exploration of case mediation where appropriate (Lisi \& Baranaga-Burch, 1995).

Related recent literature called for sweeping system-wide reforms for both private and public guardianship and was drafted primarily by legal scholars (Alexander, 1990; American Bar Association, 1988; National Guardianship Association, 1994; Select Committee on Aging, 1989; 
Wood, 1986). Reforms to court processes have been proposed as well, such as due process issues of notification to and representation of the ward (Barnes, 1996; Coleman \& Dooley, 1990; Hull, Holmes, \& Karst, 1990; Guardianship, An Agenda for Reform, 1988; Hommel, 1996; Hommel, Wang, \& Bergman, 1990; Sherman, 1980; Wood, 1995), accountability of the guardian (Frolik, 1981; Wood, 1995), guardianship monitoring (Miller \& Hurme, 1991), and the institution of limited guardianship (Frolik, 1981; Hommel, Wang, \& Bergman, 1990; Hommel \& Wood, 1990; Hurme, 1994).

Two pieces appearing in the popular press heightened the attention of policy makers and the general public alike to the issues of guardianship. The first, which attracted national attention, was a series of articles by the Associated Press (Richmond Times-Dispatch, September 20-25, 1987). The report, a year in the making, was compiled by a team of 67 reporters who covered various aspects of guardianship in the fifty states and the District of Columbia. In addition to interviews of judges, lawyers, academicians, social workers and wards, reporters examined more than 2,200 guardianship files. Reporters discovered positive examples of guardianship, such as the Cathedral Foundation in Jacksonville, but they also uncovered numerous abuses, including significant instances of ageism. A similar article by Topolnicki (1989) covered many of the same issues but not as thoroughly as the Associated Press reports. Due to the result of focused interest in guardianship, states and advocacy organizations pressed for system-wide reforms. One area of reform that received particular attention was public guardianship, and we turn now to a review of literature specifically in this area.

\section{ISSUES PERTAINING TO PUBLIC GUARDIANSHIP}

The concept of public guardianship in the United States is hardly new. The first program began in Minnesota in 1917. To date, only two books deal with the subject: Public Guardianship and the Elderly (Schmidt, Miller, Bell, \& New, 1981) and Guardianship: The Court of Last Resort for the Elderly and Disabled (Schmidt, 1995b). Public guardianship tends to be even more controversial than private guardianship because an individual's civil rights are ceded to the state.

In his article on protective services for the elderly (1972), Regan discussed necessary reforms to the guardianship process and included suggestions about improvements needed in public guardianship. He mentioned that California had the most extensive system of public guardianship, with limited forms existing in North Carolina and Kentucky. He suggested that public guardians, who should have powers nearly identical to those of private guardians, lower the costs of providing guardianship services, assist in identifying and mitigating the interests of others in the guardianship of the ward, and separate guardianship of person versus that of property.

Early articles on guardianship discussed the expanded powers of the state and identified public guardianship as a potentially problematic and inappropriate use of state power (Cohen, 
1978; Horstman, 1975). According to Mitchell (1978), public guardians overutilize institutionalization of persons once they become wards as the only means of addressing their needs. They assess fees even for indigent persons; public guardians' performance falls short of their ideals. She viewed public guardianship as a coercive arm of the state and a state-sanctioned mechanism for social control of "undesirables."

An important, if small-scale, early study of guardianship was that of Axilbund (1979), whose purpose was to highlight practices concerning limited guardianship, public guardianship, and protective services for the developmentally disabled in states that had recently adopted or revised pertinent legislation. He sanctioned the existence of the public guardian as the guardian of last resort, but with the caveat that the large size of the implementing organization could work to the detriment of the ward.

The classic and, until recently, the only book devoted entirely to public guardianship was written by Schmidt, Miller, Bell, and New (1981) and is entitled Public Guardianship and the Elderly. Its general purpose, guided by the U.S. Administration on Aging, was to determine the degree that public guardianship impeded or assisted older persons in gaining access to their rights, entitlements, and other benefits. The researchers attempted to evaluate whether the predominant approach to public guardianship should be more widely adopted and to improve guardianship laws and their implementation and administration. The authors defined a public guardian as "an official appointed by a state or local government or court whose duty is to serve incompetents who did not have relatives or friends appropriate to serve as guardian" (Schmidt, Miller, Bell, \& New, 1981, pp. 3-4).

At the time of the study by Schmidt and colleagues, only fifteen states actively provided public guardianship, although 34 had some provisions for a public guardian through statute or code. The authors identified four general models of service delivery: the court model, the independent state office, the agency as a division of a social services agency, and the county model. Provisions for guardianship varied dramatically. Eligibility for public guardianships differed widely from state to state; most states did not allow for service provision by the same agency to a combination of older persons, persons with mental retardation, and persons with developmental disabilities. Use of the term "guardian" varied according to statute, with trustee, custodian, and committee being alternatives. Other variations concerned procedures for petition, investigative procedures, examination of the potential ward, rights of wards, qualifications for guardians (generally the public guardian is the guardian of last resort), powers of the guardian, termination of the hearing, incurred costs, emergency procedures, limitations of guardians, review of the estate, and the condition of the ward. The authors stressed that statutory and other differences among states reflect the concept of federalism, where states are experimental sites for the nation, with some experiments being more successful than others. The authors specifically examined public guardianship in Illinois, Maryland, Delaware, Arizona, and Florida. 
A summary of the findings by Schmidt and colleagues on public guardianship and their in-depth study of certain state models revealed that more than half of public guardian wards were women, nearly all had low incomes, and most were institutionalized. Staffs in public guardian offices varied from a single person to more than 100. Caseloads for public guardians ranged from a low of thirty to a high of 341. Time spent on individual wards ranged from one to two hours per year to twenty hours per week. Larger offices were headed by an attorney with social workers providing direct services, although many offices included staff from many disciplines. Funding was largely a mix of local, state, and federal funds, with some agencies collecting fees from clients. Generally, government offices were unable to provide the services that wards needed.

Schmidt et al. emphasized that public guardianship should be utilized only if done properly; if adequate funding exists; if staffing is at low enough staff-to-ward ratios (1:33 recommended); and if due process safeguards are provided for wards. The study emphasized that guardianship should be a rare event, with a sweeping search for less restrictive alternatives conducted before the last resort of guardianship. Schmidt et al. argued that overall, public guardianship needed a more refined approach for the delivery of services than the current case management one. Also, the authors made these recommendations: an adversarial context for determining incompetency and the appointment of a guardian; provisions for partial, voluntary, and time-limited guardianships; offices that manage both the person and the property; and offices that do not depend on the collection of fees for services. Public guardian offices should coordinate services, advocate for their clients, and educate professionals working in guardianship as well as the general public. The public guardian should develop private sources of guardians and oversight of private guardians. Directions for future research included elucidating a role for volunteer guardians, investigating the proportion of wards who are severely confused and disturbed, discovering the mechanisms and methods for the protection of wards' rights, determining the profitability of public guardianship, researching the proportion of guardianships instituted for medical needs only, and studying how the needs of persons are met when no public guardian exists.

Presenting ideas similar to those of Schmidt and associates, John Regan (1981) advocated that public guardians need special oversight above and beyond that suggested for private guardians. Public guardians should have written plans for services to be provided to their wards, and the plans should be submitted to a regional ombudsman for periodic review. Suspicious of guardianship and emphasizing that public guardians can interfere too easily in the lives of the powerless, Regan (1981, p. 1128) contended that the "abolitionist [completely against guardianship] model rests on a belief that no such condition as mental incompetency exists" and that mental illness is merely socially deviant behavior. Regan stressed, however, that abolitionists have not determined what to do with individuals in cases of extreme neglect. He regarded that public guardianship is oppressive and should be provided only to willing persons. 
Sproger (1984) discussed public guardianship in California, but rather than concentrating on older persons exclusively, as did Schmidt et al. (1981), he focused on public guardianship for persons with mentally retardation or other developmental disabilities. Sproger's research confirmed high caseloads and conflicts of interest between agency and client needs. In the same edition, Apolloni and Vincent (1984, p. 5) cited advantages of public guardianship to be "decreased dependence on family ties, the involvement of full-time professional guardians, the capability of providing services throughout the life of the ward, less likelihood of familyoriented conflicts of interest, and the authority and stability of a government-operated organization." The authors determined that a public guardian's responsibility is that of monitoring the ward's access to, release from, and quality of services.

Apolloni and Vincent cautioned that a danger of public guardianship was that intentions of the ward become sacrificed to cost containment or the maintenance of organizational status quo. Other problems include a high job turnover rate among public guardians, lack of skills to fulfill their job responsibilities, competing organizational priorities, organizational dependency on a fee for service, and lack of needed information in order to carry out responsibilities. They emphasized that a relatively new alternative for guardianship is a corporate guardianship (a corporation established for the sole purpose for providing guardianship), which predominately serves persons with developmental disabilities due to the fact that their families are able to pay for their services. This type of guardianship includes all the advantages of public guardianship and provides individually tailored services, smaller caseloads, direct affiliation with advocacy organizations, and diminished conflict of interest problems. Its disadvantage is higher cost, which prices indigent persons out of the service.

Also in the same volume, Christie (1984) presented an alternate view of public guardianship by describing the system in Alberta, Canada. Utilizing an appointed guardianship advisory committee, the Canadian system instituted more limited guardianships and worked harder to foster community involvement through education and participation in the guardianship process, facets of U.S. public guardianship that are often neglected. Christie recommended that effective public guardianship should include review of cases on a regular basis, avoidance of conflicts of interest, encouragement of private guardians, and legislative mandates that include principles to be employed when guardians make decisions on the ward's behalf.

In 1984 the Florida Guardianship Pilot Project in the Office of the State Courts Administrator commenced with an initial appropriation by the state legislature of $\$ 160,000$. Originally employing the court model (Regan \& Springer, 1977; Schmidt, Miller, Bell, \& New, 1981), the state contracted to provide services with the Guardianship Program of Dade County in Miami and Lutheran Ministries and the Suncoast Area Public Guardianship Project in St. Petersburg (Schmidt, 1984; Schmidt, Miller, Peters, \& Loewenstein, 1988). The purpose of the pilots was to demonstrate and provide information for the evaluation of alternative service delivery models. The Dade County pilot project utilized a paid model, and the St. Petersburg pilot project used a volunteer model of service delivery. Research questions included client 
characteristics, unmet needs, cost/benefits in public guardianship, extent to which public guardianship helped or hindered incompetent persons, and how their needs were addressed. Data from the project were gathered from client assessment forms, guardianship plans, guardian activity reports (similar to attorneys' time $\operatorname{logs}$ ), and other miscellaneous reports.

The authors concluded that characteristics of the wards served were heterogenous, that few were returned from guardianship, and that a need existed for long-range planning and a narrowed definition of incompetence so that alternatives to guardianship could be more widely used. Although their research did not include a unique ward history, the authors determined that the majority of public guardians' time was spent addressing wards' medical problems and providing services and social support. In this descriptive and significant analysis, the authors suggested that future research should include changes in the guardian plan format, developed after consultation with the implementing staff. In addition, efforts to analyze the data should include qualitative analysis. The authors emphasized that volunteers are not a panacea for resource constraints; volunteers require monitoring and training and cannot replace certain aspects of paid staff oversight of a ward's condition.

Neal Dudovitz (1985) discussed responsibilities of the office of the public guardian and found that the most intense clashes concerning guardianship pertain to this institution because public guardians transfer an individual's civil rights to the government. Problems exist because the power of the public guardian is not circumscribed by law. Dudovitz cautioned that the powers of the public guardian should not abridge fundamental Bill of Rights protections; a public guardian's power is curtailed under federal civil rights laws. Dudovitz stressed that civil rights laws prevent unnecessary institutionalization of wards by limiting the state in undertaking actions that are the least restrictive of an individual's civil rights. Public guardians are defined statutorily as public case managers whose job it is to locate, secure, and monitor service delivery. Often, little training is required for public guardians, and so problems exist in the decisions that are made on behalf of the ward. However, Dudovitz stated that public guardians have a constitutional obligation to respect the rights of elderly persons and must view home placement as a responsibility. "The existence of the constitutional right to receive care in the least restrictive setting can be used to force public guardians to keep wards in their own community" (Dudovitz, 1985, p. 41).

Rather than constitutional grounding, Dubler (1987) stressed that the responsibilities of the public guardian are guided by the ethics of caregiving. She acknowledged legal responsibilities of guardianship but contended that guardianship is also synonymous with caregiving responsibilities such as the discovery and documentation of individual preferences and wishes, the preservation of autonomy through the least restrictive alternative and best interest standards when applicable, the creation of procedures that maximize individual capabilities, and the limitation of paternalism. Dubler stated that public guardians can emerge as insidious "agencies of social management able to move the poor and near poor out of the community" (Dubler, 1987, p. 152). 
Nursing home residents' need for public guardianship services was studied in the state of Tennessee, when, in 1986, the Tennessee legislature established a public guardianship program for older adults to be administered by the Tennessee Commissioner on Aging. The purpose of the study, conducted in 1988, was to determine if a substantial unmet need for public guardianship existed among elderly nursing home residents. The researchers surveyed the entire state's population of 500 licensed facilities concerning residents' characteristics and needs. Results indicated that two-fifths of residents in responding nursing homes were in need of guardianship services and that slightly more urban elderly persons had unmet needs than rural persons. This finding was consistent with previous research indicating that urban elderly persons are more socially isolated than rural elderly persons (Coward \& Smith, 1982) and that smaller facilities had a greater percentage of current residents having all types of guardian services, except that of representative payee (a person appointed to receive government paychecks and pay bills on behalf of another) (Hightower, Heckert, \& Schmidt, 1990).

Though earlier contending that public guardianship held the potential to help older persons who were indigent, Regan focused, in his 1990 book, on some of the more egregious problems of public guardianship and Adult Protective Services (APS). He reiterated that public guardians have little to no oversight and are embroiled in conflicts of interest. Regan recommended that public guardian agencies should purchase guardianship services from private organizations to decrease the power of public guardians over an individual. His other concerns centered on APS as an alternative to guardianship, where more client rights are abrogated than with private guardianship. He criticized APS programs that were combined with traditional guardianship approaches: "public guardianship places the state in a position of total control over all aspects of a ward's life, a role arguably contrary to - and certainly in tension with - the American political ethic of limited government" (Regan, 1990, p. 131). Alexander (1990) sounded many of the same themes as Regan, criticizing the enormous growth of state protective services and their replacement of the family as an individual's primary protector. He concurred with earlier work by Dubler (1987) and Mitchell (1978) and lamented that guardianship "is inherently defective because it threatens human freedom, but many are still attempting reform" (Alexander, 1990, p. 174).

Building on previous research, Siemon, Hurme, and Sabatino (1993) added a fifth model (labeled "other") to those established earlier (Regan \& Springer, 1977; Schmidt, Miller, Bell, \& New, 1981). Finding over forty states with implicit and explicit models of guardianship, the authors re-worked the definition of a public guardian and studied public guardianship in Georgia, Alaska, Idaho, Alabama, and Washington, as representative of the five models. The authors concluded that states should increase efforts toward funding least restrictive alternatives and that education and outreach to nursing homes is important because of their general misinterpretation of a 1987 OBRA nursing home reform law as requiring guardians for all incapacitated residents. (The law does not establish when a guardian is needed but does state that when a guardian is needed, he or she should exercise the resident's rights.) The authors stressed the importance of adequate funding; the elimination of conflicts of interest; the need for 
national standards; and the recruitment, retention, and training of volunteers to serve as longterm guardians, especially for individuals with developmental and mental disabilities.

Suggestions for further research included funding schemes for and identification of least restrictive alternatives, concerns over nursing home liabilities, funding sources for the provision of services, and the best possible use of volunteers in public guardianship.

Schmidt compiled and updated many earlier articles that he wrote and co-authored in Guardianship: The Court of Last Resort for the Elderly and Disabled (1995b). This edited collection reflects scholars' thinking about reforms to public guardianship, particularly in selected states such as Florida (Schmidt, 1995a; Schmidt \& Peters, 1995). Schmidt (1990) provided a review of salient quantitative literature on guardianship and suggested further research in the areas of guardianship for low income and minority elders, guardianship in divergent communities (rural versus urban), and alternatives to guardianship for both competent and incompetent persons.

Drawing from Kittrie (1971) and his conceptions of the therapeutic state (services are imposed involuntarily and persons perceived as "different" are punished by state control), Schmidt (1995c) discussed the evolution of thinking about protective services for older persons. He referred to Regan's (1978, p. 250) definition of APS as "a system of preventive, supportive, and surrogate services for the elderly living in the community to enable them to maintain independent living and avoid abuse and exploitation." Schmidt further explained that APS has also been used as a generic term that includes guardianship and civil commitment. Schmidt contended that APS, a state mechanism for care provision, has continued in the tradition of the therapeutic state. He stressed that the therapeutic state has the potential to misuse its authority by intervening in the lives of social deviants or those who are deemed in need of social control and surrogate decision making.

A study by Ganski (1994, unpublished dissertation) explored how public guardianship confronts conflicting goals of encouraging self-reliance and independence while protecting persons. She examined the Office of the State Guardian (OSG) in Illinois, in particular the regional office in Chicago, to find out to what extent goal displacement occurred. She interviewed sixteen wards, studied 122 OSG intake documents, took field notes from 22 visits to the office, reviewed 134 randomly selected case files, and interviewed sixteen caseworkers and administrators in the office. Ganski concluded that although the relationship of guardian to ward was an important one, wards' needs were secondary to the needs of the bureaucracy. She determined that "confusion and improbability of achieving both the protective/control goals of guardianship and these more empowering/independence goals of guardianship in any given guardianship case has led to the displacement of these goals by the bureaucracy known as OSG" (Ganski, 1994, pp. 8-9). 


\section{ETHICAL VALUES IMBEDDED IN GUARDIANSHIP}

Competing ethical values that are central to issues of guardianship deal with beneficence or the right of an individual to safety and protection by the state versus a person's autonomy and self-determination. Reflecting these interests, two significant strands of ethical literature are relevant to guardianship: scholarship that addresses personal autonomy and scholarship that addresses surrogate decision making. Binding these two literatures together are issues of competency that reflect the ability of an individual to make reasoned decisions.

\section{Considerations of the Principle of Respect for Autonomy}

Considerations of autonomy have undergone a number of revisions, particularly since the Progressive Era, which dramatically increased state intervention in citizen's lives. Describing the movement and its attitudes toward beneficence of the state, Rothman $(1978$, p. 69) stated that the progressives "gave a remarkable primacy to the state as parent" and did not require protection from state action. Disadvantaged persons were regarded as objects of care. The state defined the common good, not the individual, and assumed that their relationship was nonadversarial.

Because of informed consent concerns, which arose from human experimentation by the Nazis during World War II and notable court cases such as In re Quinlan, 1976 and Cruzan v. Director, Missouri Department of Health, 1990, the principle of respect for autonomy has received substantial attention from ethicists. Dworkin (1982, p. 71) defined autonomy, or selfrule, as "the capacity to reflect upon one's motivational structure and to make changes in that structure," and self-determination as the recognition by others of a person's ability to exercise and determine his or her own destiny. He contended that informed consent exhibits respect for autonomy in the way that an apology expresses regret.

Callahan proposed that autonomy is not necessarily the moral goal of a society, for by making it such, "we are equally at peril in our common life together"(Callahan, 1984, p. 40). A focus exclusively on autonomy precludes the influence of the community in decision making and reveals a misunderstanding of moral belief and ethics (Beauchamp \& Childress, 1983). Callahan suggested that autonomy is but one among competing values. Robert Veatch contributed to Callahan's discussion of autonomy by emphasizing distributive justice: "Just as in individual ethics we have learned that respect for autonomy takes precedence over producing benefit, so in social ethics we must realize that respect for justice takes precedence over producing benefit" (Veatch, 1984, p. 39). He stressed that society must determine a prevailing and consensual view of community when considering social ethics.

Hofland also reflected this view of autonomy. He regarded everyday ethical decisions as the core of long-term care, and that all participants in the long-term care arena must expand their notion of autonomy and self "to include a more transcendent and complex sense of a highly 
interdependent and interconnected world so that autonomy and community together can be advanced" (Hofland, 1988, p. 8). Hofland grounded respect for autonomy in the Constitution, particularly in the 14th Amendment, stressing that persons differ in their capacity understand abstractions of justice and beneficence and to reason from those abstractions to action.

Childress (1990) proposed a principle of respect for personal autonomy. In his view, autonomy should be esteemed; however, "it is necessary to continue to assess a person's degree of autonomy over time to determine whether he or she is autonomously revoking previous consents or dissents" (Childress, 1990, p. 14). Collopy (1988) also relaxed the definition of autonomy by presenting a typology that distinguished such concepts as decisional autonomy, executional autonomy (direct action), and delegated autonomy, which serves to empower individuals who are no longer able to act fully on their decisions.

Moody (1988) reconceptualized informed consent and its grounding in respect for autonomy to fit long-term care situations. He proposed negotiated consent, where the patient or the patient's surrogate and all other parties are actively involved in decision making through listening, communication, clarification, and consensus building. In a later work Moody regarded empowerment to include interventions that attempt to return a patient to well-established values or remove temporary impediments to true choice. He stressed that communicative ethics are needed to find principles for intervening in the lives of persons in long-term care settings and that autonomy and beneficence are secondary to the communication process (Moody, 1992).

Moody's definition of autonomy is based on a communicative ethic that allows for autonomous decision making through negotiated and uncoerced decisions. This perspective has much in common with feminist ethics, which takes into account contextual factors such as relationships in decision making. Gilligan (1982) stated that women focus on details about relationships among individuals affected and try to protect the interests of all participants. In her research, she identified a female oriented ethic of responsibility or care versus a male oriented ethic of justice. For Gilligan, an ideal world includes both. Building on Gilligan's work, Noddings (1984) underscored that men and women should facilitate conditions that create a caring relationship; one puts oneself in the service of another, sees another's perspectives, and acts on another's behalf. Deriving from an ethic of caring, women experience the world as a complex web of interrelationships and reflect this experience in making ethical decisions (Held, 1993; Sherwin, 1993).

\section{Considerations of Older Adults}

Examinations of autonomy are informed by the special needs and concerns of older adults, who are often discriminated against because of societal misconceptions regarding the aging process, i.e., viewing all older persons as frail simply because they are old (Kaufman \& Becker, 1996). Older persons tend to view themselves as having little choice and reduced autonomy. Society, itself, can be said to express an attitude of punishment regarding older 
persons, who it considers live too long and consume too many resources. This unsubtle view is especially prevalent concerning older persons with disabilities (Cohen, 1988). The autonomy of older persons is particularly vulnerable given what some regard as societal gerontophobia (Dickens, 1989; Schafer, 1988).

Scholars have commented on distributive justice regarding health care and the elderly, who are the most significant consumers of health care resources (Callahan, 1987; Daniels, 1985; Schafer, 1988). Thomasma (1984) proposed four freedoms as guidelines for the degree of health care treatment to be given to the very old: freedom from obstacles to carrying out one's desires, freedom to know one's options, freedom to choose goals and relate means to goals, and freedom to act. He regarded that the greater an individual's dependency on others, the greater effort that must be made to enhance the individual's well-being. Thomasma stressed that acting in an individual's best interest includes acting with respect for the liberty and independence of another and recognizing that any illness decreases a person's autonomy.

Honoring the health care decisions of older persons is frustrated by their inability and lack of desire to make decisions about discharge planning and post-hospital care (Coulton, Dunkle, Haug, Chow, \& Vielhaber, 1989; Dubler, 1988). Persons are reticent to make decisions about the nursing home and other long-term care environments (Kane \& Caplan, 1990; Wetle, Levkoff, Cwikel, \& Rosen, 1988). Institutional interests exist in tension with interests of the patient. The old are not like children; however, individual life is controlled with complete discretionary power by "the home." Residents do not have the right to come and go as they please, and lawyers have been relatively unwilling to vindicate the rights of older persons residing there (Glasser, 1978). Nowhere are the civil rights of others more thwarted than in the case of demented or incompetent individuals (Creyke, 1989; Graversen \& Pedersen, 1989).

\section{Considerations of Competency and Surrogate Decision Making}

Respect for autonomy is bounded by determinations and considerations of an individual's competency to make reasoned decisions. Incapacity is defined as a "term that largely defines when the state may take actions that limit an individual's right to make decisions about his person or property based in his mental disability" (Parry, 1985, p. 370). On the competency determination hangs whether persons make their own decisions, their wishes are respected and carried out by a surrogate decision maker, or whether a surrogate determines a person's best interests and acts accordingly.

Discussions of personal autonomy and competence concern surrogate decision making when surrogates make health care decisions for another person. A surrogate's ability to respect an individual's autonomy and self-determination is confounded when persons move from competency to incompetency. Surrogate decision making comes into play not only when persons' competency comes into question but also when the consequences of their decisions become more serious (Buchanan \& Brock, 1986; Culver \& Gert, 1990). According to Schafer 
(1988, p. 212), "The less likely the harm, the less serious the harm, the more oppressive the restriction of liberty and the less justified would be the imposition of restrictions." He suggested employing the civil liberties model, not the judicial model, to address moral and value issues.

Surrogate decision making assumes two dimensions: decision making when the wishes of a person are known, and decision making when the wishes of a person are unknown. Some individuals prepare for the possibility that they may some day become incapacitated, and they make their wishes known by naming a surrogate decision maker and spelling out their treatment requests legally through the use of advance directives, a viable alternative to guardianship. When the wishes of an incompetent person are known, the decision making standard to employ is that of substituted judgment; when the wishes of a person are unknown or in conflict with recommended medical treatment, the decision making standard is that of best interests. The discretion within these standards is variable (Buchanan \& Brock, 1986). Dworkin (1986) contended that the importance of precedent autonomy derives from an individual's prior statements and should govern an individual's future treatment decisions; persons must have actual past decisions that contemplate the situation in which they are now--precedent autonomy will not apply to most persons. However, Dworkin's presumptions were rebutted by Buchanan and Brock (1986) and Culver and Gert (1991) because the decisions a competent person makes reflect decisions from the perspective of a competent person, who might not adequately anticipate the exigencies of treatment decisions and alternatives from the perspective of an incompetent person.

Dresser criticized the accepted approach to decision making for incompetent persons, especially Dworkin's precedent autonomy, which is directed to a future situation that may never happen; autonomy is not the sole issue. The treatment preferences of competent persons reflects what matters to them as competent persons. For incompetent persons, lower level functioning becomes more important. "It is crucial to keep social judgments on what constitutes dignified treatment for demented patients from overriding such patients' clear and demonstrable interests in receiving treatment." (Dresser, 1992, p. 83)

Kapp and Lo (1986) examined influences of legal perceptions on medical decision making, especially concerning life-sustaining technology and older adults; halfway technologies keep patients alive but do not restore them to normal functioning. Kapp (1991) noted the primacy of the concept of informed consent within the American health care system but stressed that shared decision making facilitates ongoing dialogue. However, the law deals inadequately with ongoing relationships and processes for particular cases. Physicians often control surrogate decision making power (Mason, 1991). Annas and Glantz (1986) discussed major appellate court decisions regarding withholding or withdrawing treatment and concluded that the central consideration is the patient's wish, if it can be determined.

According to Dickens (1989, p. 498), "A cardinal principle of third party medical decision-making is that individuals do not lose their right to autonomy simply because they are 
no longer able to assert it or invoke it." Medical preferences are not invalid once competency is lost. Additional literature on surrogate decision making discusses the family's role (Brock, 1994; Cicirelli, 1992; High, 1994; High, 1988). Research by Diamond, Jernigan, Mosely, Messina, and McKeown (1989) revealed that older persons have high expectations of family involvement; members of the family are the most frequent guardians of older persons. Jecker (1990) stressed that intimacy provides the moral basis for surrogate authority, not filial relationship.

\section{Considerations of Guardianship and Surrogate Decision Making}

The problems of surrogate decision making are further frustrated if the surrogate has never known the incompetent person, as is often the case with public guardians (Iris, 1990). Kane and Caplan (1990) affirmed that autonomy is preserved only if guardians exercise substituted judgment. Frolik (1981) asserted that guardians, who are not encouraged to explore creative solutions, make decisions that least disturb the status quo. Dubler (1987) emphasized that public guardians' responsibilities should be dictated by an ethic of caring, but that caring is not dictated by any law.

Barnes (1992) addressed the ethical responsibilities of guardians and how they are bound by law to have either a narrow latitude of authority or total authority. She emphasized that the law does not recognize the importance of interrelationships among individuals with impairments. Further, public guardians, though often allied with social services agencies, must act in the best interests of impaired persons. She suggested that when employing substituted judgment, a values inventory should be conducted by the guardian.

Concerns for protecting the rights of the incompetent person are especially well articulated by Loewy (1990), who grounded respect for them by guardians not in autonomy, but in beneficence through social contract. He argued that the community's responsibility to preserve itself by respect for its members engenders civic friendships. Such civic friendships are beneficently disposed toward all citizens of the community. Therefore, out of beneficence arises respect for autonomy and disrespect for paternalism. "When, however, the tension between beneficence and autonomy favors beneficence more or when respect for autonomy emerges from beneficence as the prime consideration, guardians will be inclined to weigh and sift options and to make compassionate choices based on individual considerations. An autonomy based ethic in which guardians are bureaucrats easily becomes a technical operation in which humanity and compassion are lost" (Loewy, 1990, p. 139). Loewy emphasized beneficent grounding of all public guardians in the general will, as all citizens are, and from which all citizens should operate.

According to Cohen, (1996) guardians are morally obligated to maximize an incapacitated person's autonomy, although he conceded that on this matter the law is fairly silent. Cohen proposed steps to resolving ethical dilemmas: fact gathering, knowledge of preferences, values, and perceptions of all parties; articulation of competing interests; projection 
of alternative outcomes; characterization of the dilemma in terms of conflicting ethical principles; and assessment of how facts, values, and interests reflect principles.

\section{A NEW THEORY FOR PUBLIC ADMINISTRATION}

Issues and foundations of guardianship, the function of the public guardian, and ethical considerations have a direct impact on the fit between living a person's decisional life and the responsibility, responsivity, and reflexivity of a public administrator. Literature on this new direction for public administration acknowledges that theories for decision making as generated by Frederick Taylor (one best way), Herbert Simon (satisficing), Charles Lindblom (science of muddling though), Robert Behn (management by groping along), and the New Public Administration (social equity) leave issues of control and effectiveness unresolved. Scholars propose that public administration is fixated on "getting it right" and is asking the wrong questions given its ontological basis.

Lipsky (1980) acknowledged that the street-level bureaucrat is faced daily with dilemmas related to persons and decision making that affects them. They are the focus of citizen reactions and have an immediate, direct, and realizable impact on persons and their lives. Street-level bureaucrats work in situations that are often too complex for programmatic formats derivative of administrative neutrality and a "by the book" modus operandi. Instead, street-level bureaucrats are confronted with the human dimensions of problems. Street-level bureaucrats represent the nexus of the state and the individual. "The search for the correct balance between compassion and flexibility on the one hand, and impartiality and rigid rule-application on the other hand presents a dialectic of public service reform" (Lipsky, 1980, pp. 15-16). Lipsky proposed that, rather than buffers between citizens and government, street-level bureaucrats can emerge as facilitators. His discussion of the hands-on responsibilities and dilemmas of street-level bureaucrats is elucidated by theorists' proposals for reforms and considerations of the place of public administration within the process of democratic governance.

Literature supporting a theory for a new ontology of public administration has its genesis in Mary Parker Follett, who focused on the importance of relationships between the state and the individual. She emphasized the "law of the situation" in which exists "power with" rather than "power over." For Follett, the power and process of relating and relationship is crucial, and a primary responsibility of a public administrator is "an interweaving of willings" (Follett, 1918/1965, p. 69) of the individual and society, which does not curtail individual liberty but enhances it. She insisted that "The new state must rest on a true conception of the individual [who is the] unification of a variety of actions"(Follett, 1918/1965, p. 60).

\section{Governance that Emphasizes Community and Relationship}

Similarly, Denhardt and Perkins (1976) discussed changes in administrative man, as conceived by Herbert Simon (1966) in Administrative Behavior, and a new view of organizational participants, as conceived by feminist theorists. Instead of coalescing with the 
organization and losing one's views to it, feminists present a consensus model of decision making to replace the male adversarial one. The consensus model deemphasizes task completion; it emphasizes the importance of a process where problems are solved with mutual support and shared decision making. Denhardt and Perkins recognized that women's experiences are valid in the organization and its decision making structures.

Follett's view of bureaucracy resonates with feminist ideas regarding bureaucracy, with which an uneasy relationship exists (Ferguson, 1984). Like Follett's "power with" rather than "power over," Ferguson stressed that "Women see themselves as continuous with, rather than opposed to others"(Ferguson, 1984, p. 25). Women contemplate a participatory image of human beings in community and connected through meaningful bonds in which "individual autonomy. . is with others and for community" (Ferguson, 1984, p. 157). Rather than assuming hierarchical patterns of bureaucratic existence such as acting more like men in order to be accepted, Ferguson suggested that women should capitalize on their tendencies toward responsivity and intuition. She proposed that bureaucracy stands to gain from women's understanding that an ethic of responsibility exists in connection to others in a web of relationship, not a ladder of hierarchy.

Reflecting an ethic of caring and relationship, Frederickson and Hart stressed that in a democracy, in addition to upholding fundamental principles, public servants must develop a special relationship with and care for the citizens whom they serve. "Therefore, we define the primary moral obligation of the public service in this nation as the patriotism of benevolence: an extensive love of all people within our political boundaries and the imperative that they must be protected in all the basic rights granted to them by the enabling documents" (Frederickson \& Hart, 1985, p. 549). They emphasized the importance of a public administration grounded in patriotism (the love of regime values), benevolence, and love of others expressed by action. Bureaucrats, because of their day-to-day communication and interaction with citizens, implement public policy and impart regime values and benevolence to citizens.

Bellah, Madsen, Sullivan, Swidler, and Tipton (1985), in their landmark study on how individuals find meaning in their everyday life, contended that a strong group that respects individual differences strengthens autonomy as well as community; people are more likely to be homogenized, not in groups, but in isolation from them. They recognized the importance of narrative in human relationship and understanding; narratives build "communities of memory" (Bellah et al., 1985, p. 152) that imbue life with meaning. A key "to the survival of free institutions is the relationship between private and public life, the way in which citizens do, or do not, participate in the public sphere" (Bellah et al., 1985, p. vii).

Stivers $(1990,1993)$ focused on feminist perspectives for public administration. Feminist perspectives have implications for administrative conceptions of neutrality and objectivity, the ideal public administrator, administrative discretion, and the administrative state. In regard to administrative discretion, she suggested grounding administrative legitimacy not 
only in the Constitution and normative elements of an agency perspective (Wamsley, 1990), but also "in substantive collaboration with effected others, including members of the general public" (Stivers, 1990, p. 59). Recognizing that public administrators are agents and representatives of the people, Stivers (1993) cautioned that "Theorists may extol the virtues of the responsive, caring bureaucrat who serves the public interest, but the argument will face uphill sledding until we recognize that responsiveness, caring, and service are culturally feminine qualities and that, in public administration, we are ambivalent about them for that very reason" (Stivers, 1993, p. 55). For Stivers, a feminist approach to public administration theory questions distribution and access to resources, arrangements of power, and issues of self-perception.

Addressing administrative expertise, Stivers emphasized the particular over the universal and toleration of ambivalence and difference. She suggested taking diverse viewpoints into account by discovering connections of empathy and understanding, nonhierachical competence, and an image of the midwife as the facilitator for new possibilities of action. Regarding leadership, Stivers conceived a setting where members assume equal responsibility for achieving goals and decision making by all actors involved. She favored Cooper's (1991) conception of the virtuous citizen administrator who both makes the governance process inclusive and fosters growth of persons as respected equals.

In discussing administrative discretion, Stivers emphasized phronesis or practical wisdom, an Aristotelian concept that brings intellectual and moral abilities to bear on public issues. By definition, phronesis is public and acquired by citizens through experience in assessing situations and determining elements relevant to decision making. Diverging from the Aristotelian concept, feminist practical wisdom fosters connection with marginalized people so that practice is informed by their real life experience. She contended that public administration should regard administrative discretion as "concrete, situational, experience based, interactive, and grounded in perception and feeling as well as rational analysis" (Stivers, 1993, p. 144).

Morgan and Kass (1991) discussed how public administrators solve ethical dilemmas. They acknowledged that the role of the public administrator is ambiguous and that ultimately, the public interest governs administrative discretion. The authors remarked that administrators have an intergenerational obligation that requires them 'to become an agent of 'the generations,' to transmit to the future the most cherished values of the past, without allowing that past to become a dead and lifeless hand holding the future hostage" (Morgan \& Kass, 1991, p. 44). The authors proposed a stewardship model for public administrators that protects the constitutional system and the agency perspective (Wamsley, 1990). They suggested that technical expertise and actual interests must be considered jointly when making administrative decisions. Such a process of reasoning, which is associated with the stewardship model, emulates the Aristotelian concept of phronesis.

Selznick (1992) emphasized that responsibility is more than accountability. Rather, institutions should consider what values ought to be protected and enriched. What is prized in 
institutions reflects what is prized in communities. He said that institutions are the "chief agencies and most reliable safeguards of community" (Selznick, 1992, p. 370). In a later work, he underscored an ethic of commitment to individuals based on their connectedness. This context of connection, which respects the unique qualities of individual persons, yields concern for the well-being of others. According to Selznick (1995, p. 120), "The fundamental source of moral obligation is our own sense of identity and relatedness, not the vulnerability of others."

\section{Governance and Responsibility}

Wamsley et al. (1990) stressed a return to a public administration conceived as politics and governance. In democratic governance, the public interest is a supreme habit of mind. Public administration should foster the ongoing pursuit of the public interest, the agency perspective, and the governance process. "The Public Administration can only be responsible if his or her responsiveness is that of a trustee of that special perspective shaped by the agency's point of view, a public interest perspective and fidelity to the constitutional heritage" (Wamsley et al., 1990, p. 49). Public administrators must be committed to both praxis (critical and conscious action and/or pursuit of goals) and reflectivity (thoughtful and purposive assessment of action), as well as respecting the public.

Also considering governance, Dennard (1994) stated that public administration must recognize the primacy of character development for the polity. Processes of democracy, based on citizens' fundamental interconnectedness as human beings, stress the process of relationship between citizens regarded equally. Democratic governance encourages relationships based on human connection and promotes the development of citizens; in evolutionary democracy the community and its government evolve simultaneously. Dennard emphasized that evolutionary democracy assumes responsibility in which government addresses basic human needs in order to promote the individual development of citizens.

March and Olsen (1995) presented an institutional perspective on governance and characterized it as involved in developing citizens and groups in the political environment, enhancing their capabilities for appropriate political action among citizens, groups, and institutions, creating accounts of political events, and forging a system adaptive to environmental changes. "Democracy depends simultaneously on a set of shared values and beliefs and on tolerance for variety in commitments and accounts. It is built on a conception of individual autonomy in judgment and on processes for exposing that autonomy to challenge by others" (March \& Olsen, 1995, p. 168). The authors acknowledged that persons and their institutions must share a common life and identity in order to have concern for others. Persons are bound in interpretive communities that are organized around dialogue, around establishing temporary understanding adequate for human communication, acceptance, and action. Knowledge, values, and interpretations are created not only through interactions within a particular group but also by connections in an ecology of community. "Democratic governance involves creating identities 
and preferences that define what is appropriate, right, desirable, and acceptable, the rule by which citizens and officials are constituted" (March \& Olsen, 1995, p. 246).

Evans and Wamsley (1996, under review) emphasized that efficient and effective public management is not the appropriate end of public administration, but governance. The authors argued that intuition and feeling inform political and organizational decision making.

"Governance, thus, is more about the evocation of a relationship between citizens and their government than it is about steering toward some collective goal--the relationship evoked enables citizens to fulfill their life prospects and discover meaning and significance for their lives" (Evans \& Wamsley, 1996, p. 15, under review). Refuting Osborne and Gaebler's Reinventing Government (1992) concept where the client is reduced to the status of a customer than that of a participatory equal, the authors regarded government institutions as a both repository of and a conduit for the dissemination of tradition as well as the location for meaningful interaction between citizens and public administrators. "Increasingly, policy is formulated, implemented and adjudicated at the nexus between citizens (individuals and groups) and administrative institutions rather than being worked out through the channels of voters, parties and elected individuals" (Evans \& Wamsley, 1996, p. 30, under review).

Along the same lines, Harmon (1995, p. 11) stated that public administrators govern responsibly by "strengthening the social fabric of government institutions so that, together, public servants and citizens might struggle honestly with the moral uncertainty that inevitably attends government's work." Harmon emphasized that administrators need to understand that responsibility works within the context of social relationships and dialogue, not through the singular efforts of atomistic individuals. Social agency recognizes individual authorship and a social context where individual actions are understood through a web of collaborative relationships. Responsibility involves action congruent with community and relationships rather than action governed by abstract principles. Therefore, responsible practices join citizens in a moral community in which responsibility generates responsivity.

\section{Governance and the Importance of Dialogue}

Like scholars writing on responsibility, Barber (1984) emphasized that dialogue is at the heart of strong democracy. Entailing good listening and good speaking, talk is a "mediator of affection and affiliation as well as of interest and identity, of patriotism and individuality. It can build community as well as maintain rights and seek consensus as well as resolve conflict. It offers, along with meanings and significations, silences, rituals, symbols, myths, expressions and solicitations, and a hundred other quiet and noisy manifestations of our common humanity" (Barber, 1984, p. 177). Human discourse in a democracy enhances empathy while promoting autonomy.

Similarly, White and McSwain conceived of a social order grounded in the process of socialization and communication. Through language, meanings can be understood in a 
standardized manner. As such, "Society and the individual are inextricably connected through community. The one makes the other in a reciprocal, seamless relationship" (White \& McSwain, 1990, p. 27). The authors conceptualized a reworking of the traditionalist view of public administration, where decisions are worked out in a pragmatic context. Public administrators are communication facilitators; the agency is a partner in the process of democratic governance.

Stivers characterized a responsive bureaucrat as one who is sympathetic and empathetic, but she acknowledged that such qualities are not enough to commit people to attempting the difficult tasks that encompass being a public servant. Her thesis is that in making decisions, bureaucrats must listen to citizens. For Stivers, "listening expands justice to include the details of the situation and the significant differences among human beings" (Stivers, 1994, p. 366); listening has the potential to foster responsibility. Because listening promotes self-development, it enhances democratic accountability and effectiveness. Through listening, public administrators are facilitators who understand and appreciate the perspective of another.

\section{REFLECTIONS}

The issues of public guardianship are drawn from a variety of literatures including law, social science, psychology, ethics, and public administration. From the literatures dealing specifically with guardianship, ethics, and democratic governance, two distinct themes emerge. First, the guardianship literature reveals an overall pessimism about moral and adequate supervision of wards. From a variety of sources, public guardianship is regarded as being the mover of the poor and near poor out of society. Public guardians are reportedly inadequate to perform their tasks and have little if any supervision. Case loads are inordinately high, and public guardians institutionalize wards in order to make their jobs easier rather than aggressively pursuing less restrictive alternatives to guardianship. Second, and related to the first, public administration literature points to a hope for administrators as facilitators in democratic governance and the insistence on citizen involvement. It is imperative for democratic governance to promote citizens and their involvement in decision making, especially regarding their own lives. Rather than the application of established norms for decision making and behavior, public administrators must encourage and solicit the views of citizens.

These two themes undergird the research questions. First, is the public guardian a villain as the literature bears out? Do public guardians categorically supplant the interests of the ward with the interests of third parties, especially the bureaucracy? Second, if so or if not, can a facilitation model of public administration be introduced? Will such a model be revealed in the examination of public guardianship and is such a model appropriate? From these themes from the review of the literature, the methodology is derived and implemented in this study of public guardianship. 


\section{CHAPTER III}

\section{METHODOLOGY}

When we try to understand aging, we are both researchers and the subjects of our study. Doing qualitative research is the ultimate test of our sensitivity to our own aging.

Lucy Rose Fisher

The purpose of this chapter is to elaborate on the methodological techniques discussed in Chapter I. First, qualitative analysis and its appropriateness for the research question will be discussed. An explanation of the research population and sites follows. Procedures for data collection and analysis conclude the chapter.

\section{QUANTITATIVE VERSUS QUALITATIVE RESEARCH}

Controversy rages concerning the broad categories of scientific measurement; scientists vociferously disagree as to the validity of quantitative versus qualitative research. In large part these are questions of epistemology (theory of knowledge or how researchers view nature) and ontology (how researchers define reality). The ongoing debate over the nature of science is trapped in fervent opposition concerning methodological paradigms or scientists' world view (Kuhn, 1970). Although scientists argue as to whether either of these methodologies constitute science, a convincing body of research emphasizes that neither approach, qualitative nor quantitative analysis, has a monopoly on what is known as "the truth" (Patton, 1990). The best wisdom is to incorporate both in research when possible, but foremost, to properly fit the type of research to the questions that are being asked.

Quantitative measures, arising from a Newtonian vision of the world, are generally embraced by the hard sciences. "Quantitative measures are succinct, parsimonious, and easily aggregated for analysis; quantitative data are systematic, standardized, and easily presented in a short space" (Patton, 1990, p. 24). Alternately, qualitative measures, reflecting a post-modern view of the world, are often embraced by the soft sciences. Qualitative measures are description dense, incorporate field work and becoming close to persons, include direct quotation, are not easily categorized, and require substantial time in the field. Their presentation is equivalent to narrative literature and may be quite lengthy.

This study seeks to ask questions that offer insights not available through survey research (Fisher, 1994). I am intent on the creation of meaning and values surrounding guardianship as revealed by relevant actions and actors (Berger \& Luckmann, 1967; Jaffe \& Miller, 1994). The objects of research are intended to be presented as holistic, thinking, feeling, thoroughly human subjects. Although the study includes some quantitative information, it primarily employs 
qualitative measures, precisely because it is qualitative information that best captures the intersection of public guardians and what they do for their wards.

\section{Qualitative Research}

Qualitative research is especially suited to certain types of questions; according to Rothe (1994, p. 8), it raises "questions or alternative points of view on a social phenomenon, searching for conventions particular to the genre of actions, and interpreting the actions according to the social context." Qualitative research capitalizes on its strengths of detection, representation, perspective, and explication of the meaning of phenomena from the viewpoint of the persons who are participants (Patton, 1990; Sankar \& Gubrium, 1994). It is especially appropriate for answering "how and why" questions.

Janesick (1994) insisted that it is necessary to consider certain characteristics of qualitative design prior to embarking on a qualitative study. She offered a list of the elements of qualitative design, generated as a heuristic tool, that includes these qualities: (a) a holistic design is used; (b) relationships are within a system or culture; (c) emphasis is on situations that are personal, face-to-face, and immediate; (d) focus is on a particular social setting; (e) the researcher stays in the setting over time; (f) time in analysis is equal to time in the field; $(\mathrm{g})$ the researcher becomes the research instrument; $(\mathrm{h})$ the researcher develops a model of occurrences in the social setting; (i) informed consent documents and other ethical concerns are incorporated; (j) a description of researcher's role and biases are included; and (k) data analysis is ongoing. Testing for these requirements within the research design as well as incorporating general definitions of qualitative research, the qualitative method of research and analysis is preferable for the research questions of the study.

In qualitative research, researchers employ various orientations to approach and examine data. These orientations describe how a researcher depicts social life and its situations (Rothe, 1994). In phenomenological research, people's words and actions are purposeful, and these constitute meaning in the world. According to the phenomenological orientation, people experience the world intersubjectively. This approach is "concerned with the meaning or intention that the social world has for its actors" (Rothe, 1994, p. 44). It is through this lens that this researcher approaches qualitative data analysis.

The perceptions and reflections of the ward, the primary public guardian, the program supervisor, and the researcher are extremely significant in answering the primary research question of how public guardians meet the needs of their wards. In order to capture the perceptions, through words and actions, of the persons under study, chiefly qualitative data collection and analysis will better answer the research question(s) than will quantitative information. 


\section{SELECTION OF THE POPULATION}

In order to validate and replicate qualitative analysis, it is imperative to explain and justify each step in the various research processes: sampling techniques, data collection, and data analysis (Miles \& Huberman, 1994). A blueprint rarely exists for qualitative researchers as exists in research of a more quantitative nature. It is therefore necessary to justify selection of the population being sampled in order to increase validity and replicability. Theoretical issues involved in selecting research participants must be as closely matched as possible in order to develop and expand theories that undergird the study.

The research sites selected represent five examples of service delivery. Although they share similarities, they are constrained by individual state codes in addition to regulations and rules governing particular localities. Multiple research sites allow for significant variation in the settings and permit, within the specific research questions, comparison of similarities and differences among them.

In applying a theory of democratic governance that is reflexive and responsive to citizens, the various models of service delivery provide five avenues for testing a theory of a public administration that demands increasingly individual and contextually appropriate decision making. Comparing and contrasting the perspectives of the actors involved and aspects of individual programs make it possible to determine how government assumes the unique decisional life of a citizen.

The five research sites selected are in the eastern United States, represent different service delivery models, and are in close geographical proximity to one another. Although there were other public guardianship programs from which to consider, selection of a broader set of programs would entail more complex and costly considerations than were appropriate for the purposes of this research. Therefore, site selection was based on issues of proximity to Virginia, where two distinct models of service delivery were initiated due to a grant in July 1995 that enabled two pilot projects to operate concurrently for that fiscal year. The other sites were in geographical proximity to Virginia and had public guardianship programs that had been in existence for at least ten years.

A first site selected was the Office of the Public Guardian in Montgomery County, Maryland; the Maryland public guardian is an example of a public guardian office that is based on a social service model. The Montgomery County Public Guardian, who is guardian of the person only, serves clients both over and under the age of 65. Arrangements for conducting research were made with the program supervisor of the Office of the Public Guardian located in Rockville, Maryland.

The second research site, the Office of the Public Guardian in Delaware, is an example of the court model of public guardianship. It serves adult Delawareans with disabilities who are at 
risk, without family, and are unable to make decisions for themselves. Its main office is located in Wilmington, Delaware. It is an arm of the courts and the only state level court model office in the country. Arrangements for conducting research were made with the head of the Office of the Public Guardian.

A third research location is in Johnson City, Tennessee, and is part of the Area Agency on Aging, the First Tennessee Development District. The public guardian in Tennessee is an example of a non-profit model of service delivery, although it is housed within a public social service agency. The public guardian in Tennessee serves persons over sixty years of age and older who cannot manage their own affairs. Arrangements to conduct research were made with the Executive Director of the Area Agency on Aging and the public guardian of the First Tennessee Development District.

A fourth site is located in Falls Church, Virginia and is a non-profit model, Personal Support Network (PSN). PSN is part of the ARC (Association of Retarded Citizens) of Northern Virginia; PSN is one of two pilot projects that is operating in the Commonwealth of Virginia. The fifth research site and other demonstration project in Virginia is located in Chesapeake, Virginia and is a volunteer model of public guardianship. The Chesapeake Volunteer Guardianship Program (CVGP) is housed in the Chesapeake Department of Social Services. Arrangements for conducting research at the Virginia sites were made in agreement with the program supervisors at the pilot sites and with the permission of the Virginia Commissioner on Aging. Details concerning the organization of the sites for research will be presented in the following chapters.

\section{Selection of Research Participants}

Due to special considerations and protections afforded to the research population, permission to conduct research was approved by Virginia Polytechnic Institute and State University's Institutional Review Board regarding research with human subjects in February 1996. Informed consent documents were prepared for all persons who were interviewed: the program supervisor, the primary public guardian, and the ward. Although the ward's signature is not legally binding, the researcher and the institutional review board agreed that the ward should be offered an assent form to sign, if he or she was physically capable of signing. In all, six wards signed the document. Wards were made explicitly aware that the interview would not be conducted in the presence of the public guardian, and that wards could terminate the interview at any point and omit answering any question for any reason.

Confidentiality of the ward's records was also an issue. I coded photocopied records in order to protect anonymity, and I kept written and photocopied records and the key to the code in a locked file cabinet. The audio taped and transcribed interviews of the ward, the primary public guardian, and the program supervisor were kept under lock and key. I understand that, at the conclusion of the research, tapes and photocopied records will be destroyed to further protect 
anonymity. The names of the research participants will not appear in any printed material resulting from data collection. Vignettes are presented at the beginning of the next three chapters in order to humanize the research participants. I have used fictional names that are in keeping with the persons whose perspectives I portray.

Permission was granted to conduct a research pilot through the Maryland Office on Aging; it was conducted on October 27, 1995, in Rockville, Maryland, at the Montgomery County Department of Social Services. I consulted with the public guardian supervisor and a primary public guardian regarding the feasibility of the study. Additionally, I observed the interactions of the primary public guardian and the wards; I asked both wards and guardians a proposed set of questions for the research design in order to test for suitability and comprehension of the research questions. The questions were subsequently modified with the advice of the primary public guardian and her program supervisor. After I conducted a pilot of the research design, I selected the research population, which included the public guardian, her program supervisor, and four wards at each research site.

I observed that there are at least two types of wards: those who could communicate their wishes to some degree and those who cannot or can communicate their wishes minimally. Consequently, I modified the research design to include participant observation of the public guardian with two wards who could minimally communicate their wishes and two wards who were relatively lucid, could respond to the questions being asked, and could comprehend a written or verbal explanation of an informed consent document.

In most cases I selected ward participants from written and verbal information on a pool of wards having the qualifications that I indicated. However, selection of research participants was constrained by the availability of wards who could communicate and process information in order to answer questions, wards who would agree to answer questions posed by the researcher, and the visitation and work schedules of the primary public guardian. Research participants at the various sites were selected according to several criteria. Criteria for selection of the wards who became research participants included availability of clients, willingness to answer questions, a male/female mix (where possible), age of the client, length of time the person had been a ward, presenting conditions, ability to communicate and be understood, and lucidity. For the purposes of this research, lucidity was determined as being oriented to person, time and place, ability to understand questions and reason; ability to understand the consequences of actions; ability to recognize the public guardian; ability to recognize persons generally (i.e., ability to comprehend the researcher's questions and purpose); and ability to contextually process information. I attempted, where possible, to choose one male and one female ward for interview and observation. The participants who were available for interview and observation were predominately older adults. Consistent with prior research, persons requiring guardianship are overwhelmingly female and older than the general population (Bulcroft, Kielkropf, \& Tripp, 1991; Lisi \& Barinaga-Burch, 1995; Schmidt et al., 1981). 
In addition to wards, research participants included the primary public guardian (also referred to as the case worker or the client representative) and the program supervisor. The primary public guardian is the person who represents the nexus of the state and the individual. The primary public guardian is a "street level bureaucrat" (Lipsky, 1980) whose job it is to implement the laws of the state regarding public guardianship. In Maryland, Delaware, and Tennessee, only one primary public guardian was interviewed. In Virginia, at PSN, two primary public guardians were interviewed, and at CVGP, both the Adult Protective Services (APS) caseworkers as well as volunteer guardians were interviewed as representing the primary public guardian. The interviews of the APS caseworkers were later dropped from the pool of primary public guardians due to the fact that they serve as liaisons to the volunteer guardians at CVGP. Where pertinent, comments about them will be included as they relate to the volunteer guardians.

Questions were sent to program supervisors and public guardians well in advance of the interviews so that they could have a sense of the questions being asked and their potential impact upon the wards. Interviews of primary public guardians and program supervisors were face-toface, open-ended interviews. Participant observations were also conducted with primary public guardians and their wards. Both program supervisors and primary public guardians were given informed consent documents to sign; they were apprised that their interviews would be audio taped and subsequently transcribed to facilitate data analysis.

\section{PROCEDURES FOR DATA COLLECTION}

Data collection and analysis were accomplished through participant observation, openended interviews, and official documents contained in the ward's case file. Participant observation is consistent with qualitative research because it allows reflexivity with its subjects. It examines the research process itself in addition to any biases of the individual who is conducting the research (Allen \& Walker, 1992). According to Jorgensen (1989), participant observation is especially appropriate when phenomena are hidden from public view, not well known, and observable in everyday life settings. In participant observation, the researcher actually experiences the phenomena under investigation (Patton, 1990).

\section{Participant Observation}

Participant observation is especially appropriate to investigate the research question. I was interested in human meaning and interaction, and I wanted to understand the unique experiences and perceptions of individual wards, public guardians, and program supervisors. I participated in the work of the public guardians by visiting the ward, reviewing records kept in facilities, and questioning both caregivers and facility staff regarding the ward. Participant observation was used in conjunction with other methods of gathering data. 
Participant observation was also necessary to explore the theory of democratic governance outlined above as it applied to meeting the needs of wards of public guardians. The theory that government should reflex with, be responsive to, and represent citizens is applied to "real world" settings. This theory for public administration is tested through perceptions of the persons being observed, in the daily life experiences of wards, and by decisions of the primary public guardians and program supervisors.

\section{Open-Ended Interviews}

I utilized open-ended interviews to elicit responses to questions asked of all participants. Open-ended questions facilitate depth, detail, and meaning at a very personal level of experience of the research participant (Patton, 1990). Open-ended interviews may be either unstructured or semi-structured, that is, an outline of the questions may be prepared in advance, and other questions are asked as they evolve from the interview (Rothe, 1994). I used semi-structured interview questions.

Open-ended interviews were conducted with two wards at each research location, their primary public guardian, and the public guardian's program supervisor. Sending questions and other documentation to program supervisors in advance of field work proved especially important in securing permission to study public guardianship. The public guardianship agency understood that I would interview wards in private so that they would feel free to make comments concerning the primary public guardian's efforts to address and respect their needs and wishes. I made running notes in addition to the face-to-face interviews on audio tape. The tapes were subsequently transcribed; transcripts were saved on computer diskettes so that they could be used for computer analysis, and hard copies of the transcripts were also created. Handwritten notes of the observations and other pertinent notes were also put on computer diskettes. Later, I reviewed the transcriptions for accuracy and telephoned research participants regarding questions.

These methods of information gathering insured that the research emphasis was on the perceptions of the relevant actors. Research participants shared their views and experiences within the context of participant observation and open-ended interview questions. By using these techniques, I entered into the world of the participants and understood the phenomena under scrutiny. I rephrased research questions for wards who had difficulty understanding the questions being asked. Not all wards were able to answer all questions or follow-up questions.

The interview design for wards included questions concerning information about their life as they remembered it, how they came to be under the public guardian's care, how well they felt the public guardian knew them, how they felt about being a ward, and how the public guardian met their needs. Interview questions for the primary public guardian included the background of the primary public guardian, case load, feelings about being a public guardian, knowledge of ward's needs and wishes, characteristics of the relationship of the public guardian 
and the ward, nature of the observed guardian/ward interaction, decisions made on behalf of the ward, and accounting and paperwork requirements. Questions asked of the program supervisor focused on the background of the public guardian, the program supervisor's accountability and the primary public guardian's accountability, characteristics of persons who are primary public guardians, organizational support for the office of the public guardian, ideas for change within the department, and ideas for change in public guardianship.

By asking a set of pre-arranged questions, the ward, program supervisor, and primary public guardian could focus on answering primary and secondary research questions. Depending on the answers given, follow-up questions not in the original set of questions permitted the respondent to elaborate on thoughts, feelings, and perceptions of guardianship, unique experiences pertaining to guardianship, and the individual. In this way the interview and observation process was empowering to participants because it allowed them to give voice to their individual experiences and perceptions. Consequently, the rich and individual data permitted greater possibilities for theory construction.

\section{Documents in Case Files}

A third data source included pertinent documents in case files. All states would not permit a review of the case files, and so, particularly in Maryland, only information that was a matter of public record was available for my inspection. States and localities, according to the service delivery models and the discretion of the agency, varied in the amount of information contained in the case files and permissible for review. Common to the information that I obtained at all sites were psychological-social information on the ward and copies of the petition for guardianship. Certain other records were available for photocopy or note taking at the discretion of the public guardianship agency. Time logs on the actual time period spent on a ward by the primary public guardian were available in some files.

Official documents provided valuable information on the perspective of the agency, in addition to providing baseline data on individual wards, their needs, and plans devised for meeting their needs. At some sites, pamphlets or other official publications of the agency were provided for me to facilitate my comprehension of its administrative structure.

Information from the interviews of the wards, public guardians, and program supervisor were compared. Also, information provided in written documentation on individual cases in addition to programmatic booklets permitted cross-checking and validity of the data. Finally, field notes increased data validity. In this way, data collection methods facilitated triangulation of data; I cross-checked data against the interviews of the participants as well as participant observation notes and the review of pertinent documents in case files.

These methods of data collection allowed various avenues for understanding public guardianship. As mentioned earlier, the method of data collection that utilizes a variety of 
sources is known as triangulation and is one of the hallmarks of good qualitative research techniques. Triangulation helps to locate and define phenomena by using different methods, so that the weakness of employing one method of data gathering is overcome (Rothe, 1994). According to Patton (1990, p. 470), "Triangulation is a process by which the researcher can guard against the accusation that a study's findings are simply an artifact of a single method, a single source, or a single investigator's bias." It uses multiple perceptions in order to clarify meaning and to verify the replicability of observations or interpretations (Stake, 1994).

I employed triangulation in two different modes. First, I incorporated multiple sources of data, as explained in detail above. Second, I used three or more interview sources at each site, that of the ward and collaterals (paid and volunteer public guardians and program supervisors).

\section{DATA COLLECTION}

My research encompassed two full working days at each site, or at least sixteen hours of on-site field work at each location. I carried out on-site data gathering from February through May 1996. Analysis of data commenced with initial data collection and continued through November 1996.

\section{Data Collection in Maryland}

In late February 1996, in-person data collection began with the program supervisor concerning the interviews of wards, the primary public guardian, and herself. The supervisor oriented me in detail concerning the organization of the public guardian in Montgomery County and assisted me in establishing the schedule of interviews and observations of the primary public guardian, who serves as guardian of the person only, and wards. The supervisor also discussed confidentiality issues. Confidentiality of data was closely scrutinized. The researcher's informed consent documents and research protocols were reviewed by the Maryland Attorney General, who would not authorize review of case files of wards who were under the age of 65 .

In Maryland, there were few choices to make regarding research participants for interview and observation. Although I interviewed three wards, I was unable to independently choose the participants. Even though I made arrangements well in advance and specified selection criteria, the program supervisor insisted that the primary public guardian had to meet end-of-the month client visitation deadlines. The program supervisor wrote a letter to support her position that in allowing a narrow range of choices of ward interviews and observations, her intent was neither to thwart research nor to taint the pool of research participants.

Simply put, these restrictions reflect the constraints under which public guardianship operates. It is interesting that the Maryland sites included the greatest variation in habilitation of any of the wards who were interviewed and observed. One ward was in a nursing home, one ward was in her own home, two wards were in adult day care settings, and one ward lived in a 
group home. I interviewed three wards and observed a total of five wards: two men and one woman for interview and two additional women for observation only. At the end of the second day of data gathering, due to time constraints, I had not completed the interview of the primary public guardian that pertained specifically to two of the lucid wards. This section of the interview questions was repeated for each ward. After consultation with the public guardian, we decided that she could mail written answers to the remaining questions; she complied with this request within two months of my visit.

\section{Data Collection in Delaware}

Upon completing the in-person data gathering in Maryland, I traveled to the Office of the Public Guardian in Wilmington, Delaware for in-person data gathering at the end of February 1996. In Delaware, I was presented with a choice of 53 wards from which to interview and observe. The pool of wards for potential interview narrowed significantly when I considered the relative lucidity of the wards and their ability to communicate. Essentially, although I had more wards from which to select than in Maryland, the number of wards who could in some way answer questions was only slightly greater than the pool of wards from Maryland.

All wards were housed in an institution of some kind, and usually, the overall capabilities of the Delaware wards were more limited than those in Maryland. Unlike Maryland, confidentiality issues were not as constraining; I had access to all of the department's visible files. I gathered psychological-social information, six months reports, and copies of the wards' court petition. Public guardians in Delaware serve as guardians of the person and of the property. I observed four guardian/ward interactions and interviewed in-person one primary public guardian and one program supervisor.

\section{Data Collection in Tennessee}

In March 1996, I collected data in Johnson City, Tennessee. I interviewed the program supervisor, who was the Executive Director of the First Tennessee Development District Area Agency on Aging, the primary public guardian, and two wards. I was a participant observer of the interaction of the primary public guardian, who may serve as guardian of the person, the property, or both as well as power of attorney, and four of her wards. I was presented with a choice of three wards to interview, and after reviewing files and consulting with the public guardian concerning their lucidity and their willingness to be interviewed, I selected two older women. No male clients were lucid enough to answer questions; the only male who met the research criteria would have been disturbed by the interview questions; therefore, the public guardian recommended against interviewing him. 


\section{Data Collection in Virginia}

Data collection continued in April 1996 at the first of two pilot projects in Virginia. Although Personal Support Network (PSN) serves as guardian of person, of property, or both, as well as bill payer, power of attorney, personal advocate, and representative payee, I interviewed and observed only those persons who were wards of the agency. Because PSN represents a guardianship program in its infancy, it diverged from the first three sites in that no public guardian was full-time. All persons employed at the agency were performing guardianship functions as a portion of the time in which they fulfilled other duties at PSN. As mentioned in the first chapter, I am a co-evaluator of both pilot projects for the Virginia Department for the Aging. Consequently, I had spoken by telephone with the program supervisor on numerous occasions and visited the research site twice prior to data gathering for my study. I was restricted in selecting wards for interview by the small number of guardianship clients who were somewhat lucid and would be willing to be interviewed. Thus, only four wards comprised the pool of participants for interview and observation. One potential participant spoke primarily in Spanish, and another was combative and could not be observed with his guardian on the days of my research. I was allowed access to files, including assessments, care plans, and time logs of public guardians.

In May 1996 I traveled to Chesapeake, Virginia, in order to collect data from the Chesapeake Volunteer Guardianship Program (CVGP). Chesapeake's program is based on a volunteer guardianship model and is also a pilot program operating in Virginia. At the time of data collection, the program served eight persons, seven of whom were wards. Volunteers serve as guardians of the person, of the property, or both, as well as power of attorney, companion, and representative payee.

It is important to note that, like the pilot program in Falls Church, Virginia, CVGP has been operative only since its funding in July. Because of agency constraints on hiring, the volunteer coordinator position was not filled until September 1995, and so few persons had moved through the court system to become wards. Consequently, there were few wards in this program from which to choose for purposes of data gathering. Because I am also co-evaluating this pilot program for the Virginia Department of the Aging, I had spoken with the program supervisor on numerous occasions prior to the interview and had visited the research site twice prior to gathering data for the dissertation.

\section{DATA ANALYSIS}

Analysis of qualitative data begins with initial data collection and continues long after the researcher leaves the field (Miles \& Huberman, 1994). The overall purpose of analysis is to discover the themes and patterns that come from raw data. Thus, through analysis of the data, theory is developed and supported. This type of theory development emerges from the data and is labeled "grounded theory" (Strauss \& Corbin, 1990). In grounded theory, the data are put into 
categories and "through constantly comparing the content of them, defines the properties of the categories until they have taken on an abstract form, i.e., until a typical incident for the category could be defined conceptually in terms of the category's properties" (Tesch, 1990, p. 64).

I used Quantitative CyberQuest, computer analysis software, to help me grasp the complexities of guardianship as I was both reading and experiencing it. Quantitative CyberQuest is one of several computer programs that possesses a number of qualitative aspects that facilitate data analysis. It assisted me in reflecting on and reflexing with the data in order to comprehend, understand, and interpret the data from the perception of the research participants, as well as my own perceptions.

I coded data according to the questions asked and patterns that emerged from the raw data. Coding was checked by a fellow graduate student who reviewed my coding for goodness of fit to the phenomena of public guardianship. Microsoft Access, a relational database program, helped me categorize and organize data from the transcriptions so that I could make comparisons.

Patton (1990) emphasized that there are few agreed upon cannons regarding analysis of qualitative data; therefore, it is necessary to report honestly and fully my analytical procedures. After the collection of verbatim raw data, the creative process of data analysis began. The first step was to label the kinds of data and establish a data index. Data were analyzed inductively to establish emergent themes and patterns that came from the data. Themes, the hallmark of qualitative analysis, "provide a bridge to a mode of constructing scientific knowledge that is at once more objective, dispassionate, and less lucid, and thus credible, legitimated, and authorized because themes can be counted and share the aura of the numerical language of science" (Luborsky, 1994, p. 191). Themes are generalized statements by research participants who represent their perceptions about their life world. Alternately, patterns describe findings from the researcher's point of view; they are amassed from the reflection, observation, and analysis of the researcher about the perceptions of the research participants. (Luborsky, 1994).

In the early stages, I looked for key phrases or terms, and from this, developed certain typologies into patterns (Rothe, 1994). I searched for "recurring regularities" (Patton, 1990) and began with codes or tags for assigning meaning to descriptive information from the data (Miles \& Huberman, 1994). Then, I used codes to organize chunks of data. After initial coding, I refined the codes to include the tags that emerged. I concluded the coding when the analysis appeared to have run its course (Lincoln \& Guba, 1985; Strauss, 1987). The codes, in relation to each other, became a sort of governing structure; from this structure the codes were transferred into conceptual variables (Miles \& Huberman, 1994).

After coding and grouping the data, I used my understanding of the literature and my experience as a researcher to organize the patterns into themes as I saw them. I organized the 
separate pieces of data to interpret and explain the perceptions of the research participants and the world of the phenomena under study.

The results of my analysis and a discussion of the findings are presented in the following three chapters. For the convenience of the reader and for organizational purposes, the material is divided into a chapter on paid and volunteer public guardians, a chapter on program supervisors, and a chapter on the wards. Nonetheless, it is necessary to emphasize that the division of the chapters in no way implies that the three actors as well as others in the guardianship process act separately. Quite the contrary, all three roles are intertwined in guardianship. To fully understand guardianship, the reader should bear these relationships in mind. A vignette of one of the persons in each role is presented at the beginning of each chapter to guide the reader in remembering this point and to further humanize the men and women whom I studied. 


\section{CHAPTER IV}

\section{BACKGROUND AND EFFORTS OF PUBLIC GUARDIANS}

The moral test of government is how it treats those who are in the dawn of life, the children; those who are in the twilight of life, the aged; and those who are in the shadow of life, the needy and the handicapped.

Hubert Humphrey

\section{NANCY EVANS}

A social work administrator prior to getting her Masters Degree, Nancy carries a case load of twenty-five persons. Rather than knowing that she wanted to go into geriatrics, the position opened up for her, and she applied for it. Her previous work had been at the Department of Social Services working in the areas of Crisis Intervention and Dementia at the Assessment Center. "I thought it was one of the most challenging and certainly the most difficult job I interviewed for," she stated. "I was selected, and I got very wide exposure to a variety of situations. I worked with a lot of elderly [persons] as well as young adults." She has been in her current position as a paid public guardian for over seven years, and she confessed that it was definitely a good move. "Something l've grown in. And l'm still here."

One of Nancy's clients was looking out the window of the adult care home when we arrived. This ward was waiting for Nancy, her public guardian. Although the ward could communicate very little verbally, the ward insisted that she wanted to obtain eyeglasses worn just like her guardian, Nancy Evans. After Nancy asked questions of the facility administrator about her night wakefulness and other physical problems, the ward followed us out the door. The ward was still looking out the window as the car pulled away.

When asked about her philosophy of guardianship, Nancy replied, "I feel like I keep learning. I think that the people that have public guardians here, many of them are better off than the people with private guardians because of the high quality of commitment and the accountability. And there's a lot of satisfaction in it. It's not a job where you feel like you're counting grains of sand. You can really see tangible gains with the population." 
Five paid guardians and four volunteer guardians operating under publicly funded programs were interviewed ${ }^{4}$. Social worker liaisons for the volunteer guardians were also interviewed, but findings will be reported only as they pertain to the volunteer guardians. Public guardians were interviewed regarding their background, actions taken and decisions made to meet ward needs, accountability and effectiveness, and general philosophy of guardianship. This chapter represents the findings of the interviews, observations, and case file notes of the paid guardians; wards' satisfaction with guardians and guardianship; and programs supervisors' comments on primary public guardians. The findings are discussed at the end of the chapter.

\section{COMMENTS OF PUBLIC GUARDIANS}

The background of paid guardians revealed similarities in education and job-related experience. As shown in Table 1, paid public guardians had college degrees in social work or education. Two paid guardians had Master's Degrees, and one part-time paid guardian at Personal Support Network (PSN) in Virginia held two Master's Degrees. Guardians either had formal clinical training or through experience had developed a working knowledge of medical terms and conditions. The paid guardian in Tennessee had worked as a nursing home activities director in another state and was a volunteer ombudsman at her present agency prior to assuming her position as the public guardian. The position of paid public guardian was not an entry level position for any of the persons interviewed. Many paid guardians had worked for a number of years in other capacities in their agencies prior to the role of primary public guardian; the average time on the job for paid guardians was 7.8 years. By contrast, backgrounds of the volunteer guardians were varied, but, interestingly enough, one volunteer had a formal background in education and another had training as a nurse's aide.

Responsibilities of the paid guardians varied, depending on the organization of the agency. Table 1 shows that four of the five paid guardians worked full-time, and one paid guardian worked part-time. Guardianship was one among many responsibilities for the volunteer guardians at the Chesapeake Volunteer Guardianship Program (CVGP) in Virginia. Caseload numbers varied from one (volunteer guardians) to a high of 49. In Virginia at PSN guardians carried guardianship cases for the demonstration project along with other cases and responsibilities for PSN. Not all guardianship cases for any site were of both the person and the property. Maryland paid public guardians, by statute, could serve as guardians of the person only. This distinction did not mean, however, that public guardians were precluded from addressing financial aspects of guardianship. In Tennessee and PSN and CVGP in Virginia, guardians could serve as power of attorney. Additionally, the Virginia sites could have guardians serving as representative payee, client advocate, and companion.

${ }^{4}$ Guardians will be distinguished as paid and volunteer. When the term public guardian or primary public guardian is used, it refers to both paid and volunteer guardians. 
Table 1

Background of Public Guardians

\begin{tabular}{|c|c|c|c|c|c|c|c|}
\hline Guardian & Site & Caseload & $\begin{array}{c}\text { Guardianship } \\
\text { Cases }\end{array}$ & Sex & Education & $\begin{array}{l}\text { Years } \\
\text { Served }\end{array}$ & $\mathrm{PT} / \mathrm{FT}$ \\
\hline $\begin{array}{c}1 \\
\text { (Volunteer) }\end{array}$ & CVGP & 1 & 1 & $\mathrm{~F}$ & $\begin{array}{l}\text { Bachelor's } \\
\text { (Education) }\end{array}$ & 2 years & PT \\
\hline $\begin{array}{c}2 \\
\text { (Volunteer) }\end{array}$ & CVGP & 1 & 1 & $\mathrm{~F}$ & Nurse's aide training & 3 years & PT \\
\hline $\begin{array}{c}3 \\
\text { (Volunteer) }\end{array}$ & CVGP & 1 & 1 & $\mathrm{~F}$ & Some college & 3.5 weeks & PT \\
\hline $\begin{array}{c}4 \\
\text { (Volunteer) }\end{array}$ & CVGP & 1 & 1 & M & Post high school training & 1 month & PT \\
\hline $\begin{array}{c}5 \\
\text { (Paid) }\end{array}$ & $\mathrm{DE}$ & 49 & 49 & $\mathrm{~F}$ & $\begin{array}{c}\text { Bachelor's } \\
\text { (Sociology \& Psychology) }\end{array}$ & 19 years & FT \\
\hline $\begin{array}{c}6 \\
\text { (Paid) }\end{array}$ & MD & 25 & 25 & $\mathrm{~F}$ & $\begin{array}{c}\text { Master's } \\
\text { (Social Work) }\end{array}$ & 7 years & FT \\
\hline $\begin{array}{c}7 \\
\text { (Paid) }\end{array}$ & PSN & 10 & 2 & $\mathrm{~F}$ & $\begin{array}{c}\text { Masters (2) } \\
\text { (Education \& Liberal } \\
\text { Studies) }\end{array}$ & 3 years & PT \\
\hline $\begin{array}{c}8 \\
\text { (Paid) }\end{array}$ & PSN & 20 & 6 & $\mathrm{~F}$ & $\begin{array}{c}\text { Master's } \\
\text { (Social Work) }\end{array}$ & 3.5 months & FT \\
\hline $\begin{array}{c}9 \\
\text { (Paid) }\end{array}$ & $\mathrm{TN}$ & 39 & 39 & $\mathrm{~F}$ & $\begin{array}{l}\text { Bachelor's } \\
\text { (Education) }\end{array}$ & 6.5 months & FT \\
\hline
\end{tabular}

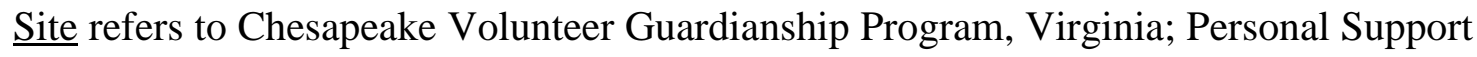

Network, Virginia; Montgomery County, Maryland; Office of the Public Guardian, Delaware; or the Tennessee Public Guardian, First Tennessee Development District.

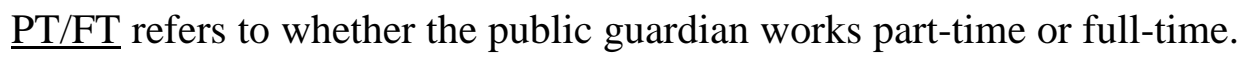




\section{Philosophy of Guardianship}

Paid public guardians were attracted to their positions for a number of reasons. Most expressed an interest in working with older adults and the potential for affecting positive outcomes in the lives of the persons for whom they served. One paid guardian stated that she was drawn to public guardianship because of its potential for continued opportunities for learning, while another stated that she was looking for challenging work and felt that guardianship provided that challenge.

By virtue of serving as public guardians as well as earlier work experiences, paid public guardians expressed some definite ideas about guardianship, including investigation, establishing relationships with caregivers, and interpersonal relationships with clients. One paid guardian emphasized the importance of investigation. "I always try to get as much information about the personal needs of the ward just so I understand what they would like if things were perfect." She also stressed the primacy of establishing a good working relationship with facility staff, particularly nurse's aides, because they directly provide personal care to institutionalized wards.

Another comment concerned guardianship in general. "Most of the time people... usually become a ward of the public guardian unless you are truly incompetent. Doctors all the time declare people incompetent. They don't want to send them home from the hospital, and the trick is they need services. So in that respect I feel that we make things better."

Along with establishing a relationship with facility staff and physicians was the importance of touching clients. Several guardians underscored the importance of physical contact and physical proximity to wards, if wards were receptive. Alternately, a guardian who acknowledged that she frequently had ward visits where the ward turned his head away from her, said that she left him alone in order to respect his wishes rather than to press him to respond to her.

Another paid guardian stated that not only was organization important but also going the extra mile versus merely fulfilling the job requirements. It was common among the paid public guardians that they invested themselves greatly in their work. They acknowledged that they put more effort in their work than perhaps they should. At least three guardians agreed that it provided a terrific learning experience for them. Said one guardian, "This is an obligation just the same as raising a child. You don't walk away from it. You can't walk away from it."

Paid guardians saw themselves as advocates for the wards. Said one guardian, "My feeling is very strong that a person needs a personal advocate no matter what their situation is." Another paid guardian had this to say, "Take people where they are. Deal with each problem as it comes up. Everyone wants you to succeed with that client. Try to put the clients first and one 
day at a time. If you want medical services for that patient you have to make sure they have Medicaid. You are becoming an advocate for the client."

One guardian admitted that it was easier to take care of multiple ward needs if the ward was in an institution. She cited that institutions had the capacity to evaluate wards' physical, medical, and personal needs thoroughly; this evaluation assisted her in planning to meet the wards' needs. She acknowledged that social needs are difficult to assess. The guardian said that when the ward had no money, she had was no other choice than to place the ward in a nursing home, even though guardians did not want to change the persons' environment unless no other option was available.

The volunteer guardians at CVGP were attracted to becoming guardians for mainly altruistic reasons. Two of the volunteers who were interviewed had prior personal relationships with their wards, i.e., they were friends of the family. The same two volunteers mentioned that they served as guardians because of their prior relationship with their ward, not because of their attraction to the demonstration project. One of the volunteer guardians, who had served as a guardian before the project began, admitted that she could not work with another ward whose situation was as complex as the one for whom she was currently guardian; "I couldn't do this often."

All participants believed that serving as a volunteer guardian was a way to contribute to the betterment of their community in a positive way. Said another volunteer guardian, "I love it. I love doing it [guardianship] for her [ward]. I'm not saying that I would take on another guardian in the event that something were to happen to her. The only way that I would take on another guardian is if somebody else was where she is now." Although volunteers are not paid by the project, they may claim five per cent of the ward's estate, as is customary for any private guardian.

\section{Changes for Guardianship}

All paid guardians expressed high job satisfaction, but most cited problems with caseloads that were inordinately high. The paid guardian in Maryland believed that her caseload was too high by at least four persons; the Tennessee guardian said that her caseload was also too high by four persons. I was made aware by the program supervisor that the full-time guardian at PSN in Virginia was being terminated for her inability to complete work in a timely fashion; she was the second such person to be terminated for this reason since the PSN demonstration project began. Shortly after my visit, a third employee filled that position. The PSN program supervisor was redistributing the number of guardianship cases prior to the employment of the third paid guardian. It was significant that the PSN guardian who was being dismissed had this to say about guardianship.

I would not come up with expectations that carrying 23-30 cases realistically is good guardianship. But I really think five to ten guardianships for heavy, intensive cases is 
about all you can really do a good job with. And one of the reasons Mr. B.'s [case] has been satisfying is that I've taken more time with him, sometimes my own personal time. But I felt it was needed. I would say change case load standards and make sure that you're not overloading people. Because guardianship is so complex. There are so many little pieces that you never think you have to deal with. So all of those little decisions that you have to make, you do not have time to carry a huge number of cases and do it well. Maybe you can do a very perfunctory job, but if you're going to do it well and really serve as a substitute family for these people, you've got to do it right. Otherwise, it's a waste of time, I think. I feel pretty strongly about that.

The paid guardian from Delaware who had worked in her position for nineteen years and was anticipating retirement made pertinent comments on public guardianship. She mentioned the changes that the office had undergone, such as an increased caseload, supervisory changes, and reporting changes. She remarked that reporting changes, such as transferring records from a manual system to a computerized system, were beneficial although they created job stress; learning to enter data into the computer added to her already numerous and complex tasks. She cautioned that over reliance on the computer could reduce the persons for whom she was guardian to a number and sheet of paper rather than the real, live persons for whom she made decisions. Through computer technology, she felt she was leaving behind a piece of herself. "I feel a lot better about retiring because of the fact that now my notes are kept on the computer, and referrals we're doing that way too. Because it's a lot easier to pass it on."

She believed that her job as a paid guardian was the best job in state government in terms of job satisfaction. When asked if she ever became depressed, she replied, "No, because we make things better." She added, "There are small changes that can be made to improve people's lives. As I leave, part of me wants to have kept my hand in and hopes that I just try to leave good records when I leave and put in what I feel are personal needs, especially the ones where they're competent enough. . .but they [wards must] really express their needs and their wishes to make sure the new people know. I just hope that they're [new employees] still going to be interested."

Complexity of tasks was one issue that was expressed by all public guardians. The Maryland paid public guardian said, "[The] system is very complicated, and instead of helping you like it's supposed to do, you run into all kinds of obstacles to access the resources you need. And you think you are working on the same side and you winding up fighting, you know, the same people you're trying to get resources from or scarce dollars. It can really be frustrating." All paid public guardians stated that cases were the most complex and required the most time at the inception of the guardianship.

In a similar fashion, volunteer guardians also admitted that their guardianship responsibilities required time for which they were unprepared. Importantly, two of the three social worker liaisons interviewed at CVGP in Virginia also stated that preparing guardianship 
cases and assisting volunteers in the early stages of work was labor intensive. One social worker liaison even prepared a packet of information for each guardian of important local and state telephone numbers and addresses to help them do their job more effectively. Social worker liaisons stated that although the early work of preparing volunteers was intense, their payoff was in locating a satisfactory volunteer guardian for a client and, over time, the reduction of their involvement with the client once the volunteer guardian was in place. Their time was reduced in some cases because the volunteer guardians could attend to some wards' needs.

\section{Coping with Guardianship}

Because of their multiple responsibilities, public guardians were questioned about how they coped with their work over time. Coping mechanisms varied among volunteer and paid public guardians. External coping mechanisms for paid guardians included involvement with friends and family, playing with family pets, working in a garden, exercise, and listening to music. Alternately, one volunteer said that she coped with the problems of guardianship through prayer.

Overall, new volunteer guardians did not anticipate the number of problems that seasoned paid guardians acknowledged. The newest volunteer guardian at CVGP in Virginia did not foresee that many coping mechanisms would be necessary. Another volunteer said that she had always coped with tough issues and enjoyed meeting challenges. In the interview of a fourth volunteer, who had only served as financial guardian for only 3.5 weeks, the volunteer said that she tried to work her responsibilities around her home and family obligations. She said that her tendency to be goal oriented would assist her in accomplishing various tasks.

Paid public guardians admitted that, while satisfying, the work was frustrating. Paid guardians remarked that although they understood that it was important for them to separate their professional lives from their private lives, it was difficult not to bring cases home with them. The Delaware guardian mentioned that weekly staff meetings provided an outlet to vent her problems and feelings. Taking extended vacations was another way that paid public guardians could distance themselves from their work. They emphasized that they coped with their many responsibilities by organization and anticipation, in addition to focusing on the tasks to be accomplished. They also said that in order to cope with the job they had to make allowances for emergencies and exercise flexibility. They acknowledged that their best planning was easily altered by emergency situations.

\section{TASKS OF GUARDIANSHIP}

"What do public guardians do?" is one of the unanswered questions of guardianship. Answering this question might appear simple, but it is not. Records are kept inconsistently, public guardians' responsibilities are often vague, and supervision is either spotty or virtually 
non-existent. Whereas it is the charge of public guardians to meet the needs of wards, this too, is an elusive concept.

My overall conclusion, reached only after much direct observation, interviews of the public guardians, and examination of case file notes is that, generally speaking, guardians perform several tasks. These tasks include discerning needs and wishes, monitoring services, providing services, brokering services, giving emotional support, and serving as surrogate decision makers. These functions are intertwined in many instances, hence creating the potential for conflicts of interest at the nexus of the state operative in its parens patriae role and the ward as a citizen retaining autonomy even after the loss of significant civil rights. We now consider each task in turn.

\section{Discerning Needs and Wishes}

Public guardians were often at a disadvantage when wards could not communicate with them or could only communicate in a minimal fashion. Efforts at discerning their needs had to be intensified and broadened so that public guardians could effectively make decisions on behalf of the ward. Guardians had to be creative in their attempts to investigate and understand the ward prior to disability. The zeal and success of their investigation affected how public guardians met the needs of wards, for if wards were unable to communicate, public guardians were forced to determine ward needs by their own instincts and the reports of others. For example, special efforts at meeting the communication needs of the wards were made by several guardians.

One paid guardian attempted to learn to communicate with her ward by expressions that she would use, such as the term, "Oh, boy!" when there was something that the ward liked. A public guardian arranged for special speech and physical therapies in order to help her ward swallow. The same paid guardian wrote a letter to distant family members to see if they knew her ward. Because the ward spoke a Slavic language, the guardian was coordinating a visit by a priest to see if he could speak to the ward in her own language; the paid guardian was also contacting a local university to see if their foreign language department could translate the family's letter that had recently arrived.

\section{Monitoring Services}

One of the main tasks of public guardians was that of monitoring services provided. This function was accomplished through a number of ways. First, guardians checked with facility staff or other caregiving professionals and read their written reports. This approach included questioning direct care providers. When public guardians visited wards, they spoke with aides and other nurses to monitor wards' physical and mental well-being. Guardians told me that cultivating a relationship with nursing staff was paramount to insure that wards received adequate treatment. They explained that although nursing facility staff tried to provide proper 
care to all residents, in fact, the monitoring of services by public guardians focused staff attention on their ward. Other professionals at facilities with whom public guardians consulted included social workers, activity directors, and nursing home administrators. Public guardians examined wards' charts in the nursing facility, including nurse's notes, administration of medications, eating patterns, behavior patterns, and pertinent lab reports. Frequently, public guardians personally accompanied their wards to physician or dentist appointments not only to spend time with their wards but also to speak directly with medical professionals who could help them assess the ward's condition and needs.

Another way public guardians monitor services is by attending the care plan meetings (generally held every six to eight months) on their ward at the nursing home or other facility. According to one paid guardian, "We work with the nursing homes. In monthly assessments we go in. . .I go to care plans. I was at. . .the care plan not too long ago, and that looks at the problems and you set up goals, something measurable." At a care plan meeting, a team approach is used to look at various aspects of individual residents' needs. Persons attending include the dietician, the social worker, the activity director, the director of nursing or the charge nurse, an involved nurse's aide, therapists of any kind, and others who might be pertinent. Most of the paid guardians attend these meetings. None of the demonstration project guardians said that they had been regularly attending, but the PSN guardians and one volunteer guardian mentioned that they were planning to do so in the near future.

\section{Providing Services}

Public guardians also provide certain direct services to wards. Direct services generally included the purchase, on the ward's behalf, of clothing and other personal items. Frequently during ward visits, the public guardians inquired about wards' need of such items as shoes, dresses, and overalls. At least two public guardians took the wards with them to allow them to pick out clothes. When asked about the importance of allowing wards choices and how she promoted ward autonomy the paid guardian in Tennessee stated, "I think letting her [ward] make those choices and acknowledging [her preferences], yes. [I say to her] if you do not want to be in this nursing home, although I am your conservator, I know that you are aware and that you know that, I mean she has an idea of what she wants, where she wants to live and how she had to live, and I think that by acknowledging her wishes, that [is] really basically trying to meet those needs."

The Maryland paid guardian mentioned that although taking the ward with her to pick out her clothes certainly respected her autonomy, it also posed other problems. The ward to whom she referred was still physically active. While they were looking at clothing for her, the ward walked away from her in the store and was lost for a time. "She kept walking away. If I turn my head for five seconds she goes the opposite way. She forgets where we're going. It's not a long time. It's a concentration of effort which is totally exhausting. She is a very tiring 
client because she's so active. It's like having a baby in an adult body. But there are months when I just monitor her briefly and call the caregiver if there are no issues."

Other examples of public guardians meeting the incidental needs of wards included the provision of money for the purchase of soda pop at the nursing home by the ward, the purchase of a radio and tapes of foreign language or music, provision of large print books, and the supply of a favorite candy.

\section{Brokering Services}

Along with purchasing items for the wards, public guardians arrange for the provision of services. They arrange physician's appointments, facility placements, and burial trusts for the wards. Two days prior to my visit, one public guardian took her ward to lunch. She commented on this experience.

The experience of standing in front of his door and him standing there with his great big long beard, disheveled appearance, wild, demented eyes, trying to persuade him to let me in. . .that was January. . .to this Wednesday when I took him out to lunch. He was waiting for me and he had his back to me. I didn't even recognize him. They [staff] had him in a suit with a white shirt. This is a man that always smelled of urine. He was spiffy. Took him out. He had a ball.

Other special services that public guardians arrange for their wards included assistive devices, such as a special chair to meet the physical needs of the ward, hearing aids, speech, occupational and physical therapies, and mitts to cover the hands of a ward who was pounding her chair and, in the process, bruising herself. Also, public guardians arranged for the services of a volunteer visitor, retained a housekeeper, had a ward's carpet cleaned and replaced, and made provisions for wards to have their hair done.

\section{Providing Emotional Support}

One of the primary avenues of providing emotional support is through face-to-face client visits, which varied by length and frequency of visit. Although the Delaware paid public guardian visited one ward every six weeks, most guardians were encouraged to visit wards at least once monthly. A monthly standard of visitation is in accordance with the National Guardianship Association standards for guardians, both public and private. Still, no agency stipulated that the guardian had to spend a certain amount of time with the ward. Time spent by public guardians with their wards varied; on average they spent longer with wards who could or would communicate with them. In at least two instances, the travel time far eclipsed the amount of time spent either with the ward or with the staff of the facility that cared for the ward. A factor in the termination of the employment of two guardians at PSN in Virginia was their inability to make timely client visits. The Maryland paid public guardian was fulfilling end-of- 
the-month visit requirements when I observed; this was a factor in my ability to freely choose the clients whom I interviewed. The other public guardians did not seem as pressed regarding fulfillment of visitation commitments as the paid public guardian in Maryland; however, the Tennessee public guardian made additional client visits while I interviewed wards.

Client visits that I observed ranged from a "breeze in" of five minutes to an hour in duration. I was unable to determine from the public guardians who claimed that they visited the ward for an hour whether the client visit was solely with the ward or included speaking with the staff and checking the charts. The ability of the ward to communicate and the ward's relationship with the public guardian proved to be relevant factors in the duration of the visit. Also significant in the client visit was the efficacy of the care providing staff. Client visits were usually shorter if the public guardian believed that the ward's needs were being met by the staff.

Guardians, once they determined that clients should be moved from their home to a nursing facility, attempted to minimize the trauma associated with changing wards' habilitation. During my observation, one paid guardian brought personal belongings from the home of a semi-comatose ward to see if they would in any way soothe her or cause her to react. She brought such personal items as a Bible, pictures that were on her wall, and a pillow that the ward might have made. The ward did make some sounds, which were the first that the guardian had ever heard, and the sound resembled the guardian's name.

\section{Serving as a Surrogate Decision Maker}

One of the most important roles that public guardians fulfill is that of surrogate decision maker; in theory, the surrogate should respect wards' wishes whenever possible. Public guardians acknowledged that wards' preferences affected their decisions, particularly if they believed that the ward's functioning was on a relatively high level and that the risk of allowing wards to make decisions was not great. However, public guardians also stated that usually they were compelled to act in the best interest of the ward. The financial situation of the ward was the primary factor affecting the decisions that guardians made for the ward. After financial influences were ward preferences (when they could be honored), quality of life and care concerns, and risks involved for the ward. Public guardians were asked specifically what types of decisions that they had made on behalf of their ward. Although decisions generally fell into health care and financial categories, specific decisions were included as follows.

The Delaware paid public guardian made a decision about who from the facility could take the ward on an outing after hours. She gave permission for certain facility staff to take her ward out, only if the ward felt like going. Her decisions involving money depended on whether the ward had any. Public guardians made habilitation decisions, Do-Not-Resuscitate (DNR) orders, and insertion of a percutaneous endoscopic gastrostomy (PEG) tube. 
The paid public guardian in Maryland made the following decisions for her wards: changing financial guardians, involuntarily committing and medicating her ward, keeping a ward in her current facility even though the guardian of the property thought differently, selling a ward's house, moving a ward from her home into a nursing home, maintaining a ward in community placement, authorizing medical tests, and selecting appropriate physicians and other health care professionals. Regarding two wards, the paid public guardian in Maryland stated that she made all decisions of consequence pertaining to the wards' "health, emotional and social well-being, and place of abode."

Decisions of paid guardians at PSN in Virginia included efforts for more far reaching therapies than facilities were attempting. One guardian said, "The same kinds of decisions and things that family would make, I make." She made the decision to have a special foam chair built for her ward, even though Medicare would not pay for it. Further, she said, "I didn't have a lot of options in terms of her [ward's] personal care decisions. I really leave that up to the medical team. I suppose the big decision would have been, you know, to cut off life supports if that would have happened." The paid public guardian decided to sell the ward's house, buy a radio for her, place the ward in a nursing home, and choose a facility close enough to the agency so that the public guardian could visit the ward on a regular basis, select which bills to pay, and determine if the ward's quality of life was good. The other paid public guardian approved a "no code" for her ward, tried to make her physically comfortable, saw that her quality of life was good and that she was treated with dignity and respect, and paid her bills on time. She mentioned that a secondary care goal for one ward was to reconcile the ward with her children; furthermore, she decided to place another ward in an assisted living facility temporarily prior to renovating his apartment and, later, pending his approval, to move him permanently to the assisted living facility.

Decisions made by the paid public guardian in Tennessee included permission to allow a ward to be treated in the hospital, permit the ward to make decisions about medication, increase social activity, improve interaction with staff, enhance quality of life, encourage the ward to talk about more than the selling of her house, complete adjustments to living in a nursing home, attend to social needs, increase activity stimulation, and make money decisions.

Volunteer guardians in Chesapeake, Virginia, were more vague than the paid guardians about the decisions that they had made for the wards, but they included financial decisions concerning Social Security, placement decisions, and determinations regarding wards' quality of care and life. One volunteer guardian (who served as guardian of the property only) attempted, as much as possible, to allow her ward to make financial decisions. Information regarding medication and DNR decisions are noticeably lacking from the volunteer guardians, but these issues have not arisen in the program yet, probably due to its early development. Social workers who serve as liaisons for the volunteer guardians and who have worked on the ward's case prior to the appointment of the volunteer guardian made decisions such as not allowing the ward to telephone the guardian because she would burn them out, placement decisions, cognitive and 
emotional support, caregiver support, and referrals. It is necessary to note the distinction in the responsibility for decision making; the social workers are not the ward's surrogate decision makers. They do maintain a client relationship, but the volunteer guardians are the legal guardians of the wards and the legally designated decision makers. Social workers work with other wards in other states but do not necessarily support the paid guardians to the degree that the volunteers are supported at CVGP.

Public guardians also make decisions about long-term care for the wards. When asked about their care goals for wards, public guardians' most frequent answer was maintenance. Alternately, the Delaware paid public guardian expressed that her goal for one ward was to keep her as independent as possible. Another care goal included housing them in the least restrictive environment for as long as possible.

\section{CHALLENGES OF GUARDIANSHIP}

Although certain tasks of guardianship were identified from the research, certain challenges of guardianship were also evident. The challenges of guardianship are accountability and effectiveness, financial and other constraints, respect for client wishes and autonomy, and the development of a relationship with the ward. We turn to a discussion of the challenges of guardianship.

\section{Public Guardians’ Accountability and Effectiveness}

All guardians had specific accountability functions for their efforts at meeting the needs of the wards. CVGP guardians were asked to submit a monthly report of activities and time spent pertaining to ward issues to the program supervisor and to fill out a yearly financial accounting. Volunteer guardians were required to attend two four-hour training sessions on guardianship. Once a week the volunteer program supervisor called the volunteer guardians to monitor their progress and provide them with support. With the volunteer guardians in place, theoretically, Adult Protective Services (APS) social worker liaisons could decrease their ward contact as well as glean information about the ward's condition from the volunteer; however, if cases proved difficult, time spent on cases was not always decreased. The two volunteers who had been guardians prior to the existence of the program felt that they did a good job as guardians, and the other two volunteers had been appointed too recently to be able to make that assessment. Two persons who were volunteers prior to the inception of the program reported spending an average of 16.5 hours a month on their ward. Recent volunteers could not necessarily say how much time per month they spent on wards because they were too new to the program.

Paid public guardians in Delaware were required to fill out six month reports for all wards and attend care conferences (every three months). The Delaware guardian reported that she was unable to attend a care conference held for her ward because she received notification of 
it after it had been held. Case file notes are also another responsibility of each paid public guardian. If there are issues or concerns with the case notes, the paid public guardian said that she e-mails her supervisor to review them. The Delaware paid public guardian stated that she spent approximately two hours a month on wards whom I saw. The Delaware guardian remarked that she was fairly effective in meeting the needs of the wards whom I interviewed and observed.

The paid public guardian in Maryland was required to write information for Guardianship Review Board reports and for Reconsideration reports, which are compiled and written every six months. Contained in the Reconsideration Report is an extensive plan of care for each ward. For the Guardianship Review Board report, the public guardian gathered and reported the diagnoses, the health status, medical status, psychiatric status, medications, living arrangements, adjustments, protective services plan, and determination as to whether or not the guardianship should be continued. Gathering information and preparing the Review Board report generally took the paid public guardian ten hours per ward. One of the semi-annual review boards must be attended by the paid public guardian, and one of the review board reports must be submitted to the Circuit Court for an annual review. She indicated that although the two reports are written within a two month period, the material they contain is not necessarily similar. Major decisions regarding invasive and life threatening situations, tests, treatments and change of habilitation require court authorization. The Maryland paid public guardian remarked that she was very effective in meeting the needs of wards.

In Tennessee, the paid public guardian also believed that she was very effective in meeting the needs of wards. Required quarterly accountings included information on the time spent and activities per ward. By statute, Tennessee public guardians are permitted to assess fees from clients who have the financial means to pay for services; the guardian reviews logs carefully to determine services for which she can bill. A bookkeeper assigned to the paid public guardian assists with financial management. The guardian must account for her travel; time sheets and travel logs must coordinate. Also, the paid public guardian is audited by the Tennessee Commission on Aging. Folders on each ward are kept that include financial and personal information as well as records of services and visitations. She reported spending approximately an hour per month on clients who were stable and could communicate minimally. The Tennessee guardian reported spending a maximum of fifteen minutes personally with each ward and the rest of the time gathering information from her caregivers during client visits.

Reporting requirements for paid guardians employed by PSN in Virginia included keeping a notebook on each client, maintaining daily time and activity logs on each client, accounting for money spent from the ward's account, and participating in weekly staff meetings with the program supervisor. A bookkeeper audits checks that are written on the ward's behalf. Both paid public guardians at PSN believed that they were effective in meeting the needs of the four wards whom I interviewed and observed. One paid guardian acknowledged that she met her ward's needs so effectively because of the caring and efficient staff at the nursing facility. 


\section{Financial Constraints}

In every interview, when public guardians were questioned about constraints at meeting the needs of wards, money proved to be the most frequently mentioned factor. Although the Maryland paid guardian does not serve as guardian of the property, in all but one case that I studied, public guardians constantly confronted financial issues. In Maryland, serving as guardian of the person created friction between the public guardian and the guardian of the property. The Maryland paid guardian admitted, that in one case, she was responsible for having a financial guardian removed for placing the ward at risk due to the private guardian's reticence to perform his duties:

I'd ask for money and I'd never get it. I'd ask him [financial guardian] to do things I promised and he didn't do it. He didn't give me money when I needed it. I had to wait to get her [ward's] shoes. I had to wait. . he didn't pay for hearing aids and he didn't set up a guardianship account, and the check was no good when he finally paid. I had many problems and I had to fight the system. . it was hard to get rid of him, but we finally got him to voluntarily resign, and now I have an attorney that works with me very [well]. He was really obstructionist and irresponsive. [It was] twice as hard for me to do the things I needed to do. Some things didn't get done, but nothing that would jeopardize her [the ward's] safety.

Guardians cited the difficulty of and the primacy given to addressing financial matters. At least one paid guardian mentioned that this task took precedence over attending to the health needs of the ward initially. One of the most consuming financial matters in an least two instances was the sale of the ward's home. The sale of the house helped the client honor medical bills that had gone unpaid and kept the client from qualifying for public assistance programs or services such as Tax Relief, Social Security, Medicare, or Medicaid. Public guardians confessed that matters regarding sale of wards' personal property consumed an enormous amount of time and that they often lacked the expertise to handle these matters. In one ward file, I found a letter from an attorney to a paid guardian regarding the sale of the ward's house. The attorney castigated the guardian and her supervisor for so ineptly handling the sale of the property and explained that she earned "every penny of her legal fee" because of the problems involved. Other financial issues involved transferring wards' checking accounts to the agency serving as guardian. In some instances, financial exploitation had occurred, and powers of attorney had to be revoked. Significantly, banks were not always willing to transfer authority to the guardian without extensive proof of the court appointment.

Another issue regarding finances that proved troublesome for public guardians was insurance matters. Said one paid guardian, "We have an outstanding debt. . from [the] hospital because [the program supervisor] appealed the decision. The hospital said that they wouldn't. . .Medicare said they wouldn't pay. I think it was two weeks worth of bills because she [ward] should have been moved to a nursing home." 


\section{Other Constraints}

Most paid public guardians reported constraints in meeting wards' needs, and the constraint of lack of money was voiced most frequently. The constraint mentioned second in importance to finances was time. Guardians remarked that they simply did not have enough time to adequately meet the needs of the wards. Also, at least two guardians had constraints beyond those of time and availability. One was referred to above, a financial guardian who was unresponsive to the financial needs of the ward. The same guardian was constrained by the demands of another ward's dying wife. The wife insisted that he visit her in the nursing home; her demands proved exhausting and costly for the ward. Also, the former physician of the same ward was not aggressive enough in following up on the client's physical complaints, which resulted in a delayed discovery of the ward's prostate cancer. At least two paid guardians said that the wards themselves constrained the public guardians in meeting needs by refusing help offered to them.

\section{Respect for Client Wishes and Autonomy}

Public guardians were given plenary authority by the courts. In no court petition of any of the wards whom I reviewed did I see guardianship petitions limited beyond that of separating guardianship of the person and the property. Although the Tennessee and both Virginia demonstration sites provided services that were less restrictive than guardianship, such as serving as power of attorney, bill payer, and client advocate, my research was limited to persons who were financial or personal wards of the state.

Guardians acknowledged that they tried to respect clients' wishes when they were reasonable. Only one volunteer guardian even hinted that her ward might eventually have the guardianship overturned; otherwise, public guardians stated that their wards would remain wards of the state for the rest of their lives. All guardians expected to be associated with the wards for the duration of the wards' life, with the exception of one of the paid public guardians, who confessed that even her ward who was the most ill might survive to become the ward of another guardian upon her retirement in approximately two years. At the time of this writing, four months after the participant observations, one ward at PSN in Virginia has died.

Public guardians respected wishes of the clients by discerning, where possible and when time permitted, what the ward would have wanted when competent. However, respecting their wishes was hardly an exact science. One guardian stated that she respected her ward's wishes by administering the least amount of psychotropic medications possible (at one time this ward was administered medications with the permission of the guardian against her will). Other attempts to respect the ward's wishes included keeping the ward in her own home for as long as money and her needs would allow, keeping other wards in an adult care home rather than a nursing home when needs did not warrant the restrictions on personal freedoms, and not forcing wards to 
attend activity sessions (the ward was not interested in making potholders or coloring). The same paid public guardian had this to say.

When she [ward] went to day care, she complained that they treated everybody like babies. And I do think that she's being forced into activities that were never to her liking when she was competent. She talks about ridiculous activities some of which I find disturbing in day care. And it is wide practice. Like coloring. Where some people will do wonderful things with crayons, but generally speaking that's not their [thing].

When possible, guardians attempted to place wards in facilities that fit their needs or requested that facilities attune themselves to ward needs and preferences. An example of this effort included a paid guardian placing her ward at a facility that had a pet visitation program because the ward was such an animal lover. Another guardian placed her ward in a facility that was close to his sister so that she could conveniently visit him. A volunteer guardian requested that the nursing home staff not wake her ward until later in the day because the ward was not a "morning person."

Guardians said that they respected the ward's wishes by listening to them talk about their past. One paid guardian completed a living will with her ward; however, this is not a legally binding document because of the ward's incapacity. Guardians alerted administration and nursing staff to the particular needs and requests of wards. Importantly, when wards questioned their guardians about returning to their home, most guardians attempted to divert their wards' attention. One volunteer guardian noted, "A lot of times she [ward] will say that she wants to go home, so I tell her that she can't go home because she needs to be taken care of and there's no one there to take care of her. But I'm honest with her."

\section{Relationships with the Wards}

Public guardians must cultivate and maintain relationships with all parties involved with the ward in order to focus staff on attending to the ward's needs and discerning requirements of or changes in wards' needs. Although the relationships among caregivers and other care providers are important, the relationships between the guardian and the ward is more important. In the interviews, public guardians were asked to characterize their relationship with their ward.

Public guardians' relationship with their wards were in various stages of development. The relationship depended largely on the amount of time that the public guardian had served in that capacity. Although I expected to find that the volunteer public guardians at CVGP had the least developed relationships with their wards, this did not prove to be the case. Three of the four volunteer guardians whom I interviewed had relationships with their wards prior to becoming involved with the program. Two volunteer guardians had served in that capacity at least two years; one of the volunteers had known her ward since she was a child. Another volunteer guardian, who had just begun serving in that capacity, had a prior relationship with the 
ward through a family member and through serving as the ward's representative payee several years earlier. The only relationship in the beginning stage of development that I observed was that of a volunteer guardian who had no previous relationship with his ward prior to entering the program. He had served as his ward's guardian for one month. Only one of the four relationships between ward and guardian was not cordial; all others seemed familiar and friendly.

The relationship of wards to the paid guardian in Delaware depended largely on the ward's level of cognizance and degree of illness. One ward whom I interviewed did not know her guardian, and the paid guardian admitted as much: “. . .to her I'm sure I'm just a person she knows comes to visit. I'm sure she's totally forgotten that she has a guardian." Because of her dementia, at least one ward has never known her public guardian at all. Another ward relationship was, according to the social worker, hampered by their age and race; "He is an elderly African American, and I am an older white social worker. . .I think I have done the best I can." She added that the ward is quiet and does not call on her to any degree because of his discomfort with their relationship.

In Maryland the paid public guardian admitted that one of her wards "was not madly in love with her." Nonetheless, she added that this ward knows that she is receiving adequate care and trusts her. Another ward, she confessed, only vaguely recognizes her. Three other wards, who are more cognizant, have a better relationship with her, which is largely positive and caring. One ward, who has a degree of dementia, warmly regards and even obsesses about her guardian, who says that she ". . attributes actions to me that I'm not capable of. She wants [guardian's name] glasses to clear up her vision. But she seems to think I can resolve her problems."

I was surprised to find that the paid public guardians at PSN had already developed relationships with their wards. For wards who were comatose when entering the program, guardians did not believe that they had a relationship. One ward was cordial to her guardian but did not know who she was. Another guardian characterized her relationship with a ward who was aphasic as warm and a little affectionate; however, the day I observed, the ward did not respond to her. The guardian was visibly disappointed, and she said, “. . she was the only person that I had become guardian for that really wanted to have a guardian and was real enthusiastic about the relationship. Although she could not talk to me, not verbally, the connection has been real strong." The other ward of this paid public guardian has grown in his relationship to his guardian. In a short amount of time, they moved from his mistrusting her to a warm and evolving relationship.

The paid public guardian in Tennessee, who had been in her position for six months when I visited and had under her care two of the most cognizant wards I interviewed, said that one ward regarded her as someone who could procure items; the other ward liked her attention. Regarding the more cognizant of the two wards, the guardian remarked, "I feel like she trusts me and relates well to me. She knows who I am and has some idea about what I do." The other two 
wards, who could not communicate their needs as well, also seemed to at least recognize her. The day I observed, one ward was more receptive to her than she had previously been. The paid guardian credited this as a growing familiarity. The other ward whom I observed acknowledged that the paid public guardian looked familiar when she asked her. The guardian believed that he too, was beginning to recognize her.

\section{SUPERVISORS’ COMMENTS ON GUARDIANS}

Program supervisors were interviewed and questioned about public guardians' job qualifications, accountability, and support provided for them. Most program supervisors did not carry a case load; however, in Maryland the program supervisor had just completed a transition from carrying a few cases to moving her cases to a paid primary public guardian. Only the program supervisor in Delaware carried a caseload.

Program supervisors were asked about their qualifications for public guardians. It is important to stress that the Chesapeake pilot project supervisor (who serves as the volunteer coordinator) was commenting on volunteer guardians; moreover, it is significant that qualifications for these individuals were in many instances the same as for those of paid public guardians.

Volunteer guardians are recruited from of a pool of persons in the Chesapeake, Virginia, area. By means of a situational interview, in which persons are asked for their responses to certain hypothetical situations, the supervisor seeks to assess an individual's suitability as a volunteer guardian. As with professional employees, the volunteer guardians undergo a background check for validation of their work background and a criminal records check.

Only one ward is assigned per volunteer guardian. Once selected, volunteer guardians are trained in two four-hour sessions on the basics of guardianship. A social worker liaison from the Chesapeake Department of Social Services remained with the case for a then undetermined period of time. As part of their ongoing responsibilities, volunteer guardians are asked, at least once a week, to spend time with their ward in some type of activity or to just visit them personally. The time that volunteers should spend in visiting wards is not stipulated, but the program supervisor indicated that "It wouldn't be a fifteen minute thing. It would be maybe more like an hour thing or something like that." The level of visitation, at least at the start up of the program, averaged less than one hour long per visit per week.

The program supervisor at CVGP indicated that they were looking for volunteers who are "caring, at least twenty-one years of age, and has some experience if not working in the world, at least the volunteer world or either with their own family, had some involvement with a mentally ill or elderly person." She also mentioned that she wanted someone who was dedicated. The program supervisor said that before they accepted a person as a volunteer guardian she tried to give volunteers an accurate picture of the needs of the clients, and in doing 
so, also gave them some "horror stories" of guardianship so that they viewed serving as a volunteer guardian realistically. She emphasized that volunteer guardians were generally persons who liked to solve complex problems. She said that, in determining a person's suitability for serving as a volunteer guardian, she also relied on her own intuition.

Even though the Delaware Program Supervisor had been in her current position for three years, she had not had the opportunity to hire a case worker. Still, she stressed the importance of hiring someone who is a strong advocate for the ward. She emphasized,

You have to be able to sort of take on that person, become that person. I think it takes a unique person, an individual to fulfill that. . .it's not just routine. It's never routine. And I'd look for someone who can be creative and kind of a step ahead of everyone else in thinking. So there has to be some organizational ability. And really. . .and this is probably obvious, but I'm really systems oriented, and I think. . .that's why advocacy is so important. I think you have to be able to work that to someone's advantage and just make sure you take care of that person.

She emphasized that she preferred a person with a Bachelor's Degree in social work or a related field. She also emphasized, in dealing with the wards and the context of their situation, the importance of "starting where a person is."

The Maryland program supervisor deviated from the Delaware supervisor by stating that social work was not her primary qualification for the paid public guardian. "But it's not just social work. I mean nursing is really important, and I think if I had my druthers, I'd have a nurse on staff as well as a social worker." Conversely, she stressed that having a nurse as a public guardian would also not completely fit her qualifications; a nurse would have to be grounded in social work. She also emphasized the importance of finding a caring person who respected an individual's right to self-determination. Persons must be able to work with extremely difficult cases and be able to deal effectively with the legal and medical professions. She looked for persons who wanted to grapple with tough ethical decisions. Other characteristics she sought were a willingness to take risks, to develop relationships with clients, and to effectively prioritize work obligations.

The program supervisor at PSN in Virginia gave the most thorough qualifications for paid guardians of the supervisors whom I interviewed, perhaps because she had been most recently involved in hiring new guardians. She emphasized that she conducted two interviews, one herself and the other with her staff supervisor and herself. She acknowledged problems in hiring the right person for the job.

We give a grueling interview and then they get on the job, and it's a totally different person. They [client representatives] work hard, they mean well, but they just haven't been able to. . .make good judgments. I look for evidence of good judgment, 
organization skills, good communication skills. And a history of working with people with mental illness. My feeling is that if you can work with people with mental illness, you can work with any other population.

She added that she looks for persons with maturity and trustworthiness, who know the system, possess a Bachelor's Degree but preferably a Master's Degree (although she did not specify a particular field), and have case management experience. The program supervisor also added a personal dimension to her qualifications for primary public guardians. "They have to have pretty high standards, because I do. And they have to be able to deal with me."

The Tennessee program supervisor had also recently hired a new paid public guardian. As at CVGP, she mentioned using scenarios to effectively select the appropriate candidate for the position. She emphasized the importance of a knowledge of law and the court system. Additionally, she looked for someone who was caring and had good problem solving skills. She specified the importance of a degree in such fields as sociology, social work, or public administration, in addition to a broad knowledge or experience of the world. She said that if an individual did not have a formal degree but instead had a great deal of personal experience, she would still consider this person as a viable candidate for the position of paid public guardian.

\section{Supervisors’ Accountability for Public Guardians}

Supervisors hold guardians responsible for their work by a variety of methods. In Chesapeake, Virginia, volunteer guardians were the least accountable to the program supervisor, in large part due to the voluntary nature of the guardian/ward relationship. Guardians of the property are required by the court to do a yearly accounting of how they spend the ward's income. Additionally, the program requires that volunteer guardians report to the program supervisor monthly regarding time spent and actions taken on behalf of their ward.

In the paid public guardianship programs, other methods were used for accountability of guardians. In Delaware, paid public guardians kept case file notes. Also, weekly staff meetings were held in which the supervisor and guardians reviewed the new referrals. Additionally, pending referrals were discussed along with the results of decisions made regarding a wards' care plan. Guardians must also complete six month reports. The Delaware office is a small one, and so it is possible for the program supervisor to either e-mail a guardian concerning a question or simply walk down the hall. The program supervisor acknowledged that if the program grew much larger, there would be less hands-on means of supervision.

The supervisor in Maryland holds paid public guardians accountable through formal meetings every other week in which all clients are reviewed. Guardians are encouraged to come to the program supervisor for particular questions or concerns. Reconsideration and Review Board reports, discussed earlier, make paid guardians accountable. The Maryland program supervisor stated that she gave more freedom to paid public guardians who were more 
experienced and had more formal training through education. One public guardian who worked with a few guardianship cases had the title of case manager; the program supervisor reported that she talked with the case manager every morning to supervise her work. She also stated that her guardians scrutinize nursing home records in fine detail and reflect this information in their reports.

The program supervisor at PSN in Virginia supervised her client representatives herself as well as through a staff supervisor. The staff supervisor met weekly with individual guardians. The program supervisor held weekly meetings with the staff supervisor so that she could stay abreast of what was going on with the guardians and their wards. In addition, she required all guardians to maintain a case notebook that she reviewed personally. Staff were also kept accountable through voice mail.

The program supervisor at the Tennessee site stated that the financial office of the First Tennessee Development District, the Area Agency on Aging (AAA) that includes the Office of the Public Guardian as one of its programs, holds the guardian accountable. It is responsible for accounting issues, depositing wards' money, and writing checks for supplies and services. The program supervisor (who is also the Executive Director of the AAA) holds the paid public guardian accountable through informal staff meetings (not at a set time) and an open door policy of supervision. The bookkeeper who works with the paid public guardian is also overseen by the First Tennessee Development District.

\section{Meeting the Needs of Wards}

Program supervisors were asked how they believed that public guardians meet the needs of wards. The Tennessee program supervisor emphasized that paid public guardians meet the total needs of the wards, cut down on abusive situations, assist nursing homes and other agencies, take care of clients who fall through cracks in service delivery, and serve the families. The CVGP program supervisor emphasized that volunteer guardians address the financial needs of the wards and make service arrangements. The Delaware supervisor highlighted the caring aspect of what paid public guardians do through helping wards access service delivery systems. She also emphasized advocacy and financial assistance. Significantly, she cited a chief role of paid public guardians as protector; "[guardians] protect these vulnerable people who can't advocate for themselves. Protect them. And make sure that their personal and financial resources are protected."

The Maryland program supervisor revealed a strong case management approach. She stated that paid public guardians meet the needs of wards by providing transportation to medical appointments; providing needed personal items; backing up direct services when needed; and monitoring, reassessing, and evaluating wards' care plans. In addition to monitoring services and assisting with decision making, the program supervisor at PSN stressed the emotional aspect 
of meeting the wards' needs through guardians' efforts towards knowing the wards personally and personal visits.

\section{Supervisor's Emotional Support of Public Guardians}

All program supervisors recognized the intricate issues involved in public guardianship. They stressed that their programs were only as strong as the persons who were acting on the front lines of guardianship. Consequently, each program supervisor had devised ways to address the emotional needs of public guardians. The support of volunteer guardians at the Chesapeake, Virginia, demonstration site differed from that of the paid public guardians. For example, volunteers meet in a monthly support group and were given certificates upon completion of their training session. Additionally, a guardianship committee meets in advisory fashion to assist the volunteers. Social workers within the Chesapeake Department of Social Services serve as a referral source for the volunteer guardian. The program supervisor telephones all volunteer guardians weekly to see how they are doing and what they have done for their ward.

The supervisor at the PSN demonstration site stated that she tried to be available for questions or problems and that she was willing to assist with decisions that paid public guardians made. Because of the northern Virginia traffic situation as well as being attuned to individual employee's work habits, the program supervisor allows her employees to set their own schedules. She stressed that she did not care what her employees' work schedule was as long as they completed their work. She also stated that she is flexible regarding sick leave.

The program supervisor in Maryland noted that the Department of Social Services, where they are housed, stressed personal development through a variety of training sessions offered. She confessed that she often does what may appear as silly in order to encourage employees and boost morale, such as using colored markers on their papers, decorating her office, and putting stickers on their work. Additional support includes permitting flexibility regarding time off, allowing employees to work at home when possible, providing an empathetic and listening environment, offering verbal praise for good work, helping out when paid guardians are pressed for time, and, like PSN, adjusting work time to suit an individual's best working hours.

In Delaware the program supervisor emphasized communication as the way she supported public guardians' emotional needs, stressing that because of the small size of the office as well as the state, they worked as a problem solving team. "We try to act as a group. It's not just the public guardian. . it's almost like we're in this together. And if you've got a problem or if you're finding it difficult or you're not sure what to do, throw it out there, and we're all takers." She emphasized the importance of their weekly staff meetings as a way to address guardian's emotional needs. The Tennessee program supervisor stressed the importance of empathizing and communicating with the paid public guardian so that she would know that her work is appreciated. 


\section{WARDS' COMMENTS ON GUARDIANS}

Certain wards could not remember who their guardian was or understand that they were wards at all, while other wards were quite vocal about their relationship with their guardian. A ward who continuously rolled a paper in her hand during the time she spoke with her volunteer guardian had this to say: "Her and I don't get along at all. She just acts like she doesn't understand how it is. She makes me feel like she doesn't have a heart." She added, she don't know me very well, she does what she can. She makes excuses for everything."

Two female wards said that they were not important to their paid public guardians. One ward stated that her guardian did not know her very well at all. Another ward said, "I am not that much to [her]. I don't know whether she knows me or not. She acts like she does." When I asked her again if she thought her guardian knew her well, she said, "I don't think anybody does." Another ward stated flatly that she did not like her guardian at all.

One male ward commented that he knew his guardian well and that they got along well; he had known her for years. Another male ward believed that he and his guardian did get along, but he confessed that he could not identify her. A third male ward stated that his guardian did not really think about him and did not know all that he could do.

Most wards who recognized their guardian appeared relaxed in their presence; however, the duration of my observation of guardian/ward interaction varied. Wards who could communicate with their public guardians generally did so by asking and answering short questions. The most cognizant wards began interactions by immediately asking for money, clothing, personal items, or explanations of health issues. Interestingly, both Tennessee wards whom I interviewed asked their public guardian to help them get out of the institution in which they were living; these wards appeared more agitated than the wards who did not make such a request.

Alternately, public guardians appeared generally relaxed with their wards. If wards were seated in a chair or were in a wheelchair, all guardians knelt down to speak to them on eye level. One public guardian turned off the television in her ward's room so that she could speak to her, although she did so without asking the ward if it was all right with her. Only the Tennessee guardian knocked before entering the room of a ward in an institution. Public guardians signed in as a visitor to their ward's facility only twice. During my observations, if a ward was sleeping, he or she was aroused so that public guardians could speak to them, but recorded in several of the Delaware public guardians' six month reports was that a sleeping ward was not awakened for a guardians' visit. The only guardian who did not appear at ease was the newest volunteer guardian at the Chesapeake demonstration site. He stood shyly with his ward and kept his hands in his pockets virtually the entire time of the interaction, although he did, upon leaving, shake his ward's hand. 


\section{Satisfaction with Guardianship}

Two wards had clearly expressed their desire for a public guardian prior to the guardian's appointment. Although one ward emphatically did not like her paid public guardian, she acknowledged that her guardian respected her wishes. The same ward understood well the stigma that accompanies guardianship, "Well, they kind of wonder what's the matter with her [the ward] if she has to have a guardian."

One ward, when asked if his needs were met, stated that his guardian was congenial and brought him things like a radio and clothing. Interestingly, when asked whether he thought guardianship was good for him, another ward acknowledged, "In a way it is. It just keeps me in tow. . .I feel like a prisoner. I'm just not used to being tied down." Other wards could only acknowledge that their guardian did very specific things for them and did not know whether or not they respected their wishes.

Several wards were not satisfied with the number of visits that the public guardian made to them. When asked how often their guardian came to see them, one ward reported, "Not as often as she was for a while, but not very often." One female ward stated that she needed to see her guardian every two weeks. A significant complaint from three female wards was that they felt lonely. They did not feel that their guardian paid any attention to them, cared about them, or respected their wishes. They did indicate, though, that they were glad that someone was managing their money.

A male ward said that he felt that he needed a representative payee rather than a guardian, even though he acknowledged that he liked the person who served as his volunteer guardian. He pointed out that lots of people mismanaged their money and did not have a guardian. He acknowledged that his guardians had helped him understand the importance of managing his money.

Also, two wards were not satisfied with the facility in which they were staying. Two wards resented the intrusion of their guardians prying into their lives and asking them personal questions. They felt that their guardian was too nosy or not their type. They coped with this by not asking the public guardian for anything or stating their needs. Said one ward, who stressed that he did not like his guardian's visits, "I don't talk to her about nothin'."

\section{DISCUSSION}

Public guardians are typically women, and their program supervisors are also women. Guardians tend to be persons who are empathetic and have backgrounds in or are familiar with medicine, social work, and law. With the exception of the volunteer guardians at the Chesapeake demonstration site, all public guardians had significant experience in related positions prior to assuming the job of public guardian. All paid public guardians possessed at 
least a Bachelor's Degree in sociology or social work, and most paid public guardians worked full time. At the PSN demonstration site in Virginia, both paid guardians whom I interviewed had responsibilities for guardianship as well as for other services that PSN provided prior to receiving funds from the state.

Four of the five paid public guardians whom I interviewed (all of the full time workers) regarded that their caseloads were too high or that their agencies needed more staff persons. Although the agencies did have some discretion as to how many and which wards they would accept, it is likely that the need for public guardians will increase due to the creation of a service where none existed. Also, as the Baby Boom transitions into older adulthood, more guardianships will be required. In the first year of the PSN demonstration project alone, over seventy referrals were made to the agency for 25 case openings. PSN carried five more persons than they contracted to carry under the terms of the Request for Proposals. Given this level of unmet need, the issue of caseload looms large if pressures increase on the agencies to take on more clients.

All public guardians exhibited a significant desire to make the lives of wards better. Volunteer guardians, more than paid guardians, voiced largely altruistic reasons for serving an individual in this capacity. Three of the volunteer guardians had served in that capacity prior to the inception of the publicly funded program, and two of the three persons had a prior relationship with their wards. This finding raises a question as to the longevity of service and availability of the volunteer guardians, especially if the cases of the wards prove to be extremely difficult. The program supervisor regarded that only exceptional persons would be willing to serve in this capacity. She also stressed that there are cases of guardianship where the liability is too great for a volunteer guardian, and therefore, such a ward would not be appropriate for their program.

One of the advantages of the volunteer guardianship program is its one-to-one nature and the potential for volunteers to devote more time and attention to one ward. An adequate pool of volunteers allows the program supervisor to closely match the individual needs and personality of the ward with the individual traits and qualifications of the volunteer guardian. The successful match of volunteer to ward could contribute to more successfully meeting the needs of the ward than a paid public guardian who has an extensive caseload that includes many wards with multiple and complex needs.

It is essential that volunteer and paid guardians be able to turn off their work related problems as much as possible when business hours are over. Although all guardians stated that they found their work rewarding, it would be easy to become immersed in living the decisional life of another person. All guardians said that the initial work required upon being appointed guardian is labor intensive. Guardians need to be able to handle the stresses of the job. It is essential, also, that the program supervisor provide back up to the public guardian when and if this becomes a problem. 
Particularly in Tennessee, the program supervisor's responsibilities extend over numerous programs in her agency. Here is an instance where the public guardian may need additional attention and consultation from the supervisor due to the all-encompassing nature of her work. Staff meetings are not necessarily held on a regular basis; however, due to the complex and significant issues involved, all public guardians would do well to meet with program supervisors at a set time as well as informally. This approach would provide an important check on guardians' emotional health and would serve to familiarize all supervisors with the cases of the public guardian. In all agencies, a team meeting approach would provide additional support and advice. Serving as a primary public guardian is not a position in which an employee who has unaddressed emotional problems can operate for long without serious delays and misjudgements that could work to the ward's detriment.

\section{Visits to Wards}

Although it is the responsibility of public guardians to visit the ward personally, paid guardians' visits are often perfunctory, due either to the condition of the ward or the pressing need to fulfill organizational requirements, of which a client visit is only a small part. Visitation may appear as an unimpressive outcome as opposed to the sale of a house or the authorization of a DNR order. When confronting priorities for the allocation of public dollars, it is unlikely that spending an hour with a client in order to develop a relationship with him or her will be regarded by legislatures as a justifiable use of a public guardian's time. Driving to and from client visits often requires far more time than the actual visit with the ward, and all public guardians carried an abundant case load, whether or not they worked full time. It is also true that most wards are placed in a facility, usually a nursing home, which in many aspects meets the wards' needs, including some socialization needs. Stated earlier, finances play a large part in determining public guardians' decisions regarding habilitation.

Still, establishing a relationship with a client is crucial, especially when considering the last resort nature of public guardianship. The state has an obligation to commit to the development of a guardian/ward relationship. A potential and appropriate use of volunteers would be for the purpose of socialization. However, this would require a financial and staff commitment on the part of the agency. In times of fiscal constraint, additional time allotted to ward visitation is unlikely, but it is an appropriate action for the state.

\section{Emphasis on Personal Needs and Decisions of the Wards}

Public guardians worked to discern wards' needs and wishes as much as possible in spite of due time constraints and communication constraints, monitoring services, brokering services, making financial arrangements, and advocating for their ward. Historically, meeting the financial needs of wards has been the primary function of serving as a guardian, with all other functions taking a secondary position. In an effort to direct the public guardian toward meeting needs other than financial, the Maryland public guardian serves only as guardian of the person. 
Evidenced by the comments of public guardians, most were ill-equipped to deal with the multiplicity of financial issues. Tennessee handled this concern well by having a bookkeeper solely dedicated to the public guardian's office, which freed the public guardian to do leg work on cases. Even the public guardian in Maryland had to deal with financial issues nonetheless, particularly in one instance when the individual serving as the financial guardian would not cooperate with the authorization of needed funds on behalf of the ward.

Advocating for the client was not always synonymous with respecting client wishes and respecting client autonomy. In general, public guardians were given plenary authority for guardianship by the courts, even though judges are encouraged to institute limited guardianships to restrict guardians' powers. Beyond a guardianship that was divided between the person and the property, I saw no evidence of employing this judicial option in any of the twenty-one court petitions that I reviewed. Although it could be that all persons were so incompetent that they were unable to have limited guardianships, guardians' comments, notes, and my observations and interviews did not reveal this. In general, preservation and enhancement of client autonomy was only accomplished in some minor ways or not at all. Some guardians gave some wards choices in some matters, but no guardian revealed or expressed a strong tendency to develop client autonomy.

Yet, preservation and enhancement of client autonomy is an important function of the public guardian. If this function is not accomplished at the nexus of the state and the individual, it will not happen elsewhere. Wards are far too powerless in the wake of vocal and powerful third party interests to do more than voice their objections. When questioned, one paid public guardian stated that just because they were given plenary authority over the wards did not mean that the guardians had to exercise that power. However, numerous indications of the nature of bureaucracy reveal that if the power exists, it will be used to its fullest. Hence, the focus of public guardians on preservation and enhancement of client autonomy is an area where significant improvements may be made.

One suggestion for enhancing client autonomy would be though surrogate decision making. No chart contained a values history for any ward, and yet the values history is touted as an excellent tool in discerning who the ward is or was prior to a determination of incompetency. Making this important piece of psychological-social history for each client a requirement would facilitate decisions that are less paternalistic and reflective of best interests and more reflective of expressed values of the ward when competent. It would also help guardians to reflect more effectively the wishes of wards who may be able to express themselves. In this way, some measure of consistency would be attained.

\section{Provision of Guardianship Services}

A conflict of interest existed in some programs between the provision of services, even for a short period of time, and client advocacy. The potential for this exists, particularly in 
Maryland and Chesapeake, where the agencies are housed physically in a Department of Social Services. This conflict of interest even occurs to an extent in Delaware, where the agency sometimes serves as the petitioner and then becomes guardian of the ward. The Tennessee AAA provides no direct services, and so the conflict of interest problem there was minimized. Because of the nonprofit nature of the PSN demonstration site in Virginia, there was no conflict of interest problem of this nature. Other conflicts of interest that were not legal also occurred. Guardians had little actual time to spend with wards due to other demands that their agency placed upon them. Also, different values of guardians and their wards created a conflict of interest in decision making. Significantly, conflicts of interest were usually acknowledged but not regarded as problematic, still, the loser in this struggle is the ward, who cannot advocate on his or her own behalf.

Public guardians had varying accounting responsibilities. All were required to present reports to their supervisors that were then passed along to be reviewed by other sources. Two excellent features of the Maryland Public Guardian were the Review Board report and the Reconsideration report, where the guardianship of the ward was reviewed on an ongoing basis. Taken seriously, these reports fulfilled the important function of continually attempting to overturn guardianship where appropriate. Although it is certainly possible that none of the clients interviewed or observed will ever reach a level of competence that will permit having their guardianship overturned, it does happen on occasion. As with autonomy, without the refocusing of attention on the goal of working oneself out of job, the care goal most expressed for the ward will continue to be maintenance. Each agency should, no matter what the screening process, make as an accounting function of the primary public guardian, the reconsideration of overturning guardianship in more than just a pro forma matter.

Oftentimes, wards received better treatment particularly because of the public guardian's relationships among wards' hands-on caregivers. Public guardians stressed the importance of maintaining good working relationships with the staff many times. The majority of public guardians were careful to thank the staff for the work that they did, and they even praised the staff in my presence. Public guardians cultivate relationships with caregivers to obtain more complete information about ward needs than they could though observation, ward interviews, and reading nurse's notes.

Program supervisors emphasized various qualities that public guardians should possess. The programs generally varied in response to their overarching administration. The Chesapeake, Virginia, agency's volunteer coordinator stressed the importance of persons who were committed, caring, and desired to be problem solvers; this philosophy undoubtedly evolves from the fact that the guardians are volunteering their time.

The paid guardianship models differed in the areas of emphasis and the experience of the program supervisor. The PSN program supervisor emphasized organization to a great extent when asked about her qualifications for guardians. This emphasis was likely due to the fact that 
the two public guardians whom she had hired and terminated had lacked this job skill. The Delaware program supervisor looked for persons who had a background in social work, while the Tennessee program supervisor emphasized legal knowledge and life experience over a disciplinary emphasis. The Maryland program supervisor emphasized the importance of having a nursing background.

Wards were not pleased with their guardianship in some instances, and in some instances, they emphasized that they disliked their guardian. It is difficult to tell if the wards, even though their guardian was out of the room during the interviews, felt comfortable in telling me the truth, due to a fear of their own health problems, uncertainty of their future, or their feelings of loneliness. Because of the usurpation of rights by the state, it is even more important to attempt to cultivate a relationship with the ward that is satisfactory. As much as possible, public guardians should enable wards to understand the relationship of their guardian to them, and, even if they can only remember from one visit to the next, they should be told again about the relationship. Understanding what their guardian can do for them could be a potential step toward effectuating their needs.

\section{SUMMARY}

In summary, public administrators on the front lines of guardianship are required to fulfill the many and complex needs of wards. They are thwarted by high caseloads, financial as well as ward initiated constraints, and the tug of funding questions at the state level. Program supervisors attempt to support these persons, but they are sometimes prevented in this task by their own extensive job requirements. Understandably, not all wards are satisfied with guardianship or their public guardians. Ward relationships are given a low priority in the face of reporting requirements of the bureaucracy and other third party interests. It is significant and commendable that public guardians meet baseline needs of wards. Public administrators at the supervisory level must continue to search for creative solutions to lighten the load of these individuals as well as to channel their efforts towards priorities that are not necessarily consonant with the nature of bureaucracy. 


\title{
CHAPTER V
}

\author{
PROGRAM SUPERVISORS AND GUARDIANSHIP
}

Over himself, over his own body and mind, the individual is sovereign.

John Stuart Mill

\section{MICHELLE BERRY}

While Michelle was in college, she served as a nursing assistant in a nursing home to make some extra money. She graduated from college with a Bachelor's Degree in technology in the human services field. Her first position was with one of her state's long term care facilities. Within three years she became the facility's social service director. She worked there for six years and during that time her position was changed to an administrative one, where she was responsible for the entire social work department, the activity department, volunteer services program, and the chaplains. She changed positions again and became the admissions director at the state psychiatric facility. From there, she applied for the newly created position of Deputy Public Guardian and was selected for the position. During that time she returned to school to get her Master's Degree in social work. At the conclusion of the degree, Michelle became the head of the office.

Michelle has been the head of the Office of the Public Guardian for three years and says that she is very satisfied with her position. "It is difficult at times. [l]t's the kind of job where I don't make a lot of money, but the small things you do are good things. I don't have any trouble sleeping at night because of what I do. I think that is worth something. It's not monetary, but the reward is good. It's not always glamour. One week I could be in court, a nursing home, hospital, or some home--I could be sorting through someone's papers." In addition to her administrative duties, she carries her own caseload of 34 persons.

The responsibility of the program supervisor is to administer the guardianship program and be accountable for her actions as well as those of the persons she supervises. Program supervisors are public administrators who facilitate communication among employees, encourage teamwork, are part of the surrogate decision making tree, and focus primary public guardians on important aspects of the mission of the organization. Program supervisors were interviewed concerning aspects of their job, the organization and functioning of their agency, and their views concerning guardianship. Along with studying written materials about the agency, I conducted face-to-face interviews with five program supervisors. Of the five program 
supervisors, four supervised paid guardians, and one program supervisor, a volunteer coordinator, supervised volunteer guardians. Findings are presented on supervisors' background and the organizational mission and structure of the agency. A discussion follows the findings.

\section{BACKGROUND OF PROGRAM SUPERVISORS}

Program supervisors were attracted to their position because they had a history of wanting to improve the lives of vulnerable people. As noted in Table 2, all program supervisors of paid guardianship programs that I interviewed hold a Master's Degree in social work or sociology. The program supervisor in charge of volunteers holds a Bachelor's Degree in social work. Two program supervisors had worked in some form of nursing prior to completing a college degree. Two program supervisors worked in an Area Agency on Aging (AAA) prior to working with guardianship. Two program supervisors had extensive experience working in the mental health field prior to working with guardianship.

Table 2 reflects that all program supervisors, with the exception of the program supervisor in charge of the Chesapeake Volunteer Guardianship Program (CVGP) in Virginia had worked at their agency for a period of time prior to assuming the position of program supervisor of the guardianship program. The program supervisor in Delaware carried a case load in addition to her administrative responsibilities; the program supervisor in Maryland had recently turned the remainder of her cases over to her staff so that she could more adequately perform her administrative responsibilities and provide backup support for her paid guardians when problems arose. Two program supervisors of guardianship programs had never carried any guardianship cases.

\section{ORGANIZATION AND ADMINISTRATIVE MISSION OF THE RESEARCH SITES}

In order to best comprehend the program supervisors and their responsibilities, it is necessary to understand the organization and mission of the research sites. An explanation of the organization and mission of the research sites is included below followed by findings on specific themes discussed during the in-person interviews.

\section{Personal Support Network in Virginia}

In operation for eight years prior to its involvement with the Guardianship of Last Resort Project (GOLR), Personal Support Network (PSN) is located in Falls Church, Virginia. Created as a response to the question of parents of mentally ill persons, "What happens when I die?" it is a non-profit program of The ARC (Association of Retarded Citizens) of Northern Virginia. PSN attempts to fulfill a need that was unmet by sheriffs, who currently may serve as guardians of last resort in Virginia. 
Table 2

\section{Background of Program Supervisors}

\begin{tabular}{|c|c|c|c|c|}
\hline Site & Education & Years With Agency & Supervision Responsibilities & Caseload \\
\hline Chesapeake, VA & $\begin{array}{c}\text { Bachelor's } \\
\text { (Social Work) }\end{array}$ & 7.5 months & Volunteer Coordinator & None \\
\hline Delaware & $\begin{array}{c}\text { Master's } \\
\text { (Social Work) }\end{array}$ & 6 years & Office of the Public Guardian & 34 \\
\hline Maryland & $\begin{array}{c}\text { Master's } \\
\text { (Social Work) }\end{array}$ & 18 years & Office of the Public Guardian & $\begin{array}{l}\text { Concluded } \\
\text { recently }\end{array}$ \\
\hline PSN, VA & $\begin{array}{c}\text { Master's } \\
\text { (Social Work) }\end{array}$ & 8 years & $\begin{array}{l}\text { PSN activities plus demonstration } \\
\text { project }\end{array}$ & None \\
\hline Tennessee & $\begin{array}{l}\text { Master's } \\
\text { (Sociology) }\end{array}$ & 20 years & $\begin{array}{l}\text { Executive Director, } \\
\text { Area Agency on Aging }\end{array}$ & None \\
\hline
\end{tabular}


The objective of the program is to serve as guardian or alternative substitute decision maker of last resort for at least 25 persons in Falls Church City, Fairfax City, Arlington County, Alexandria City, and Fairfax County, Virginia. Serving a primarily urban population, PSN seeks to provide a variety of alternatives to diverse populations in a least restrictive manner that respects autonomy and protects the safety of its clients. It serves persons with all disabilities, including those with mental illness, mental retardation and other developmental disabilities, head injuries, learning and physical disabilities, and older persons with age-related impairments.

PSN gave priority to Adult Protective Services (APS) clients, originally allocating 15-25 clients from APS referrals. PSN applies the following criteria in determining whether it will serve as surrogate decision maker: (a) harm is likely to occur if no decision maker is appointed, (b) the least restrictive form of decision making is requested (i.e., power of attorney or bill payer), (c) no other appropriate decision maker is available, and (d) the role that PSN is requested to play will address the presented problem. PSN collects fees on a sliding fee scale. Aside from guardianship, PSN serves as representative payee, advocate, power of attorney, and bill payer.

PSN acts as an extended family for persons with disabilities, performing functions of family members if the family is not present or if the family needs assistance. PSN employs six persons working part-time on the project, plus a bookkeeper. The project also retains a legal advisor. Staff positions include a program manager, a staff supervisor, and four social workers, who are referred to as client representatives. Public guardians are monitored by a staff supervisor, who serves as the program's clinical expert. In turn, the program supervisor oversees the entire staff and directly supervises the staff supervisor. The program supervisor, who serves as PSN's guardianship expert, meets with the staff supervisor weekly as well as informally.

Paid public guardians work directly with individuals served by the organization; they visit their clients and get to know them. Public guardians ascertain ward needs and make sure that they receive appropriate services and benefits. Guardians make decisions and provide emotional support for their wards. Major decisions, such as decisions to terminate life support, are made in consultation with other staff members; outside guidance is solicited as needed.

Of the seventy referrals PSN received in the first year, PSN currently serves thirty clients and is turning down referrals due to exceeding their caseload cap. PSN's clients include seven wards, eleven representative payeeships, one power of attorney, and eleven bill payers and/or advocates.

\section{Chesapeake Volunteer Guardianship Program in Virginia}

The mission of the Chesapeake Volunteer Guardianship Program (CVGP) is to recruit, select, train, and support volunteer guardians. As with PSN, the sheriff served as guardian of 
last resort prior to the inception of the program. Organizationally, the program is staffed by a full-time volunteer coordinator and her part-time assistant. It is housed physically in the Chesapeake Social Services Bureau in the City of Chesapeake, that jurisdiction's lead agency in this inter-agency model of service delivery.

CVGP receives its referrals for wards from APS workers who, after exhausting all other possibilities for problem resolution, recommend clients to the program. Its mission is to enlist a broad community response; prevent abuse, neglect, and exploitation of older and disabled adults; minimize the need for guardians of last resort through education concerning guardianship and its alternatives; establish and maintain a system of volunteer guardians; and develop a comprehensive view of the target population for forecasting needs and services. The target population includes elderly and disabled adults who require substitute decision making services. In addition to serving as guardians, volunteers may serve as powers of attorney, representative payees, and companions. CVGP serves predominately rural and urban communities.

Another component of CVGP is the Chesapeake Guardianship Committee. It is a multidisciplinary panel that assists and oversees the volunteer coordinator, reviews appropriateness for guardianship, and serves in an advisory capacity for volunteer guardians. Members of the committee include three representatives from the Chesapeake Department of Social Services (the APS supervisor chairs the Committee), plus one member each from the Health Department, Community Services Board, Sheriff's Department, City Attorney's Office, and Personnel Department. The Chesapeake Guardianship Committee engages in educational initiatives in the community, helps in training volunteers, and provides support and expertise for volunteers on a case-by-case basis, by agency or by the whole committee.

Currently, the program includes 24 volunteers who have completed guardianship training, eight of whom are assigned wards or serve as powers of attorney. When I visited the site, CVGP had placed all clients with volunteer guardians; as a result, it is taking over guardianships that were previously the local sheriff's responsibility. Volunteers are to assume guardianship for twelve of the sheriff's wards.

\section{Maryland Office of the Public Guardian}

The research site for the Maryland Office of the Public Guardian is located in Montgomery County in Rockville and is housed physically in the Montgomery County Department of Social Services. Authorized by Maryland law in 1977, the Public Guardianship Program comprises a statewide system of APS to provide for adults who are unable to care for their basic physical or mental needs and require "services sufficient to protect their health, safety, and welfare" (Lord, 1995, p.1). Upon determination of the court, public guardians of the person provide case management for persons who cannot make and communicate responsible decisions about day-to-day care; live at risk of abuse, neglect and/or exploitation; and have no 
one to assume decision making responsibilities. "The guardian has all the rights, duties and responsibilities of a parent to a child." (Lord, 1995, p.1).

These decisions of public guardians were enumerated specifically in the 1995 annual report. Public guardians are authorized to establish residence; provide for care, comfort and maintenance; take reasonable care of wards' possessions; give necessary consent or approval for medical or other professional care for withholding or withdrawing of care (court authorization is necessary for the guardian to authorize, withhold, or withdraw any medical procedure, to change residence and to commit a ward to a mental facility); file an annual report with the court; and present the ward to the Adult Public Guardianship Review Board annually (Lord, 1995).

The Director of the Department of Social Services is the designated guardian of last resort for persons aged 18-54 years of age, and the Director of the Local Office on Aging is the appointed guardian of last resort for persons 65 years of age and older. Both Junior and Senior Guardianship Programs function in tandem at the Department of Health and Human Services and are subsumed under the Public Guardianship Program in the Long Term Care Section of Adult and Disability Services.

In 1995, 58 senior clients were served, including 48 women and ten men; 38 clients were aged 80 or above. Twenty-two persons had incomes above poverty level, and 36 had incomes below poverty level. Forty clients were housed in a nursing home, ten remained in their own home, four were in a group home, three were in domiciliary care, and one resided in an assisted living facility. Also during that year, one person no longer required a guardianship. Nineteen junior wards included 14 females and five males; four were ages 51-64, and three were over the age of 65 .

Much of the program supervisor's time is spent providing information and consultation to Assessment Center staff (an on-site facility for determining client need) and professionals associated with guardianship including attorneys, social workers, discharge planners, and the community at large. The supervisor approves the acceptance of a client as a ward if guardianship solves a discernable problem.

Senior wards must be visited by their paid public guardian monthly if they are residing in the community and every other month if they are residing in a nursing home. Public guardians visited their wards an average of 1.4 visits per client per month in 1995 . The program includes a volunteer component in which volunteers act as friendly visitors to wards in addition to liaisons between wards, their caregivers, and the program.

\section{Delaware Office of the Public Guardian}

The mission of the Office of the Public Guardian, who is appointed by the court, is to serve as a guardian for persons with mental or physical disabilities who are unable to manage 
personal and/or financial matters. Wards of the public guardian often have no family or friends able to or willing to assume guardianship. The Office of the Public Guardian was established as a result of enabling legislation passed in July 1974; persons served by the Office reflect the increasing number of predominately older adults who are impaired physically, mentally, or both and who cannot pay their bills or perform necessary activities of daily living. The Office was created as a protective services program. It was the first APS agency in Delaware, the intent of which is to serve primarily vulnerable elderly persons.

The Office acts through the Court of Chancery as a neutral guardian in contested guardianship cases, operates as guardian at the recommendation of APS where exploitation or abuse is suspected, and functions as interim or emergency guardian. The program supervisor is assisted by a Deputy Public Guardian and case workers. Striving to serve those persons who are most in need, the agency provides care and services over time. To determine persons' eligibility for the program, the supervisor employs a formula that includes disability plus inability or incapacity plus risk. Responsibilities of the guardianship arrangement include establishing services to assure that wards' needs are met in all activities of daily living (ADLs). The public guardian functions as an advocate and assists directly at-risk persons as well as those who have fallen through gaps in the service delivery network. Also, the agency provides "guidance and leadership" regarding issues dealing with voluntary and involuntary transfer of decision making to both social and legal communities and other professionals in the social services network (Williams, 1995).

In 1995, the Office of the Public Guardian served as court appointed guardian for 132 persons, an 8\% increase in the number of cases in FY 1994. The number of persons served by the agency has increased steadily since 1990 when the Deputy Public Guardian was hired to handle the influx of referrals from state facilities; from 1990 to 1995 the number of open and active cases has grown from 67 to 132 . Sixty-three percent of the guardianship cases are for the person for the purposes of medical decision making, especially for persons residing in institutions without legally designated surrogate decision makers. Use of computers at all sites enabled the office to embrace a greater team management approach to begin to build a database not only of client files but also of intra-agency information on guardianship.

Potential clients are screened in order to determine whether or not they need guardianship services. If not, persons are counseled about alternatives or the possibility of having a family member or another party assume guardianship. If an individual is determined to be in need of public guardianship, then arrangements are made for the necessary evaluations for the petition to the court. If guardianship of the person is established, the paid public guardian appointed must attend care plan meetings and semiannually submit progress reports for review by the court. Guardians consult with physicians so that treatment decisions can be made, advocate for quality of care and other services, and refer the client to appropriate social or medical services. If guardianship of the property is established, the primary public guardian must locate and inventory the ward's property, prepare realty and personal belongings for sale, 
including contacting the services of intermediaries as needed to complete the sale, conduct and monitor all other financial matters on the ward's behalf, make burial and funeral arrangements for the ward, and, upon the wards' death, present a final accounting of the wards' estate to the court. (Williams, 1995)

\section{Tennessee Public Guardianship Program for the Elderly}

The public guardianship program for older adults was authorized by the Tennessee Legislature in 1986; it is administratively supervised by the Tennessee Commission on Aging. Its mission is to serve persons unable to make decisions and actions for maintaining their health or for managing their finances. The paid public guardian does not impose fees against the estate of persons who receive guardianship services unless the income or assets of the individual meet the cost exemptions established by the Tennessee Commission on Aging. The Public Guardianship Program for the Elderly, associated with the Area Agencies on Aging (AAA), is a non-profit program that provides both conservatorship services and related services, such as power of attorney, to adult Tennesseans aged sixty or older. The First Tennessee Development District, which is the local AAA, has as one of its programs the Public Guardianship Program for the Elderly. It is the only program that provides direct services at the AAA.

A paid public guardian is located in each of nine Planning and Service Areas in Tennessee. The public guardian in Johnson City, Tennessee, serves the Counties of Carter, Greene, Hancock, Hawkins, Johnson, Sullivan, Unicoi, and Washington. Public guardians (referred to in Tennessee as District Public Conservators) do not petition the court for guardianship but do provide information and guidance on procedures and preparations of petitions. Although agencies in the state differ in some respects with regard to their operation, policy and interpretation of that policy is done in Nashville. Largely state funded, there is a public guardian coordinator for all the nine public guardians, who all have the same reporting requirements.

The Johnson City program includes a volunteer component; these persons serve as friendly visitors. The public guardian in Tennessee stated, "They [volunteers] are capable people who have worked with the aging. So they can go in and purchase things for the patients through the trust accounts. They can be an advocate in certain ways. They are the eyes and ears, just like the Hospice. If they see something that is not right, they are supposed to let us know."

In Fiscal Year 1996, 43 persons were served by the public guardian. Their ages ranged from 66 to 95, with the majority of clients in their eighties and nineties. Thirteen were males and thirty were females. The majority of referrals to the public guardian come from APS.

The public guardian is allowed discretion as to the cases that she accepts. Although the guardianship may be of the person and the property, the public guardian may also separate the 
responsibilities that she assumes, depending on her caseload. Travel for client visits takes up the greatest amount of her time. Due to the Tennessee legislature's inability to give cost of living raises to its public guardians, they reduced the work load for the public guardian by reducing the number of hours that they had to work; however, their work responsibilities were not subsequently decreased.

\section{COMMENTS ON ACCOUNTABILITY AND EFFECTIVENESS}

All program supervisors indicated that their programs were effective. Various methods of accountability existed, but common to all programs was an annual program audit. This information was required to monitor the guardian's expenses on behalf of the wards. Common to most programs is an annual accounting of some kind that must be presented to the courts.

In Tennessee, the accounting for the program was executed by the First Tennessee Development District AAA. The program is audited at the state level. The Tennessee public guardian interacts with other public guardians in the state, but is involved little if at all with other state programs. The public guardianship program is supported by approximately $\$ 67,000$ in state funding and $\$ 25,000$ from the development district. The program supervisor did not believe that the funds allocated for the program would grow; in fact, she remarked that the program was recently cut in state funding by $\$ 2,000$, through a determination by the state that more funds are required to maintain persons in their home than to place them in a nursing home. She acknowledged that state funding was deficient in other programs as well.

The Delaware Office of the Public Guardian, an agent of the Court of Chancery, provides semiannual reports on the ward's condition and a recommendation concerning the appropriateness of continuation of guardianship to the Court of Chancery. Though not required to file an annual accounting of the ward's finances, the Office must provide an initial accounting upon assumption of guardianship. The sale of property by the public guardian must be authorized by the court. Funds received from the state toward the guardianship program are earmarked for administrative use, not toward use for the wards. Should the public guardian be away for any period of time, she delegates her authority to the Deputy Public Guardian, who like her, carries his own caseload. At the agency level, the program supervisor conducts weekly staff meetings, and she shares an office, at least one day a week, with a case worker who is not located at the central office in Wilmington.

Similar to Delaware, the Maryland Public Guardian also is required to conduct semiannual reports, a Guardianship Review Board and a Reconsideration report, explained earlier. Under Maryland law, if a person is age 65 or older then the Office on Aging serves as the guardian. The program supervisor acts as the designated agent for the Director of the Office on Aging. The Director of the Department of Health and Human Services (DHHS) is the guardian for persons under 65. If persons become wards under DHHS, then they continue to be the Department's ward, even when they turn 65. In 1992, the two programs were consolidated 
administratively and were located at the Montgomery County DSS. In July 1996, the Department of Social Service was reorganized into the Department of Health and Human Services. The Maryland office in Montgomery County is the only one in the state with combined programs. A disadvantage is that a conflict of interest was created; the program supervisor is now administratively located within the department that is providing many of the services to the wards for whom they are acting as an advocate. One advantage, however, is that if a guardianship staff person is not available, other professional social workers can handle situations that arise. The program receives approximately $\$ 40,000$ from the State Office on Aging. The rest of the funding is received either locally or from the State Unit on Aging.

PSN in Virginia is funded entirely though the Virginia Department for the Aging; PSN requested \$70,000 for FY 1995. Accountability for work on behalf of a client by a client representative is accomplished through time records and logs kept on each client in a notebook that is then checked by the program supervisor. Individual accountability for financial matters is maintained by a voucher system. A bookkeeper, who is separate from the client representatives, monitors each client's checking account. The organization is held accountable by being evaluated as part of the demonstration project, by the court's yearly accounting, by the PSN Board that includes a quality assurance committee as well as the ARC board who monitors PSN, and finally, the ARC staff. Also, PSN is audited as part of the ARC.

The organization has ultimate authority for the wards. The supervisor stated, when asked who holds the agency accountable to preserve the client's autonomy,

Quite frankly, in terms of accountability, I don't think anyone holds us accountable to the client's autonomy except ourselves. I mean that's really. . .I hold the staff accountable in that. But I don't think anyone else does. It is an interesting thing. But you know the courts don't even look at any personal statement. And we haven't worked out that if we write the. . .client status reports, where they should go.

At the other demonstration project in Virginia, CVGP, the program supervisor (volunteer coordinator) screens, interviews, recruits, conducts public relations efforts, and monitors volunteer guardians. She telephones the guardians once a week to supervise their work with their ward and answer any questions or address any concerns that they might have. The program supervisor presents cases to the Guardianship Committee, and matches wards with volunteer guardians. She maintains quarterly accounting files and time sheets that the guardians are required to file and she functions as a liaison between the volunteers and the APS supervisor, who assigns social workers to various cases. Additionally, she serves as a liaison between volunteer guardians and wards' social workers.

The program supervisor must report to the Guardianship Committee prior to any major decisions that she makes. She is responsible for reimbursement of bonding fees to the volunteer guardians and is also accountable to the APS supervisor and the Volunteer Guardianship 
Committee. She is not directly accountable for guardians' financial matters; such matters fall to the Commissioner of Accounts. Volunteers must complete a monthly report of their activities with the wards, and the program supervisor (Volunteer Guardian Coordinator) checks in by phone with the volunteers weekly. Stated earlier and like PSN, CVGP is being evaluated by Winsor C. Schmidt, Hillel Abramson, and me. As part of the evaluation data, both projects are required to submit a Uniform Assessment Instrument for each client, care plans for each client, and time logs for activities by any actors involved in the project. Data from the projects will be aggregated and presented in a final report in July 1997.

\section{SUPPORT AND INTERACTION WITH OTHER PROGRAMS}

PSN derives support and consultation from an advisory board made up of representatives from the Arlington Area Agency on Aging, Fairfax Adult Protective Services, a citizen, and an attorney from Legal Services. Other networks that offer support include the Northern Virginia Aging Network, community groups, and directors of mental health programs or services. In Fairfax, a Pre-Guardianship Panel reviews persons as appropriate and serves as a resource for guardians. PSN interacts with other programs across the country due to its program supervisor who is active in the National Guardianship Association and the Virginia Guardianship Association.

CVGP derives support from the city of Chesapeake and surrounding communities from its volunteers, local advocates, and the agencies involved in the Chesapeake Guardianship Committee. The program interacts with the other guardianship demonstration project in the state, and like PSN, receives inquiries about the project from other state projects.

The supervisor in Delaware reported limited interaction with other state guardianship programs. She said that the programs vary so from state to state that it is difficult to interact with them. She emphasized that the Delaware Office of the Public Guardian works primarily with protective services, under the Division of Aging in the Division of Services for Aging and Adults with Physical Disabilities.

The program supervisor stated that their support from outside agencies has grown significantly in the past six to seven years. Because the agency was tied to the courts and because it was a small agency, it kept a low profile for a number of years. She stated that once the word got out, which she wanted, the number of cases ballooned. Her support derives from the courts, the Department of Health and Human Services, and the legal community.

In Maryland, Montgomery County supports the program through its attorneys and at the Department of Human Resources. Also, the program receives the support of the county's "on call" system of social service backup. The program interacts very little with other state guardianship programs. Within the state, the Director of the Public Guardian with the State 
Office on Aging conducts regular meetings with representatives from the programs and provides other support as needed.

The Tennessee public guardian reported little interaction with other programs in the state. However, the State Public Guardianship Program conducts statewide workshops on guardianship. The public guardian mentioned to me in November 1996 that she had recently attended the National Guardianship Association Conference.

\section{SUGGESTIONS FOR CHANGE}

Most programs, particularly the established programs of public guardianship, suggested changes for their programs as well as guardianship in general. The Tennessee public guardian ${ }^{5}$ addressed problems associated with getting attorneys to prepare documentation for court hearings. She asserted that it is difficult to find persons to do appraisals on the ward's property in a timely fashion; paying for their services is often hard to arrange. In fact, she believes that the conservator of property would be best served by a trust department at a bank, because many wards already have accounts at the financial institutions. She argued that the public guardian should serve as guardian of the person only. She added that her office should do more with record keeping on social assessments in files.

The Tennessee public guardian's supervisor suggested that the public guardian needs to be able to make prior decisions regarding DNR orders for the ward. The supervisor stated that she would like to review in-depth all the ward cases with the public guardian, although they have talked about issues with the wards from time to time. Also, she stated that she would like to go on several home visits with the public guardian to understand the wards better. However, she recognized that, with the heavy demands of her own position, coupled with the heavy demands on the public guardian, actually addressing her "wish list" would be difficult.

Like the public guardian in Tennessee, the Maryland program supervisor cited a problem with court appointed attorneys. She said that she would prefer to return to the state's previous system in which judges appointed attorneys for guardianship cases.

When you would get [certain attorneys] you had somebody who was going to fight you. They were going to really fight [for] the rights of that client, and they were going to give you a run for your money. And that's the best kind of lawyer. That's the role you want. That's what I want. I don't want somebody who's going to rubber stamp what I do. I know that sounds crazy. . .it's very unclear about the role of the attorney, and we're

${ }^{5}$ The public guardian's comments are included here due to the supervisory nature of the program in Tennessee. 
trying to get that changed because it [law] says you have to file a report to the judge, an independent fact finder. But you're also supposed to represent the client.

In addition to the attorney issues, she stressed that public guardianship is not the answer to every problem with difficult clients. Sometimes, even if the client meets the criteria for acceptance, the imposition of such a sanction is inappropriate. She emphasized that the program must have access to a variety of professionals such as physicians, psychiatrists, and attorneys, particularly at the assumption of guardianship.

Within her program, she would like more funding so that they could employ another staff person. She would like everyone on her staff to have clinical training and possess a Master's Degree. She supported the judicial trend toward limited rather than plenary guardianships, but she said that it was a double edged sword. Limited guardianships fit well with the public guardian's role as client advocate, but administratively, limited guardianships created difficulties such as arranging for services. Finally, she said that she did not favor hospitals filing petitions for guardianship, but she recognized that if they did not do so, the Department's Assessment Center would be overwhelmed and the state would have to foot the bill.

When asked about program and general changes for guardianship, the program supervisor in Delaware began by saying that she wished that a need for public guardianship did not exist; she cited the necessity for all citizens to make advance directives, but she pointed to a more insidious problem.

What I see happening. . .and this may be just in Delaware. . . is that public guardianship and guardianship in general is not necessarily used to protect the individual. It's used to protect the institutions. And I have a real problem with that. I don't see it getting any better. I see that getting worse. How can we make that better? I don't know. Because people are so fearful of law suits. And maybe if they could get tort reform or get something, get that whole thing under control, maybe it would have a secondary effect on guardianship and whatever other areas like guardianship are affected by that. I happen to know guardianship. People secure guardianships not necessarily to protect the individual but to protect the interests of the nursing home, the interests of a state institution. And we're always, when we're reviewing referrals, we think, wait a minute. Who are we protecting here?

She explained that oftentimes agencies or institutions, particularly nursing homes and hospitals, simply want to have their bills paid and regard the public guardian as the avenue for debt collection. She also indicated that her office receives referrals because a physician wants protection from legal suits regarding a medical decision. The program supervisor stressed that the physician referral is inappropriate because emergency petitions are to be used only for the guardianship of person when an individual's life is at substantial risk of harm. She stressed that 
it is necessary that she focus her agency on meeting the needs of the ward, not meeting the needs of third parties.

The program supervisor indicated that the most difficult cases are those concerning health care decision making in life and death situations because she does not believe that society has come to a consensus regarding a standard for an acceptable decision when the wishes of persons are not made known. She noted that research, court decisions, and the implementation of the Patient Self-Determination Act support the use of advance directives and reflect a societal tendency to approve less extraordinary measures when a person's condition is deemed futile. At the same time, the supervisor finds these cases difficult when addressing them on an individual basis:

We have to decide that that's not how we're going to care for our people who have advanced Alzheimer's. That that's not appropriate. There has to be a different protocol and that it's okay for someone to not, you know, just be kept comfortable in that state. But I can't do it individually. I just recently saw someone in a nursing home down state with that situation. You know, I'll give consent to a PEG [percutaneous endoscopic gastrostomy] feeding tube, but that's. . .we have to catch up. But I can't decide those issues on an individual basis. That is probably the toughest part of this job when those issues come up. And they do. And I don't shy away from it, but if I have any sleepless nights it's because of [that issue].

The supervisor's programmatic changes included increased funding, more caseworkers on staff, and alteration of the program's mission to include the provision of information and referral to family members and other private individuals who are securing guardianship. She would like the agency to become recognized as a "guardianship clearinghouse." She added that even something as simple as keeping guardianship packets in their agency rather than at the courthouse would help persons determine where to seek information and referral. She did not want to include legal advice as part of the information available, however, except in a limited fashion. Additionally, she would like to do more for people in nursing homes and advocate for persons in them, but she acknowledged that this would be taking on another role for the public guardian, that of the Long-Term Care Ombudsman. This would create an additional mission for the agency, one for which they are not equipped to handle without substantial increases in funding and staffing.

The supervisor at PSN had only a few changes to suggest for the program and for guardianship in general, probably due to the fact that the project had been operating for such a short time. Unlike the program supervisor at the other projects, she did not state overtly that she would like more money for the program, although she did express a wish to serve other clients. She discussed a problem with having to return to court to obtain permission to sell a client's house; the additional attorney's fees cost the client an additional $\$ 5,000$ in order to sell a $\$ 64,000$ house in the Washington, D.C. area. She also was concerned with the disparity of costs 
charged by various guardians ad litem. Programmatically, she stressed that their records should be more organized.

The program supervisor at CVGP had no recommendations for changes in guardianship and few suggestions for program changes. She stated that she would like to see volunteers become more acquainted with the agency and with other aspects of agency decision making pertaining to the ward. She would like to better assist the volunteers if a problem arises and prevent them from being burned out from their responsibilities.

\section{DISCUSSION}

The findings from the program supervisors group into three major areas. These are financial issues, administrative structure and mission issues, and issues of public administration and are discussed below.

\section{Financial Issues}

Financial issues plagued all established paid public guardianship agencies. All established paid public guardianship agencies needed more staff persons and more money to serve clients. The program supervisors reported that their primary guardians' caseloads either were already too high or were approaching the limit in cases that they could handle effectively. Especially problematic was the instance in Tennessee where the travel budget was decreased along with a reduction in the number of hours for which public guardians were paid. The public guardian's responsibilities are unchanged, even though her work hours were curtailed.

At the same time, it is curious that the two demonstration projects did not express the same concerns, even though the PSN program supervisor alluded to them. She remarked that she had to turn down referrals for the program. There were over seventy referrals for twentyfive service slots, and the program supervisor even took on five additional wards. With increased funding, more persons truly in need of guardianship could be the recipients of guardianship and guardianship services. CVGP overestimated its initial need of guardianships in the community and used far less than its original allocation of $\$ 56,598$. Consequently, CVGP was in the process of taking over guardianships for the volunteer program from the sheriff, who was, on the whole, more than delighted to relinquish his responsibilities. At the time of this writing, CVGP has still not completed the transfer of the guardianships to volunteers.

Issues concerning the disparity of fees for attorneys and the level of investigation provided by some guardians ad litem highlighted the fact that public guardians often serve third party interests. According to both paid public guardians and program supervisor alike, many attorneys were woefully unqualified to serve as guardians ad litem or guardians of the property, and the public guardians were forced to compensate. One paid guardian and program supervisor discussed having to remove an ineffectual guardian of the property; the primary public guardian 
acknowledged her difficulty in removing the attorney and that, even though the guardian did not fulfill necessary responsibilities, there were no life threatening consequences for the ward.

\section{Issues of Administrative Structure and Mission}

Five issues of administrative structure and mission emerged from the interviews and literature on the agency. These concerned carrying caseloads in addition to the other responsibilities of program supervisor, knowledge of wards, provision of guardianship and related services, community education, and interaction with other programs.

With the complex demands of public guardians, it was surprising to learn that two agencies did give or had given personal caseloads to program supervisors. The Maryland public guardian had transferred her cases to her social workers between the time I visited them for the research pilot and commenced actual data gathering. The Delaware public guardian acknowledged that, should their agency grow (its caseload had doubled in five years), she would find it difficult to maintain two roles. The Tennessee public guardian has no real backup in terms of day-to-day services, and the program supervisor shares her supervision of the program with her supervision of other programs in the agency. It is significant that, in a year's time, she had not been on one client visit, nor did she know the functions of the public guardian intimately. This situation is not a fault of her administration within the agency; however, it is a fault of the administrative structure of the Tennessee public guardian system in general. Should case loads increase, there will be no day-to-day coverage in the absence of the only local public guardian.

Although not carrying a caseload is certainly preferable for program supervisors, the disadvantage is that they know the wards only from a distance. Program supervisors should be thoroughly acquainted with the wards, and this will only happen if it is a focus of the agency. The idea of the Tennessee public guardian, to furnish all persons in their decision tree with a notebook of relevant information, is a good one. An easily accessible and updated notebook or a set of files should be in the possession of and reviewed periodically with program supervisors and others who could potentially serve as a backup to the primary public guardian.

A third issue is the difference in provision of guardianship and related services by the demonstration projects and the established paid programs. It arises from the fact that the demonstration programs provide guardianship and guardianship-related services. The same is not true for the other agencies. Tennessee may serve as guardian of the person and property as well as power of attorney. Delaware may serve as guardian of the person and the property, while Maryland may serve as guardian of the person only. Alternately, at PSN, persons may serve as representative payees, bill payers, powers of attorney, and client advocates, and at Chesapeake, guardians may serve as payees, bill payers, powers of attorney, and companions. Hence, their responsibilities per client may not be as comprehensive as those who provide guardianship only. Finally, the demonstration projects exhibited an overall reticence to discuss 
any significant problems, financial or otherwise, with me at the time I interviewed them. Data gathering for this study was conducted prior to the preliminary evaluation report, and, while all programs that I studied were anxious to showcase themselves, it is likely that the demonstration programs were not anxious to identify problem areas before they were revealed in the report.

A recognized mission of the public guardian is to disseminate information on guardianship and its alternatives. However, program supervisors indicated that recognition of this function is not universal and barely supported, if at all. Though not always stated explicitly, education is an implicit mission of the agency.

A final issue, a corollary to focusing the community on the office of the public guardian as an important information and referral source, is the amazing lack of interaction with other programs in the state and across the country. Of the established programs, only Delaware does not have a local interaction problem due to the small size of the agency and the state's geographic size.

\section{Issues of Public Administration}

Issues of public administration, especially administrative style, conflict of interest, and treatment of clients also arose from the study of program supervisors. The style of administering a public guardianship program is not commensurate with traditional methods of supervision. Supervisors allow primary public guardians a significant degree of freedom and flexibility in decision making. Notably, the Delaware program supervisor discussed how she employed a team approach to decision making and office management when solving problems, supporting employees, and reviewing referrals. Communication among equals was one of the best ways that program supervisors stayed in touch with the actions of the public guardians. All program supervisors met with their employees, either formally or informally, and indicated that they had an "open door policy." They stressed that they tried to "be there" for their employees and that they tried to appreciate them.

Another public administration issue raised by the study is conflict of interest. Conflicts of interest were potentially evident in most of the public guardianship agencies. Delaware could and did petition for guardianship of the persons who became wards of the agency. Maryland's 1992 departmental reorganization created the problem of a department that advocates for clients while it is part of the same agency that petitions for guardianship and provides direct services to its clients. Tennessee is housed in an agency that contracts for direct services to older clients. The Chesapeake, Virginia, program has several potential conflicts of interest: it is housed in a Department of Social Services and its office is contiguous with that of the APS department. Additionally, rather than the agency serving as the guardian, the volunteers do, even though they receive supervision, guidance, and training from both the APS social worker liaisons, the Guardianship Committee, and the volunteer coordinator. 
Although most program supervisors acknowledged that these conflicts of interest existed, they inferred that they worked around them. I was unable to witness specific instances where this problem arose; however, it is a real problem. Although one program supervisor stated that guardianship was all about relationships, conflicts of interest create the potential for questionable service to wards. Though I offer no solutions here, I do note that the problem does exist, and it is embedded in the structure of most agencies that I studied.

A third issue concerns treatment of clients. Guardianship clients are of course very special. Although many wards are easily controlled, it is essential that the agency maintain a commitment to ward autonomy. Most guardians and program supervisors admitted that they attempted to recognize ward autonomy as best they could. However, they did not receive administrative encouragement to do so. The Maryland public guardian and program supervisor were quick to say that, although the courts generally granted them plenary authority, they did not necessarily invoke it. Still, it is worrisome that no documents akin to a values history were contained in the files of any of the wards who were either interviewed or observed. A values history would be one method of focusing public guardians on this responsibility and will be discussed in greater detail in the final chapter. 


\section{CHAPTER VI}

\section{THE VOICE OF THE WARDS: PERSONAL GLIMPSES}

It is the meaning that men attribute to their life, it is their entire system of values that define the meaning and value of old age. The reverse applied: by the way in which a society behaves toward its old people it uncovers the naked, and often carefully-hidden, truth about its real principles and aims.

Simone de Beauvior

\section{KATIE SCOTT}

Katie's room has a bulletin board that is full of pictures, cards, and a certificate from the Army with her husband's picture on it. Her husband died over ten years ago, and their only child survived only five days. There is also a calendar in her room, which faces the blue Appalachian mountains of Tennessee. Pink and red balloons hang from the call button in her room. She sits in a wheelchair in a nursing home. Her meager monthly income consists of $\$ 335$ from Social Security and \$90 from a Veteran's Pension. Born in June of 1910, Katie's life is anything but typical. She admitted that she was an abused child, something that few older adults will admit. "I was adopted and at eight months old, my mother throwed me away. She did." She was not hesitant to show the scar she retained from being thrown against a grate by her mother.

Her medical diagnoses are few, only arthritis and dementia. Katie can be cantankerous; nurse's notes in her chart revealed that she had recently slapped a nurse. She craves attention from her guardian and facility staff. Katie's Tennessee public guardian is appointed for guardianship of person and property.

Katie does not like the facility in which she is living, but still, she cannot seem to make up her mind about where she would prefer to move. She is quick to tell her guardian about her need for shoes and clothes, and she asks her if she can get her out of the nursing home. She insisted, "There are a lot of crazy people here. I try to stay away from them." She is lucid enough to make some decisions about health care and where she would like to live.

She wants her freedom. She sighed, "I'd give anything in the world if they'd let me get out of here and give me an apartment. If they'd give me my money. I've been keeping house all these years. My mind has come back. I remember everything." 
In most guardianship studies information concerning the ward is either non-existent or sketchy at best. What little information that is provided generally pertains only to the age, sex, and race of wards. The following chapter consists of comments on the wards from four sources: the primary public guardian, the program supervisor, observational comments by me, and, most importantly, comments by the wards themselves. A discussion of the findings concludes the chapter.

This section is based upon in-depth interviews of eleven wards in five states. The wards were observed while with their public guardian and interviewed privately about their background, needs and wishes, and satisfaction with guardianship. Public guardians were questioned about the ward's background and needs; program supervisors were questioned on how well they knew the wards. The wards' answers to questions on their background, health, decision making, and needs and wishes are presented below.

\section{COMMENTS OF INTERVIEWED WARDS}

As stated earlier, interviewing the wards was often difficult due to the severity of their dementia and other medical problems. The interviewed wards, all of whom were adjudicated incompetent to make decisions regarding their person, property, or both, were usually the most lucid persons under the supervision of the public guardian. Because a degree of lucidity was necessary in order to conduct the interview and there were generally few participants from the selection pool, the ages of the wards differed, with the youngest ward being 28 and the oldest 109 , as shown in Tables 3 and 4 . The average age of the wards was 76.5 years of age. Tables 3 and 4 also reveal great variety in wards' level of cognizance and functioning. The youngest ward worked part-time, owned his own car, and lived in his own apartment; however, the majority of wards lived in an institution, either in a group home or in a nursing facility. Wards frequently had difficulty following questions and tended to give short, simple answers. Many wards could not identify their guardian, even though the guardian had just left the room in which the interview was conducted. The first section of the findings captures the wards' description of themselves and their background.

Although wards were at first wary of being interviewed by me, after I was introduced to them by the primary public guardian, they were generally eager to be interviewed and to share their stories. Only one ward in Tennessee initially refused being interviewed, due to her health, but when asked if she would answer a few questions and I explained that she could stop the interview any time she desired, she agreed to be interviewed. No wards objected to being audio taped, and all wards expressed their opinions and answered the questions with the understanding that their guardian would not be present or notified of their answers. Interviews ranged in duration from twenty minutes to slightly over an hour. Observations were made during the ward interview and also during the interaction of the ward and the public guardian. 
Table 3

\section{Characteristics of Wards Who Were Interviewed and Observed}

\begin{tabular}{|c|c|c|c|c|c|c|c|}
\hline Ward & Site & Sex & Age & Habilitation & $\begin{array}{l}\text { Assistive } \\
\text { Devices }\end{array}$ & Major Diagnoses & Guardianship \\
\hline 1 & $\begin{array}{l}\text { CVGP- } \\
\text { VA }\end{array}$ & M & 28 & apartment & none & schizo affective disorder & property \\
\hline 2 & $\begin{array}{l}\text { CVGP- } \\
\text { VA }\end{array}$ & $\mathrm{F}$ & 62 & nursing home & none & seizures, depression, noncompliance for medications & person \& property \\
\hline 3 & $\mathrm{DE}$ & $\mathrm{F}$ & 109 & nursing home & wheelchair & $\begin{array}{l}\text { senile weakness and infirmity, abdominal aneurysm, } \\
\text { arteriosclerotic heart disease, recurrent urinary tract } \\
\text { infections }\end{array}$ & person \& property \\
\hline 4 & DE & M & 83 & nursing home & none & $\begin{array}{l}\text { hypertension, dementia, renal failure, chronic urinary tract } \\
\text { infections anemia, pericarditis, glucose intolerance }\end{array}$ & person \& property \\
\hline 5 & MD & M & 85 & group home & cane & $\begin{array}{l}\text { degenerative disc \& compression fractures of thoracic } \\
\text { vertebra, emphysema, anemia, CHF, COPD }\end{array}$ & person \\
\hline 6 & MD & M & 74 & group home & none & multi-infarct dementia & person \\
\hline 7 & MD & $\mathrm{F}$ & 75 & nursing home & wheelchair & $\begin{array}{l}\text { asthma, organic brain syndrome, Alzheimer's Disease, } \\
\text { Dementia , bipolar, fracture of L. Distal radius }\end{array}$ & person \\
\hline 8 & PSN-VA & $\mathrm{F}$ & 94 & nursing home & walker & $\begin{array}{l}\text { arthritis, congestive heart failure, dementia, legally blind, } \\
\text { urinary incontinence }\end{array}$ & person \& property \\
\hline 9 & PSN-VA & M & 82 & home for adults & none & dementia, urinary incontinence, vitamin B-12 deficiency & person $\&$ property \\
\hline 10 & $\mathrm{TN}$ & $\mathrm{F}$ & 67 & nursing home & wheelchair & $\begin{array}{l}\text { early dementia, organic delusional disorder, blind, } \\
\text { incontinent urine and bowel }\end{array}$ & person \\
\hline 11 & $\mathrm{TN}$ & $\mathrm{F}$ & 86 & nursing home & wheelchair & arthritis, dementia & person \& property \\
\hline
\end{tabular}

Note: By statute, MD Public Guardians may only assume guardianship of the person. 
Table 4

Characteristics of Wards Who Were Unable to Communicate Clearly

\begin{tabular}{|c|c|c|c|c|c|c|c|}
\hline Ward & Site & Sex & Age & Habilitation & $\begin{array}{l}\text { Assistive } \\
\text { Devices }\end{array}$ & Major Diagnoses & Guardianship \\
\hline 1 & $\begin{array}{l}\text { CVGP- } \\
\text { VA }\end{array}$ & M & 46 & adult family home & none & severe MR & person \& property \\
\hline 2 & $\begin{array}{l}\text { CVGP- } \\
\text { VA }\end{array}$ & $\mathrm{F}$ & 66 & nursing home & wheelchair & muscular dystrophy, dementia & person \& property \\
\hline 3 & DE & $\mathrm{F}$ & 87 & nursing home & wheelchair & $\begin{array}{l}\text { bilateral glaucoma w extraction of cataract, scoliosis of the } \\
\text { spine, hiatal hernia, senile dementia }\end{array}$ & person \& property \\
\hline 4 & $\mathrm{DE}$ & $\mathrm{M}$ & 87 & hospital & bedridden & $\begin{array}{l}\text { glaucoma, chronic renal insufficiency with catheter, } \\
\text { schizophrenia, depression, peripheral vascular disease }\end{array}$ & person \& property \\
\hline 5 & MD & $\mathrm{F}$ & 86 & $\begin{array}{l}\text { own home, full- } \\
\text { time caregiver }\end{array}$ & walker & senile dementia & person \\
\hline 6 & MD & $\mathrm{F}$ & 88 & group home & none & $\begin{array}{l}\text { organic brain syndrome, cardiovascular disease, aortic } \\
\text { sclerosis, cataracts, insomnia, arthritis, questionable nodule } \\
\text { on R lower lobe o lung, scoliosis, fractured rib }\end{array}$ & person \\
\hline 7 & PSN-VA & $\mathrm{F}$ & 83 & nursing home & wheelchair & $\begin{array}{l}\text { hyper epidemia, hypertension, angina, arthritis, diabetes, } \\
\text { semi-comatose }\end{array}$ & person \& property \\
\hline 8 & PSN-VA & $\mathrm{F}$ & 63 & nursing home & bedridden & cirrhosis, hypertension diabetes, congestive heart failure & person \& property \\
\hline 9 & $\mathrm{TN}$ & M & 66 & nursing home & none & early history of epilepsy, speech impediment, MR & person \& property \\
\hline 10 & $\mathrm{TN}$ & $\mathrm{F}$ & 91 & nursing home & none & moderate MR, schizophrenic, syncope & person \& property \\
\hline
\end{tabular}

Note: By statute, MD Public Guardians may only assume guardianship of the person. 


\section{Background and Health}

Questions were asked about wards' personal background and health. They tended to focus on general aspects of their background including work, families, health, and feelings. Wards reported a variety of work backgrounds. Surprisingly, female wards often had worked outside the home: as a waitress in a coffee shop, as a bookkeeper in an insurance company, as a secretary, and as a babysitter. One ward reported working only a little due to illness, and one ward could not remember whether or not she worked at all. When questioned about her work responsibilities, the ward who worked as a bookkeeper responded, "All I had to do was sign the books when they come in and pay."

Male wards reported working for the federal government, working for the government as a draftsman, working as a dental assistant, and working at a racetrack. One ward currently works part-time on his volunteer guardian's farm. "[I] work when I can. I paint fences that hold the horses in. I do weed eating with a gas powered weed eater. I do trim work with the push lawn mower. Sometimes I ride their [guardian's] tractor to cut grass. I weed flower beds."

Wards occasionally commented on their marital background and families. One female respondent reported that her second husband would "buy her anything she wanted," while another ward said that she had been married to the same man for over fifty years prior to her husband's death. Male respondents spoke of the recent death of a spouse, a divorce, and a former wife's occupation. The others did not comment on their families. A female ward commented on her love of animals, stating that prior to guardianship she owned approximately 20 dogs and 35 cats, all at the same time. Two female wards reported that their children had nothing to do with them; another woman emphatically did not want her sisters to have anything to do with her or the property that she had owned. Male wards either had no children or did not mention them. Approximately half of the wards reported being natives of the state which now has guardianship of them.

As another aspect of their background, wards were asked to comment on their health. Four male wards reported that they did not have any complaints; however, one man reported not being able to walk during the month prior to the interview. "I got a piece of [shrapnel] right there behind my kneecap, and it started to act up and started giving me a lot of trouble. Of course, this leg has been all operated [on]. I'm all scarred. Nasty scars. Well, there's so much wrong with me."

By contrast, only one of the female wards felt well. One ward reported experiencing problems with her eyes, asthma, hearing, and falling. "I had fallen but I don't know if anything will come of it . . I couldn't hear too well. But now I seem to be coming back to normal. I haven't felt very good in a month or two." 
Other health problems voiced by female wards included not feeling well overall (no specifics), blindness and arthritis neck pain, pain in legs, and problems with nerves due to an attempt to stop smoking. One ward, who was in a wheelchair and hoarse, stated flatly, "Ain't nothing wrong with me, I ain't sick."

Several wards asserted that they were afraid. One woman said that she was frightened of being alone. Another woman was afraid of elevators because one had closed on her recently; one ward was afraid that the facility was trying to drug her. She stated that she did not take her medication and that she mistrusted the staff. Several wards were fearful of their health: "I'm so afraid I'll get even more [sick]. I'm afraid I'll find out I feel less and less [well and] that I can see less and less. I'm afraid to ... tell you the truth." Some wards were concerned that their possessions would be stolen by staff.

Several of the wards expressed feelings of entrapment, loneliness, fear, and boredom. It is possible that interviewing the wards capitalized on their feelings of loneliness, and so the interview became a chance for the wards to express themselves and have some attention paid to them by a person who would actively listen to their comments. During the interview, at least three wards cried when discussing their feelings and their backgrounds. Although I asked if they would like to stop the interview, they declined, composed themselves, and continued to answer questions. Some wards were unable to follow the questions asked, and so, after three or more attempts at explaining or rephrasing the question to aid in comprehension or clarification, I moved on to the next question.

Wards appeared to be well cared for, and only in one instance had nursing facility staff not bathed a ward when I arrived. Wards in nursing homes generally shared their rooms with another person. One facility at the Chesapeake, Virginia, demonstration project only housed two other residents and needed repairs, a problem which was mentioned to me by the ward during the interview. Otherwise, the facilities in which the wards resided appeared neat and clean.

\section{Needs and Wishes}

Perhaps the most frequent wish that wards expressed was that they wanted to go home; all wards interviewed except for one were living in an institution of some sort. Wards reported that they felt as though they were in prison. One ward insisted, "I want out of here, and [the guardian] can get me out of here, but she wouldn't because she has my money and she can get me out of here. Now, she can take me home; that is where I want to go. I've not done nothing wrong. All I do is just sit here, and I want out of here. . .all she [guardian] has to do is take me home. I would go home, but I can't walk out." Additionally, one male ward who lived in a group home reported that he would most like to "get up and go out when I can. I feel like a prisoner." 
A female ward asked me point blank, "Do you think I can get out?" Two other female wards asked me the same question. Interestingly, a ward with severe mental retardation who rarely communicated walked around his facility with a notepad in his hand. On it was written the word "discharge."

Other ward wishes were less intense and were related to recreation or spirituality. One ward wanted to be reminded what day it was so that she could attend church services. Two wards indicated that they desired greater contact with their family. Wards expressed needs and wishes for personal items such as a new coat and a new toothbrush, a favorite dresser, and clothing, such as shoes. Other wishes included having a lock put on a door for privacy, petting dogs and cats, going shopping, being able to see better, and not wanting to do anything. The ward who worked part-time wanted to be able to hold down a forty-hour a week position, although he admitted that he would need additional training and education. Said one ward, "I want a lot of things that nobody knows about. . because I won't say anything about it because I know I can't get there to get them."

\section{Activities, Past and Present}

As an extension of the question about needs and wishes, wards were asked about the activities that they used to enjoy and in what activities they currently enjoyed participating. When questioned, one male ward stated that he used to like photography and golf; he now enjoys making place mats with other participants at the facility. He stated further, "I used to do a lot of things that I don't have any chance to do now." Another ward reported that he enjoyed doing needlework and the activities at the day care center that he attended, such as viewing television. One male ward reported that he did very little at the nursing home in which he resided. Still another ward reported that he liked doing things associated with his work.

When asked about her activities, one female ward responded that she did not do anything. One ward reported staying in her room the majority of the time. "You see how it is? I can't stand it. I stay in the bedroom here $95 \%$ of the time at least because I cannot stand that furniture out there in the sitting room; that's supposed to be the meeting room for company." Two female wards reported liking to sew in the past; one research participant did not comment on her past or current activities.

\section{Ability to Make Decisions}

As a final aspect of ward background, I questioned wards on what decisions they believed they could make that they were not making now. One ward stated, "I don't know what to do now, you know. Like a blank wall on this thing. I can't get over the wall. . I guess I'm very stubborn." 
Another ward stated, "I don't know what I'm capable of yet." A different ward stated that he made a decision to attend the adult day care center six days a week rather than five because he liked to stay active. Some wards were incapable of following the line of questioning or said that they could not think of any decisions that they would like to be making.

One ward was making a decision regarding whether to stay at the nursing facility in which he was currently residing or to move back to his apartment. He stated that he was not comfortable making a decision by himself. "What am I going to do? So, I don't know. I can't make that decision by myself." Later in the discussion he stated, "Let's see. . let's make a decision to my benefit as well as other people." After his guardian encouraged him to stay at the facility, he said, "It sounds good. I think I'm on the right road now."

The most cognizant ward with whom I spoke had this to say about making a decision, "I feel like that at times in the past I've had to have somebody make decisions for me to be placed in a hospital even when I didn't want to go and I refused to go, and then I ended up getting escorted to the hospital. But the last time I went to the hospital I voluntarily went. I think I would be better at handling my money than I would be at all the time handling knowing when I'm going to get sick and need to go to the hospital possibly." Importantly, one ward stated that she would like to make her own decisions but no one would pay any attention to her.

\section{Background of Wards Not Interviewed}

Although it was not possible to interview certain wards due to their lucidity, it was possible nonetheless to glean some personal information about them. Of the wards who were not interviewed, Table 4 shows that seven were women and three were men. As with the communicating wards, these wards came from a variety of work backgrounds including one ward who served as a secretary to a senator on Capitol Hill, a nurse, and one ward who currently worked at a vocational center. One ward had lived in an public institution virtually her entire life. Case file notes reflected less information about wards who were not communicative or semi-communicative, especially if the guardianship had been assumed fairly recently. Discerning mental or physical status of wards who could not communicate tended to be more complicated than if the ward could communicate. Though it was difficult to determine ward preferences or needs and wishes, involvement with a ward prior to the debilitating situation that usually precipitated guardianship provided clues.

\section{PUBLIC GUARDIANS’ KNOWLEDGE OF THE WARDS}

Primary public guardians were interviewed regarding the background, health, needs and wishes, and decisions afforded to each ward under their care. Guardians exhibited some knowledge of ward history, approximate age, health conditions, medications, and pertinent experiences with each ward. 
The public guardians knew varying amounts about the background of their assigned wards. First, public guardians personally knew their wards better if they had been wards of the agency for a long period of time. Related to this, public guardians knew their wards better if they had knowledge of the ward prior to dementia or debilitation. This prior experience allowed guardians to assemble information from the ward, guardians ad litem, family members, physicians, facility care conferences, ministers, neighbors, facility staff, and other social agencies providing services to the ward. Notably, at Chesapeake Volunteer Guardianship Program (CVGP), various Adult Protective Services (APS) workers had carried the clients as part of their case load, sometimes for a number of years. Second, if wards were able to communicate in some way and were less affected by dementia or another health condition, the ward was valuable in providing personal background information. Third, if guardians had developed a relationship with the communicating ward, they stood a better chance of learning the wards' history. One guardian felt hampered by her own age and race when attempting to communicate with her ward.

It is significant that in the case of CVGP and Tennessee, which drew wards from rural populations, neighbors of the wards were reported by the public guardians as instrumental in caregiving prior to guardianship and thus in providing information about ward background. Neighbors were mentioned by guardians as a reliable source of background information on wards in only one instance in sites serving metropolitan areas.

Volunteer guardians in the case of CVGP permitted a further exploration of guardians' personal knowledge of wards. Two volunteer guardians who were interviewed had served as a guardian prior to the initiation of the program as a demonstration project. One volunteer had lived in close proximity to her ward as she was growing up, and another woman had voluntarily served as a private guardian for her ward for approximately two years. A third volunteer learned of her ward's background through a family member who was acquainted with the man for whom she and her husband now serve as financial co-guardians; they had also served as his representative payee for a period of seven months several years earlier prior to assuming guardianship. The fourth volunteer guardian, who had recently assumed guardianship, stated that he did not know his ward well at all because he had no previous relationship with his ward prior to assuming guardianship. He learned about his ward's background through information provided by the social worker liaison and a family member who was relinquishing guardianship. Social worker liaisons reported a varying degree of knowing the wards at Chesapeake. I discovered that volunteer guardians often believed that their social worker liaisons had a greater personal knowledge of their wards than the social workers reported. Still, unless a prior relationship existed, guardians at both Virginia pilot sites reported knowing their wards less well than did guardians from sites that had both been in operation for a longer period of time and, consequently, that had worked with wards for a longer period of time.

Length of time serving as a guardian also affected the knowledge of wards by the Tennessee public guardian. Due to the fact that she had taken over the position of paid public 
guardian in October 1995 (six months prior to the interview), she did not know well personally the majority of her wards. In fact, she stated that one of her objectives for her first year as public guardian was to know the wards more fully than she did at present. She did, however, rely on information provided by the previous public guardian and the institutional knowledge of an office assistant who handled mainly paperwork aspects of the office and had been in her position for over five years.

\section{Knowledge and Identification of Needs and Wishes}

Public guardians determined the needs and wishes of their wards through a variety of sources. These included communications with facility staff, reading nursing charts, regular attendance at care conferences held on the resident at the facility, the report of the guardian ad litem, comments by physicians and psychiatrists, information provided by social workers involved with the case, neighbors, concerned citizens, observation of the ward and the facility, and comments and reactions of the ward. These sources were also invaluable in discerning changes in wards' needs and wishes, particularly if the wards were in denial about their health care or could not communicate. Stated earlier, public guardians commented that they often personally took wards to physician and dentist appointments because it allowed them to communicate directly with doctors rather than reading their notes in charts or telephoning doctors concerning examinations. As with personal knowledge of the ward, public guardians reported that they knew wards' needs and wishes far better if the ward was able to communicate with them. However, ward comments were not always a reliable indicator of needs, and public guardians emphasized that their own personal observations were crucial.

The paid public guardian in Maryland had this to say about how she determined the needs and wishes of one of her wards who could communicate very little.

I observe her nutritional status, swelling of her legs. . .look around the house. Most of my clients, before they had a guardian were in denial, didn't want invasion into their life, and they denied their problems anyway. So my observations and reactions to what I was hearing, what I was seeing, would tell me what their needs were. Clients would usually minimize the difficulties in their lives. So I'm very used to having to [use] my senses.

Alternately, public guardians readily admitted that, when they had very little history to rely on, they turned to facility staff or caregivers to discern and meet the needs of their wards. Particularly if the ward was not able to communicate, the guardian relied more heavily on reading the facility chart on the ward in addition to information provided by the nurses who were directly involved with their ward's care. Also, I saw that the public guardian was more likely to examine skin and other physical indicators of health if wards were not able to communicate.

Public guardians were generally knowledgeable about the needs and wishes of their wards, for example, they knew if their ward needed clothes, visits to the doctor, spending money, and in one instance, cigarettes. Small requests such as these, whether initiated by the client or by the facility, were generally honored. 
Participation by wards in decision making was circumscribed by guardians' perceptions of potential risks of the decision and assessment of the ward's ability to make them. Wards were seldom allowed to make any decisions about their finances, and decisions regarding their health care were minimal. When possible, guardians attempted to match types of facilities with ward background and preferences, but they were constrained by financial and geographic considerations. The ability of a ward to communicate orally allowed guardians to make better decisions using a substituted judgment rather than best interests standard.

\section{PROGRAM SUPERVISORS' KNOWLEDGE OF WARDS}

Program supervisors were also questioned about their knowledge of the wards. Stated earlier, only the Delaware program supervisor carried a caseload of wards; the Maryland program supervisor had recently relinquished her caseload and had transferred her cases to the primary guardians whom she supervised. By virtue of working in her position for 18 years, the Maryland program supervisor had a working knowledge of the majority of her wards. However, other program supervisors often knew little about the background, needs and wishes, and decisional ability of individual wards.

The Tennessee supervisor, who serves as the executive director of the Area Agency on Aging, was least familiar with the wards, due to her position within the agency. There, the public guardianship is one among many programs she supervises. PSN did not have the institutional knowledge of having wards over a period of years. CVGP had the advantage of APS social worker liaisons, many of whom had worked on cases involving clients who ultimately became wards, for several years. In general, program supervisors relied heavily on the primary public guardian to manage the wards, provide supervisors with pertinent information, and apprise them of any problems that arose.

\section{DISCUSSION}

Interviewed wards tended to be in better physical and mental health than wards who could not communicate. With initial trepidation, interviewed wards exhibited a willingness to share their perspectives about themselves and their feelings about their treatment. Although it is possible that interviewing the wards capitalized on their feelings of fear, boredom, and loneliness, it is also likely that giving the wards voice empowered them and validated their feelings. Even though wards were adjudged incompetent to make decisions for themselves, it is significant that most were able to answer questions with short, simple answers.

Wards came from a variety of backgrounds, and although most were of advanced age, not all were senior citizens. Although my preference was to interview wards whom I freely selected, the pool of wards available to interview did not always permit this distinction, particularly in the case of the CVGP which at the time, had only seven appointed wards and volunteer guardians. Schedules of professional guardians, volunteer guardians, the agencies, and the wards also restricted the pools of interviewees at other sites. 
Although no social worker liaison or guardian stated that any ward would likely return from guardianship, the ability of wards to communicate and comprehend my questions is somewhat surprising, especially in light of the restrictive nature of public guardianship and its distinction of being of last resort. Wards admitted that they do not always communicate their needs and wishes with their guardian, conceding that they were often prompted by fear that guardians and others providing and monitoring their care would not listen to them or that they would somehow be thrown out of their facility.

It is meaningful that wards who do not communicate or communicate very little are also able to express some rudimentary needs and wishes. Eye expressions and physical and verbal reactions to stimuli provided important clues to preferences and needs. Time spent with the ward and knowledge of ward background assisted public guardians greatly in knowing and therefore meeting wards' needs.

Although the CVGP and PSN guardians generally knew less about their wards due to the newness of their programs, it may be that, because of the scrutiny afforded them, public guardians will make greater efforts to understand the wards than with programs that have been running longer. In addition, the demonstration projects may be more likely to consider and implement experimental approaches to gathering information. For example, although they have not implemented this aspect yet, the request for proposals from PSN included conducting values histories for each client so that guardians may be more familiar with their wards' background, needs and wishes, and decision making preferences both in their present condition and in their condition prior to dementia or other debilitating conditions.

If wards were unable to communicate, the public guardian relied heavily on outside sources to construct an accurate picture of the ward's background and health, needs and wishes, decisional abilities, and preferences. Fostering a relationship with professionals and coordinating and monitoring services is labor intensive. It requires sufficient time to know various service providers, financial institutions, and as much as possible, the object of care, the ward. If guardians are unable, due to time constraints, to observe for themselves such important aspects of ward condition, then they are not adequate advocates of the ward's interest. Understanding and knowing ward background is a key factor in accurate surrogate decision making and preserving ward autonomy. Cultivating relationships with the ward, care providers, physicians, and other social service professionals is integral to that understanding.

If paid guardians did know their wards and felt that they were capable of making decisions about themselves, they only allowed them to make decisions where there was not a significant degree of risk. Where a decision that the ward might make would harm him or her, the guardian pursued a best interests standard of decision making.

Program supervisors are vital links in preserving autonomy and promoting advocacy on behalf of the wards. Although the trend in larger programs is for the supervisors to know aspects of ward background and to be apprised of problems as they arise, it is also important that all program supervisors are familiar with the wards, especially for emergency situations and for 
program responsivity. This problem was handled especially well in Tennessee, where the program supervisor had less contact with the wards than in any other program. However, she was acquainted with them through the maintenance of a notebook that contained a profile of all wards, including their background, medications and medical condition, and other vital information, such as DNR orders.

In summary, it is necessary for wards to retain a quality of life through the preservation of who they were and who they are. If ward autonomy is to be maintained in any real sense, then public guardians must be familiar with ward background and health, needs and wishes, and their decisional abilities. Preservation of and respect for ward autonomy demands intensive casework and a focus on the importance of knowing, listening, and responding to wards when possible, rather than a cursory fifteen minute, once-a-month mandatory visit to each ward. Wards have weak and powerless voices, but public guardians as public administrators must listen to wards and act on their behalf. Though they have lost virtually all their civil rights, they are still citizens in our democracy. The knowing and listening public guardian realizes that sensitivity to each client begins with the vigilant protection of the remaining rights of those who, because of monetary and health problems, rely on the power of the state, vested in the public guardian, to live their decisional life. The job of public administrators is to consider, not discount the voice of the wards. 


\title{
CHAPTER VII
}

\section{CONCLUSIONS AND RECOMMENDATIONS}

\author{
If men were angels, no government would be necessary.
}

Federalist No. 51

The purpose of the preceding three chapters was to present and discuss the findings of the interviews and observations. Outside agents, public guardians, program supervisors, and wards do not act independently of each other. Their relationships and their actions are an "interweaving of willings"(Follett, 1918/1965). Perhaps the best image to consider is a set of overlapping circles. The ward is in the center, and in interconnection, are the public guardians, program supervisors, and others involved in the drama of guardianship. Relationships are everywhere embedded in dealing with wards and meeting their needs.

The final chapter concludes with major themes regarding the public guardian, the program supervisor, and the ward in addition to an overall assessment of guardianship. Afterwards, we consider recommendations for public guardianship and directions for future research. We now turn to conclusions regarding public guardians.

\section{CONCLUSIONS REGARDING PUBLIC GUARDIANS}

Paid public guardians are usually seasoned social workers who, if they have not had years of experience in some form of social work, have had experience working in related areas. In any event, persons who serve as paid public guardians are highly trained individuals who navigate many service delivery systems and deal with a variety of professionals and service providers. Their tasks range from dealing with the minutiae of shopping for shoes or authorizing fifty cents a weekend for soda pop to authorizing the termination of life support. For any public guardian, such tasks can be performed all in the same day. Considering the complexities of the position, combined with not enough hours in the day to perform the requirements of the job adequately, why would anyone do such a job, and who would be drawn to it?

The answers to this question take us to subtle issues of personal motivation and support. Paid public guardians are caring individuals who are buoyed by tangible gains that they can see with the population. They are generally satisfied in their position, because they enjoy a great deal of freedom and are persons who look forward to a challenge. Many go "the extra mile" in trying to meet the needs of wards. They are supported in their position by program supervisors who understand the complexities of their position. Public guardians receive guidance in the performance of these duties from the backing of the program supervisor and others who work with them. In small agencies, especially noted in Delaware, a team approach helps public guardians both cope with their job and resolve thorny issues. Program supervisors, when possible, arrange work hours to fit the times that the individual public guardians function best. 
Paid public guardians are also required, due to their intense responsibilities, to fill out numerous reports that document the travel and telephone calls they make, the care plans they devise, the assessments they conduct, the property they sell, and the money they spend on the ward's behalf. Paid guardians are adept at deciphering patient charts and physician's notes, negotiating between recalcitrant family members and others in the community, and advising attorneys on drafting court petitions. In addition, and within the confines of the system in which they work, the public guardian tries to build an ongoing and working relationship with the wards for whom he or she is responsible. Public guardians attempt this relationship often at great odds, but most do attempt it. Understandably, this is a tall order. It is a difficult task to be so many things to so many people. From my interviews, observations, and study of case file notes, public guardians, to a greater or lesser extent, fulfill these roles: service monitor, service broker (W.C. Schmidt, personal communication, September 24, 1996), client advocate, surrogate decision maker, client and community educator, and what I call "relationship architect." We now consider them in turn.

\section{Service Monitor}

The function of service monitor is one of the primary duties of the public guardian. The task is made far easier if wards are in an institution, because their service needs can be met in a comprehensive fashion. Most wards whom I interviewed were in an institution of some kind, either in a group home of some sort or a nursing home, which is substantiated by earlier scholarship on public guardians (Mitchell, 1978). Two wards lived in their own home, and one of these wards had twenty-four hour, in-home care provided by paid caregivers. Costs of maintaining wards in the community eclipse maintaining wards in a total care institution such as a nursing home, and so, if the ward qualifies for Medicaid, or, as in most cases, does not have adequate funds to meet needs, the only alternative is to be institutionalized. Thus, high institutionalization rates by public guardians are promoted not only from a case management point of view (more staff to attend to needs, many wards could conceivably be placed in the same institution) as well as from a social control point of view (a cost effective measure to house individuals, have wards associated with each other, decrease liability, and protect wards from themselves and from society).

Public guardians monitor services such as medical care, nutrition, cleanliness, hair cuts, dental services, and various therapies. Public guardians are often assisted by social workers who provide access to such services as homemaker and chore services. Although the public guardian in Tennessee is the only officer at the agency who provides direct service, most public guardians proffered that they are not usually involved in the provision of direct services. Admittedly, most perform some direct service provision occasionally. One illustration of direct service is transportation, whereby public guardians drive wards to and from dental and physician appointments. This activity serves a two-fold function. It permits the public guardian to visit and assess the ward personally as well as allows the public guardian to consult with the care providing professional regarding the ward's condition. Public guardians also purchase articles for the wards such as shoes, radios, and other personal items. Some public guardians went 
beyond the purchase for items for basic ward needs. For example, the public guardian from Tennessee was delivering a late Christmas present, that of the ward's favorite candy, to one ward when I traveled with her.

\section{Service Broker}

Related to the function of service monitor is that of service broker. In this instance, public guardians organize services to be provided for wards. Public guardians arrange for financial services, including appraisals of clients' homes and other property, Social Security payments, and other government benefits. Additionally, public guardians are service brokers for personal needs of the ward. They may contract for housekeeping services. Another example of brokering on behalf of wards includes arrangements for physical or occupational therapies or for the provision of special assistive devices such as a special chair or cane. Public guardians negotiate with physicians regarding the type of care the client needs, and in one instance, demanded that a physician prescribe for the ward a generic brand of medicine rather than the type he had originally prescribed so that the ward could afford to purchase the medicines.

\section{Client Advocate}

Related to brokering and monitoring services is the essential function of client advocacy. All paid guardians and program supervisors stipulated that advocacy is an important aspect of public guardianship. One important way that public guardians advocate for their clients is through their visibility with care providing professionals. When the public guardian accompanies a ward to visit a physician, the visible presence of the public guardian insures that the ward does not receive minimal care or fall through the cracks of service brokering and service delivery. Similarly, the public guardian advocates for the ward though appearances at the nursing home, group home, or hospital. Checking the charts not only fulfills the role of client monitor, it also directs attention of the staff or other formal caregivers to the client by illustrating that the public guardian is aware of and will request services for the ward if they are warranted.

An important avenue for client advocacy is through the care plan conference. Because all significant professionals in the facility are present and focusing on the needs of the ward, this presents an excellent opportunity for client advocacy. The public guardian voices what is in the best interest of the ward. One public guardian in Maryland advocated for her client who had psychiatric problems. She vociferously disagreed with physicians whom she felt were not aggressive enough in treating her client. The same public guardian finally succeeded in removing a private guardian of the property who would not pay his ward's bills. A public guardian at Personal Support Network (PSN) requested special therapies for her ward to help her swallow despite the staff's determination not to do perform them. Client advocacy is also accomplished inter and intra agency. When a client is one ward among many, public guardians advocate for their ward if he or she needs special attention. 
Although no instances were specifically cited in the interviews, undoubtedly advocacy is negotiated through conflicts of interest, such as when the public guardian's agency also provides direct services to the ward. Another conflict of interest in which client advocacy is frustrated is when the agency is both the petitioner and becomes the guardian. This situation occurs in Delaware in some instances and the Chesapeake Volunteer Guardianship Program (CVGP) and Maryland where the agency is physically located in the Department of Social Services. Even though the very persons who are familiar with the ward are recommending guardianship and assisting in drawing the court petition, the same persons must also arrange and advocate for services on the ward's behalf once the guardianship is established. Thus, advocacy efforts to avoid guardianship or fully explore alternatives to guardianship as well as to broker and to monitor services may be thwarted.

\section{Surrogate Decision Maker}

One of the most important aspects of guardianship is that of serving as a ward's surrogate decision maker, for guardianship is concerned, ultimately, with living the decisional life of another person. Surrogate decision making is accomplished through annual or semi-annual reports that are required by the agency and the personal decisions made by the public guardian. Some agencies, the best example being Maryland, require a reconsideration of guardianship as well as a semi-annual report to their Guardianship Review Board. This affords a great deal of protection to the ward by re-examining, with agents outside the public guardian's agency, the appropriateness of guardianship and decision making on behalf of the ward. Delaware is similar in its six month reports to those of Maryland, although the same level of detail is not required. Nothing similar was required either by the public guardian in Tennessee or by either of the Virginia demonstration projects.

Public guardians make financial and personal decisions for wards. Sometimes wards were allowed some input into their decision making, but it was based largely on their perceived level of lucidity coupled with the risk of following their wishes. If a ward wanted some spending money or a personal item such as a new toothbrush, then the request was usually granted. However, if wards wanted to leave the facility and return to their home, the request was not granted. Surrogate decisions made by public guardians consisted of these: medication and other medical decisions, habilitation decisions, financial decisions and care and quality of life decisions. The public guardian did make decisions regarding Do-Not-Resuscitate (DNR) orders and the selling of property, but these decisions, perceived by the courts as potentially lifethreatening, require its approval prior to implementation.

\section{Client and Community Educator}

In addition to the roles cited earlier, another is that of community educator. When possible, public guardians educate their ward about alternatives available to them and the outcomes of their choices and behaviors. Also, they can educate wards about their own role as public guardian. Public guardians develop and recommend alternatives to guardianship to the facilities which they monitor, families and friends who are directly and tangentially involved 
with guardianship, and professionals with whom they come in contact. Occasionally, they are a referral source to private guardians with questions about guardianship.

Particularly at both pilot projects in Virginia, public guardians educate persons in the community to take steps to avoid the imposition of guardianship by making provisions for other methods of surrogate decision making, should they be required. The dissemination of information about avoiding guardianship is one avenue to ensure that an individual's rights will be respected, should that person become incapacitated. Volunteer guardians especially are able to sensitize a wide dispersion of persons about guardianship because of their diverse positions in the community and the service that they render to it through association.

\section{Relationship Architect}

Another aspect of public administration, mentioned often by public guardians, is that of building relationships. Working to focus these diverse actors on the needs of one ward is undeniably difficult. Yet, to forge working relationships with them is a necessary component of public guardianship. Constructing and maintaining relationships occurs on many levels, because so many persons perform a role in the theatre of guardianship: the legal, medical, and social services professionals, aging network, advocates for citizens with physical disabilities, mental illness, and mental retardation. Building a web of interconnection with these professionals requires reflexivity with philosophies from various disciples regarding treatment, constraints on time, financial constraints, system-imposed requirements, acceptance of cases, decision making, and constraints on reporting. Added to this, public guardians continue to direct the actors' attention to what is best for the ward, and whether even that is the appropriate decision making standard to use.

Aside from being the "relationship architect" with professionals and community advocates, the public guardian builds relationships with wards and their families, if they exist. Public guardians work to reconcile family members and friends of the ward and to solicit their help, if it is in the best interest of the ward. Also, public guardians build relationships with wards by visiting with them, listening to their wishes, and honoring them when possible.

\section{COMMENTS REGARDING VOLUNTEER GUARDIANS}

As discussed in Chapter IV, volunteer guardians possess characteristics and attributes that are both similar to and different from those of professional public guardians. At the outset, it is necessary to reiterate that when I conducted fieldwork, Chesapeake Volunteer Guardianship Program (CVGP) had not concluded its first fiscal year. CVGP, while having the Guardianship Committee in place, did not have a volunteer program established until being awarded the grant and was delayed in commencing volunteer recruitment due to a local hiring freeze on government workers. The program supervisor (volunteer guardian coordinator) was not hired until mid-September of 1995. At the time I visited the program, there were only eight assigned guardians, and due to the research design, only four guardian/ward combinations were appropriate and available for interview. 
It is difficult to determine whether the few volunteer guardians I interviewed were typical of all volunteer guardians in the program. Certainly, their backgrounds varied as well as their motivation for serving as volunteer guardians. In general, volunteer guardians expressed more altruistic reasons for serving than did paid guardians. I did not expect to find volunteer guardians who had previous relationships with their ward. Yet one volunteer guardian had known her ward all her life, and another other volunteer guardian had previously served as the ward's representative payee and was familiar with the ward due to his friendship with the family. I was also surprised to find that one volunteer had served in her position as guardian for over two years, and the ward's social worker liaison, whom I also interviewed, stated that this ward was one of her more difficult cases. The social worker stated that the ward required a tremendous amount of attention from anyone who tried to help her and that she tended to "burn out people." It is commendable that the volunteer guardian has continued to work with this ward in spite of her difficult behaviors and requests. It is possible that rural ties of friends and family are important in solidifying the longevity of volunteer guardianship relationships.

Volunteers are not plagued by voluminous reporting requirements or high caseload numbers; their "caseload" is one-to-one. They are supported by a number of resources at CVGP, including the social worker liaisons, Guardianship Committee, program supervisor, and their own support group. At their best, volunteer guardians can facilitate citizen participation where the local community addresses the problems of wards and disseminates information about guardianship and its alternatives.

Still, no volunteer guardian whom I interviewed had a professional background comparable to that of the paid public guardians. Although they performed many of the roles of the paid public guardians, volunteers did not have a comparable knowledge of how to gain access to a variety of service delivery systems with which the paid public guardian works with on a daily or weekly basis. In addition, volunteer guardians, who typically had not served in this capacity before, did not have the experience in decision making possessed by the paid public guardians nor the experience of knowing a variety of wards and their problems. The analysis by Schmidt, Miller, Peters, and Loewenstein (1988) came to the same conclusion. As in teaching, the kids look the same later but not when you start, as the Tennessee public guardian remarked.

Two of the paid programs included a volunteer component. The paid program in Tennessee had a few volunteers, but the guardian acknowledged difficulty with liability issues and in recruitment and retention of suitable volunteers. The Maryland program dropped its volunteer program due to other requirements of the position as well as a general lack of continuity for those persons serving as guardians. The Maryland program supervisor admitted that she did not like having volunteer guardians and believed that they could only meet the needs of the ward on a limited basis. She suggested that roles for volunteers include performing some tasks that public guardians were largely responsible for such as purchasing shoes and other personal items and visiting the ward. "National experience demonstrates that the use of volunteers as guardians has limitations and cannot substitute for public guardianship; the guardian of last resort must be a public guardian. Therefore, we do not recommend the initiation 
of a program in which volunteers are appointed by the court to serve as guardians" (Lord, 1992, p.11).

Essentially, I found that individual volunteer and paid public guardians were at least adequately performing a difficult and complex job. However, good intentions or "doing the best that they can" is simply not good enough when the state assumes the decisional life of another person. Therefore, it is up to administrative discretion and oversight at the level of the primary public guardian as well as the program supervisor to prioritize their various and important roles. Program supervisors, especially, can help provide such an administrative focus.

\section{CONCLUSIONS REGARDING PROGRAM SUPERVISORS}

The five program supervisors whom I interviewed administered very different organizations. The differences in organizational mission and structure were reflected in the responsibilities and philosophies of the program supervisors. Although it was not the focus of this research design to study all the functions and responsibilities of program supervisors, some themes for supervisors emerged. These include responsibilities and philosophies and setting priorities.

\section{Responsibilities and Philosophies}

The responsibilities of program supervisors varied widely, with Tennessee being the least hands-on administration and Delaware's program supervisor carrying a caseload of 34 wards in addition to her other duties. In many ways the program supervisors are overloaded in a manner similar to that of the paid primary public guardians. The overload in responsibility is not conducive to helping public guardians meet ward's needs. The Maryland program supervisor acknowledged that she worked around sixty hours a week, and the Tennessee program supervisor was the Executive Director for the entire Area Agency on Aging (AAA) in upper East Tennessee, of which the public guardian program was only a part. The program supervisor at PSN already had numerous responsibilities at her organization, and the demands of the demonstration project together with its evaluation were an added burden. The program supervisor of the volunteer program actively recruited volunteers by making many presentations in the community, performing background checks on them, telephoning volunteer guardians weekly to supervise their activities, and providing support for them. Her responsibilities were not as extensive as those of the paid model public guardian supervisors because her duties did not include creating or implementing care plans or making reports to the state on financial or personal decision making.

Most of the program supervisors stated that public guardians had the responsibility of a mother to a child. They acknowledged that public guardians should respect ward's wishes when possible. However, great potential exists for the relationship of parent to child to devolve into paternalism; the guardian/ward relationship should be expanded to include wards' age and experience to insure that paternalism is not the result. PSN differed from the philosophies of the other agencies in that their relationship to their wards was that of a caring family member. This 
implies a guardian/ward relationship that is slightly more at a distance than that of the other guardianship agencies. The program supervisor at Chesapeake did not articulate a philosophy as such, but implied that guardians "fixed problems." One guardian at PSN took exception to the philosophy of the caring family member and instead equated the guardianship relationship to that of a parent to a child. She was terminated in her position shortly after I interviewed her. Obviously, the philosophy of the program supervisor has an impact on the way primary public guardians meet the needs of wards by affecting the relationship of the public guardian and the ward.

The responsibilities of program supervisors also affected how much they directly were familiar with the wards. Several program supervisors mentioned that they served as a backup to the public guardian when problems arose or when public guardians were away. Knowledge of the wards was also enhanced by time. The Maryland program supervisor, who had been in her position longer than any other, had an extensive knowledge of the wards due to the fact that she had been with the agency in various capacities for so long. Also, until recently, she had carried her own caseload. Familiarity with the wards facilitates regarding them as unique human beings in contextual situations rather than simply a set of files in a caseload. It is important that the individuality of the wards is preserved as much as possible so that their needs are not supplanted by those of the bureaucracy or other third party interests.

\section{Setting Priorities}

A major role of the program supervisor, aside from overseeing the primary public guardian, checking reports, and seeing that regulations are followed, is that of setting the tone of the program and gatekeeping regarding which clients are ultimately accepted. Program supervisors all spoke of attempting to be sure that they accepted wards for whom their agency could do something. They admitted receiving intense pressures to accept problem cases as well as the looming potential for burgeoning caseloads, and they saw a function of their job as that of weeding out those cases, not necessarily for whom guardianship might not be appropriate, but for whom guardianship would not solve a problem. The three program supervisors who worked directly with the public guardians had formulas or rules of thumb that they used in accepting wards. They reflected, in some way, the model of guardianship in which they operated. The Maryland public guardian is employed by a government agency also providing social services and only accepted wards if guardianship solved a discernable problem. The Delaware public guardian, who is employed by a single state agency devoted only to guardianship, accepted wards by considering disability, inability, and risk. PSN, organized like the county model (where a locality appoints or elects a public guardian for a number of years), accepted wards if harm is likely to occur if no decision maker is appointed, the least restrictive form of decision maker is requested and no other decision maker is available, and the role PSN fulfills will likely address the presenting problem. Perhaps due to its demonstration project nature, the guardians' caseload at PSN was significantly smaller than the other paid programs.

Related to the transmission of the organizational philosophy and gatekeeping, program supervisors had much to do with how public guardians met the needs of the wards in terms of 
respecting autonomy. Maryland, where public guardians serve as guardian of the person only, had the most explicit requirements regarding this focus, even though the courts usually granted them plenary authority. The program supervisor said that they did not necessarily use all the power that they were delegated. The Delaware program completed six month reports like the Maryland program, but they were not as comprehensive. Due to the fact that Delaware public guardians receive no funds for the wards and serve as guardian of finances and person, there was less of a focus on ward autonomy from this program supervisor. Still, she was the most vocal of the supervisors when questioning why guardianships were instituted in the first place. The program supervisor at PSN in Virginia admitted that she had not focused on this concern to a great extent, and that she hoped to do so in the second year of the grant.

Even though certain reporting requirements focus guardians on this issue, as well as their own sensitivity, it is at the level of the program supervisor that this emphasis is most keenly felt. Program supervisors as public administrators convey the importance of client autonomy. As discussed by Dudovitz (1985), there are few concrete safeguards to ensure preservation and enhancement of client autonomy, and if program supervisors do not see this as an emphasis, it can easily become lost in addressing baseline needs of the ward, day-to-day agency problems, and other third-party interests.

\section{CONCLUSIONS REGARDING WARDS}

Wards came from a variety of backgrounds and, although the literature bears out the fact that the majority of wards are older and female (Lisa \& Baranaga-Burch, 1995; Schmidt, Miller, Bell, \& New, 1981), I also interviewed a number of men, along with one ward who was in his late twenties. Although they were screened by me prior to study, far more wards were able to answer questions than I thought would be able to respond. No wards refused to be interviewed, and although three wards were upset by the questions that I posed, they answered my questions anyway. Still, many wards whom I saw were quite frail, and one ward whom I observed has since died. Several wards were alcohol abusers, and most wards had varying stages of dementia.

Wards expressed a variety of feelings about their condition. Significantly, wards were afraid for themselves in a number of instances. They feared retribution by facility staff or guardians. One ward in particular feared that her belongings were being stolen. Four wards were not happy with their guardian and felt as though she did not fully address their concerns. Several regarded that they were in prison, and one ward, even though she suffered from a significant degree of dementia, acknowledged the stigma associated with being a ward. Alternately, some wards acknowledged that they needed someone to look after them. Nevertheless, a number of wards realized that their voice in their own decision making, except regarding decisions where risk was not a factor, was significantly diminished.

\section{Assessment of Public Guardianship}

It is important to bind the theoretical and the practical (Wamsley et al., 1990). It is also important to commit to praxis and reflectivity in public guardianship. Although public 
guardianship has the potential for usurping ward freedoms through exploitation and neglect, it is also possible to improve the quality of wards' lives through substitute decision making (W.C. Schmidt, personal communication, January 7, 1997) . Public guardianship, when performed by caring and qualified guardians who function with appropriate administrative safeguards, is such a vehicle. Yet, literature on guardianship reveals an overall pessimism, particularly regarding public guardianship (Cohen, 1978; Horstman, 1975; Regan, 1981; Schmidt, Peters, Bell, \& New, 1981). Concerns were articulated about a government sanctioned system for moving the poor and "different" into a managed society (Kittrie, 1971; Mitchell, 1978). In particular, authors cited an overwhelming and insidious propensity by public guardians to institutionalize persons and disregard their rights once they were adjudicated incompetent (Dubler, 1987; Horstman, 1975).

They are certainly justified in voicing their concerns, but at the nexus of the state and the individual, I observed different phenomena. The public guardians I observed were not villains. They did not categorically supplant the interests of their wards with the interests of third parties. They exhibited a remarkable understanding of the complex issues involved in guardianship. Although it is quite possible that I studied the "best of the best," I found, from the interviews, observations, and case file notes, that paid and volunteer public guardians were at least adequately performing their duties, probably about as well as possible without revisions to their agency objectives and mission. I was surprised to find that public guardians performed as well as they did. In instances and documentation by the paid guardians, they advocated for their wards and worked to broker and monitor services on their behalf.

Paid guardians are overworked, and it is likely that their caseload will increase, even if the offices can place meaningful caps on the number of cases that they assume. To safeguard wards of the state, it is essential that legislatures and localities take public guardianship seriously and provide adequate funding to these programs. This entails the recognition that the unbefriended of the state have worth and deserve both its protection and its provision for maximum autonomy and the least restrictive environment in which to live. This involves a societal commitment to improving the quality of life for all persons.

A second major issue of guardianship is that of preservation of the centrality of the wards. The centrality of wards is protected in two ways, by promoting their participation in decision making and by an ethic of caring that makes the interests of third parties secondary to those of wards. Both ideas are bolstered by public administration literature that supports precisely these functions (Evans \& Wamsley, 1996, under review; Selznick, 1992; Stivers, 1993; Wamsley, et al., 1990). The importance of public guardianship and the persons it serves reflect determinations about promoting and protecting the weak and helpless (Stivers, 1993). Within a governance model where they are reflective with, responsive to, and representative of wards as citizens of the polity (Cooper, 1991), public administrators must interpret society's commitment to meeting their needs.

Wards, who have lost the right to live their lives as they please, are at the heart of guardianship and cannot demand better services. States, acting under parens patriae power, 
must address and reckon with guardianship's fundamental tension between protection and autonomy. All actors in the theatre of guardianship must concentrate on fulfilling their roles for wards and for others involved, but their ultimate responsibility is that of addressing the needs of the wards. Public guardians as public administrators must struggle, through practical wisdom (Stivers, 1993), communication (Barber, 1984; White \& McSwain, 1990; Stivers, 1994), and relationship (Evans \& Wamsley, 1996; under review, Harmon, 1995), to address wards' needs and to amplify their weak voices in our democracy.

\section{RECOMMENDATIONS}

Because of the great power that the state subsumes when assuming the civil rights of another person, the protections afforded to the wards should also be great. Unfortunately, this is not necessarily the case in many states and jurisdictions. Through observation, interview, and study, several recommendations regarding public guardianship emerged. These include education initiatives, use of technology, use of volunteer guardians, funding and staffing, decisional accounting, respecting the ward's voice, and implications for public administration. We will now address these recommendations in turn.

\section{Education Initiatives}

Public guardians have as an implicit function the education of wards and the larger community about guardianship. Stated earlier, paid guardians in all states acknowledged that judges were often more comfortable assigning them as guardians than to appoint private guardians because the judges recognized that the public guardians would do a better job. Public guardians must educate the community not only on guardianship, but also on the importance of making decisions that would prevent or delay such a court determination. One excellent way to disseminate information to the community is through use of the computer. A home page could be posted on the Internet with directions for persons about where and how to obtain assistance. Another source for the dissemination of information regarding guardianship and its alternatives would be through community access television. Because of the possibility of more guardians needed for more persons, it follows that states must overtly recognize that the education function is an explicit rather than implicit function of the office and make provisions for the education initiatives to meet that challenge.

Another area where education initiatives should take place is within and across agencies. Guardians rarely communicate with other agencies in the state, with the exception of Delaware, and there is little, if any communication with guardianship agencies in other states. Education among guardians would serve to improve the quality of public guardianship by establishing standards of performance. It is now possible to certify guardians through the National Guardianship Agency; the certification of guardians could raise working standards for public as well as private guardians. State agencies should bring public guardians together to network and train them regarding the complex issues that they face and agree on operational norms. While the National Guardianship Association holds yearly conferences, several public guardians who 
attended it said that its focus was on issues that concern private guardians. Also, they indicated that their limited budgets did not always permit their attendance at its meetings.

Agencies should consider a regional guardianship conference that addresses issues specific to public guardians. Although states differ in their models of service delivery, a regional conference would serve to address problems of guardianship that are similar as well as to provide a forum for suggestions to changes within the various models of service delivery. In this way, public guardians could better serve the persons who are the object of guardianship.

\section{Use of Technology}

Education initiatives can be further enhanced by promoting the use of technology. Although all agencies incorporated computer technology, it was used mainly to write reports, and in many cases, only rough drafts of the reports. Technology should be used in more creative ways. Computer technology has the potential to allow for the transmission and preservation of knowledge from one guardian to another. It can enhance communication among office members. For example, the public guardians in Delaware made good use of a networked system even though their offices were side by side. All public guardianship agencies should consider further uses of the computer for the purposes of disseminating information throughout the office and throughout the state. The systematic aggregation of information has benefits, such as the manipulation of data in a variety of ways and in recording and projecting state trends regarding guardianship and its alternatives.

\section{Volunteer Guardians}

Volunteer guardians came from a variety of backgrounds and serve for largely altruistic reasons. They fill a need for guardianship when no other guardians will come forward and provide one-on-one guardianship. They permit unique opportunities for citizen participation and community education. At CVGP they are well supported by persons in the community, social worker liaisons, the Guardianship Committee, and the volunteer coordinator. I could not assess the continuity of the program over time due to the nature of my research.

However, as mentioned earlier, no volunteer guardian whom I interviewed had the formal training that paid guardians did. No volunteer guardian had a working knowledge of how to gain access to various avenues of service delivery. Access to services were accomplished through social worker liaisons and other support mechanisms, and these support mechanisms were not necessarily compensated for the additional work and consultation that they performed for the volunteer guardians. Without their support, the volunteer guardians would have done far less for their wards. Therefore, I conclude that the role of the volunteer in guardianship should be circumscribed to aiding the paid guardian in important but specific aspects of guardianship such as client visitation and social support, community education, paying bills, and performing errands. Although it is more than most private guardians receive, a two-day training session does not make the volunteers able to deal with the complexities of public guardianship without substantial support, and the duties that the state owes its wards is greater than that of a private 
citizen. For the amount of work, both funded and unfunded, that is used to recruit, train, and support the volunteers, other wards could be served better by a paid public guardian.

\section{Funding and Staffing}

In an instance where theory and practice diverge, it is not hard to see that caseload numbers are simply too high in most agencies. Even the Virginia demonstration project in Northern Virginia succumbed to a tendency to increase case numbers beyond what guardians thought was reasonable. The problems are clear. If guardians burn out; guardians minimally perform their job requirements; reports are late, particularly when the inevitable crisis situation arises; and the ward, ultimately, suffers.

Alluded to earlier, the unmet need for guardianship drives the case numbers ever higher. Still, governments are loathe to invest dollars in a program that deals largely with old and poor persons. Completely out of the power loop, wards are hardly in a position to align as an interest group to lobby for needed monies. Demographic trends point to an increase in the number of guardianships due to persons who are living longer, persons with mental illness and mental retardation who are outliving their parents, and the transiency of society in general such that the community no longer takes responsibility for taking care of its own. The public guardian in Tennessee lost $\$ 2,000$ in funding in fiscal year 1995, and her allocation for travel expenses in addition to her working hours were decreased. Another factor that will certainly change the mix is that of the block granting of federal dollars. This mechanism will no doubt rearrange the ways that funds are allocated currently in the states. If welfare assistance is cut, there may be more homeless persons, more impoverished persons. Should this happen, there will be more persons who are at risk and who may need guardianship or related services.

The litigious nature of society also drives the need for guardianship. Nursing homes and hospitals, not necessarily as benevolently interested in caring for others as one would wish, seek protection from legal suit. The increase of older and sicker persons who are entering these institutions, and the shortening of hospital stays, curtailed due to managed care and institutional downsizing, will make them increasingly anxious to locate surrogate decision makers who will remove their liability.

Another issue could also affect caseload numbers. In spite of the problems involved in public guardianship, at least in the sites that I studied, public guardians were regarded as more responsive and reflexive than were many private guardians. Many attorneys and other private citizens serve as guardians. In addition to other responsibilities, a single individual may serve as guardian to over a hundred wards at the same time. Although it is true that institutions do provide the majority of care for wards, and that public guardians display a tendency to institutionalize them, many public guardians give greater attention to wards than do private guardians. Rather than working themselves out of a job, as public guardians should aspire, public guardians who do a good job will secure their position more than ever. Especially if funding streams are altered so that they affect services offered, public guardians will be forced more and more to depend on fees for services. Then, mostly people who have sums of money 
will be candidates for guardianship so that the agency can continue to function. Persons who have estates will be sought for guardianship, and persons who are poor may not receive the guardianship services that they need. Instead, even at the public level, the market rather than need will determine the recipients of guardianship and related services.

The quality of life of the ward is directly affected by funding levels. Public guardians are bound constitutionally to place persons in the least restrictive environment possible. Although community-based care is presumed to be preferable to a nursing facility or other domiciliary facility, costs for community-based care are often higher than congregate housing. Thus, because of cost-containment, the tendency of public guardians to place wards in a nursing facility could be increased.

\section{Decisional Accounting}

Private guardians and public guardians, although required by law to submit a yearly financial accounting to the court (reflecting a historical emphasis in English common law on protection of the property) often do not do so. Rarely are any sanctions imposed for inattention

to this requirement. Reflecting this, conspicuously absent was any type of systematic accounting for decisions made concerning the ward's person.

It is critical that governments should place the importance of decisions about a ward's person on equal footing with decisions made regarding a ward's property. Requiring the completion of a decisional accounting that is a corollary to the financial accounting would be an appropriate mechanism. The decisional accounting would reflect the surrogate decisions made by the public guardian on behalf of wards that affect their person. The decisional accounting should be directly related to another important piece of documentation that was notably missing in the files of the wards. This is the values history, which captures on paper the decisional preferences of the ward and thus serves as a guide for future decisions made on behalf of the ward. It has the advantage of focusing the public guardian on investigation of the wishes of the ward prior to incapacity and that the ward is able to make known at present.

Limited guardianships are being employed by certain states; however, all too often judges grant private guardians and public guardians alike plenary authority where guardianship is concerned. The completion of a values history would serve to preserve and enhance ward autonomy. The type of autonomy that would be preserved would be delegated autonomy (Collopy, 1988), where the ward may be unable to act on his or her own, but nevertheless would be in some ways able to have his or her wishes honored. Through the use of this document, public guardians would be able to employ the more preferable substituted judgement standard more often due to their increased knowledge of the ward. Even when decisions are made in the best interest of the ward, they will be easier to make with guidance from the values history.

It follows that the institution of this document would increase the time that a public guardian would have to spend on the ward's case. It has already been established earlier, particularly from the comments of the paid guardians, that case load numbers are too high. 
Clearly, caseload numbers would have to be adjusted in order for this type of investigation to be done in the level of detail that it deserves. However, the values history would have the advantage of providing baseline data against which the decisional accounting could be measured. Without such a set of documents and requirements for them in place, it is unlikely that with all the complexities of guardianship already stated, this would receive appropriate attention, effort, and scrutiny.

Merely requiring the completion of a values history and a decisional accounting is not enough to insure that surrogate decisions will be made using the substituted judgement standard or the best interests standard. There must be an institutional mechanism in place that provides oversight and quality assurance on behalf of the ward. The model of the Guardianship Review Board in Maryland is an excellent example from which to draw. I propose a Committee for the Ward, named so that the focus is on the ward. Like Maryland, the Committee for the Ward should meet no less than semi-annually and be comprised of persons who would actively advocate on the ward's behalf, particularly to see that decisions regarding the ward's person are made as the ward would want them or in the ward's best interest. The Committee for the Ward should be comprised of the program supervisor; the long-term care ombudsman; the ward, if possible; an attorney who serves as a guardian ad litem; and a volunteer ward visitor. Their job would be to review and make recommendations to the decisional accounting that should also be prepared semi-annually. They should also consider whether guardianship is still appropriate for the ward. The ombudsman would monitor the public guardian to see that suggestions are implemented. Egregious deviations from the suggestions or other problems should go before a judge.

To institute such a focus on ward autonomy would serve to empower the ward. It would not only direct efforts to ascertain and record ward's wishes, but it would also serve to prompt the public guardian to think and act using the substituted judgment of wards whenever possible. As the Maryland public guardian commented concerning the Review Board reports that are required every six months, "The Review Board reports are really a nuisance, but they're wonderful because they make you really get in there, get in there and dig." This is precisely what they should do. The result, rather than performing case management triage, is client empowerment and a continued focus on overturning guardianship whenever possible.

\section{Respecting the Ward's Voice}

It is important to consider that although the wards have been adjudicated incompetent to make health care decisions or decisions about their property, many are still able to articulate feelings and wishes. Public guardians as public administrators must not dismiss their wishes as simply "the mad ravings of a lunatic." It is dangerous to drop into a paternalistic mode when dealing with wards. The analogy of a mother to child relationship is appropriate only if the guardian as mother practices "tough love" or an ethic of caring. Always, guardians should encourage wards to think for themselves. 
Several factors are important to respecting the ward's voice. The first is developing a relationship. Several wards did not like their public guardian at all. If this is the case and the agency is large enough, guardians should be changed so that they are a better match with the ward. The relationship between guardian and ward is critical. Some wards indicated that their guardians were nice enough, but that they really did not know them very well. In fact, one ward told me that he purposefully did not tell his guardian anything more than he had to tell her. The voice of the ward cannot be respected if it is not known or understood. It is important to remember that, for persons who have lost so much, respecting their wishes, even in small ways, represents a victory for the ward.

Second, communication is key in developing relationships. There are many barriers to the guardian/ward relationship if the guardian has never known the ward when he or she could communicate. Still, many wards who could not communicate or could communicate minimally had ways of indicating preferences. A notable example was the ward who was aphasic who would say "Oh, boy" when there was something that she liked. If preserving the ward's voice is not considered important in meeting the needs of the ward, then such valuable information as this or other more subtle indicators of ward preference will go unnoticed. Building a relationship with a ward takes time. It is right that the state allows for that time.

Third, every effort should be made to ensure that visits to wards are meaningful, not just perfunctory. Although administrative problems are inherent in allowing for more time, spending time with wards is one important way of meeting their needs and preserving their voice. Spending time with wards keeps them in a web of interconnection with other citizens in the democracy. Preserving the ward's voice also keeps them from being reduced to just another case file. Attempting to respect ward wishes and their context, where at all possible, is an important factor in doing just that.

Wards must not be "written off" as having nothing to contribute to the course of their lives in any meaningful way. They are at the heart of decision making. They are citizens of the polity, and they must be treated as such. Their voice must prevail over the clamor of third parties who seek to control virtually all their rights. Because such an approach is counter to the predominant characteristics of bureaucracy, public guardianship may well be regarded as bureaucracy's greatest challenge.

\section{Implications for Public Administration}

Especially where tasks are so complex and individual lives are so keenly intertwined, it is imperative that bureaucratic business as usual does not prevail. Guardianship should be about an ethic of caring. The Delaware program supervisor stressed, ". . .you have to be ready to respond in whatever way you need to for that person. You have to be able to sort of take on that person, become that person." To do so is to be a listening, responsive, and reflexive bureaucrat; to do so is to practice democratic governance by incorporating the concept of the public administrator as facilitator through phronesis, responsibility, and dialogue. 
Public guardians as public administrators use phronesis (Stivers, 1993). They realize that with guardianship, it is impossible to slot people into boxes on a form to fill out or apply a standard set of rules to a situation. Individual lives have a rich fabric that prevents reducing them to minimal requirements of bureaucratic reporting or easy answers. Each life is a tapestry, a web of interconnection, and has a history that deserves to be honored. So it is that public guardians make use of practical wisdom when working with wards and the constellation of persons who deal with them. They make use of their knowledge and experiences in dealing with other wards while at the same time they are attuned to the unique aspects of the ward with whom they are dealing. Public guardians as public administrators rely on their intuition when attempting to make decisions and develop relationships with wards. They make use of phronesis when they are in connection with wards, who are marginalized individuals in real and complex life situations. Public guardians, who make use of their own life experiences, are facilitators when they act as surrogate decision makers for wards and advocate for them (Morgan \& Kass, 1991).

Another aspect of the public guardian as facilitator concerns democratic governance and responsibility (March \& Olsen, 1995; Wamsley, et al., 1990). In this respect, public guardians as public administrators have a special responsibility to respect ward autonomy, to be a relationship architect, and to build community through interconnection. Public guardians must continually strive to maintain ward autonomy to the greatest degree possible. They must continue to employ the substituted judgment standard of decision making over best interests when possible. To do so is to respect the autonomy of the ward.

At the same time public guardians must facilitate the development of relationships with the ward and with the larger community of persons who are associated with the ward. Public guardianship does not occur in a vacuum; decisions and actions on behalf of wards do affect others in the community who are interconnected (Evans \& Wamsley, 1996, under review). Not only is it important that public guardians build relationships with the ward and with others who are connected with the ward, it is necessary to keep the ward in the community of the living as much as possible. Even though wards have lost virtually all their civil rights, they are still citizens with the rest of us (Cooper, 1991). They are still citizens in the community. Public guardians who are public administrators must continue to work to keep these persons continuous with the community, for even though their contributions are limited, their voice is still important. A vehicle for accomplishing this is dialogue (Barber, 1984; White \& McSwain, 1990).

Two highly important parties are the public guardians, who are on the front lines of administration, and the wards. It is vital to keep the lines of communication open for both. In the act of dialogue there is the sharing of information about what it is that the guardian can do for the ward, which is largely about decision making of one kind or another. Good public guardianship involves highly personal and complex decision making. Thus, it is imperative that public guardians be emotionally supported. Also, it is vital that public guardians be supported by their program supervisor in an environment that promotes the sharing of ideas. Elegance and creativity in effective problem solving outweigh merely getting the work done in a timely 
fashion. Program supervisors must provide emotional support and encourage the interchange of creative problem solving. Rather than holding infrequent meetings to apprise supervisors of activities, decisions, and problems, a regular meeting provides an excellent vehicle for fostering teamwork and collegiality.

Public guardians as public administrators must also listen and respond to wards and other parties (Stivers, 1994). They must be responsive in addressing the needs and wishes of wards. They must continue to advocate for them in the face of demanding third party interests. Foremost, they must listen to what wards have to say. Public guardians as public administrators must not discount the importance of listening to wards even though they are adjudicated incompetent and also may have lost the ability to communicate in conventional ways. Public guardians must search for creative ways to "listen" to their wards and be responsive to them.

Particularly in the example of public guardianship, a moral imperative for public administration is to legitimize the importance of listening, responsiveness, and reflexivity. It is clear that standards of the bureaucracy and attention to third party interests often subsume more of the public guardian's time than actually listening to, reflecting upon, or responding to the ward and the ward's needs. Yet, given the intimate and contextual nature of this peculiar endeavor of democratic governance, a facilitation model for public administration is not only appropriate, it is also feasible. It does occur at times in public guardianship, and in this and like purposes of governance, it should be fostered.

Further, a facilitation model of public administration that incorporates phronesis, responsibility, and dialogue should be increased. Marginalized persons deserve this kind of treatment by a bureaucracy that is ultimately grounded as Loewy (1990) articulated, in benevolence. This is the imperative for a public administration that is derived in an ethic of caring. Listening, responding, and reflexing by the public guardian as public administrator must focus on the ward and ripple outward. This is how public guardians as public administrators facilitate meeting the needs of wards, who are still citizens in the community. This is how public guardians as public administrators must live the decisional life of another person.

\section{DIRECTIONS FOR FUTURE RESEARCH}

It was not within the scope of this study to examine the various systems of service delivery or compare state statutes with one another. It was not necessarily the focus of this study to compare public guardians. It was a focus of this study to discern what public guardians do, and further, how they meet the needs of wards. Possibilities for future research are great. A systematic study of more state systems and more wards would give greater insight into the types of functions that public guardians are fulfilling. This research could be handled in an interstate study or a comparison of one state to another. Though there has been a comprehensive national study, it was completed nearly twenty years ago when public guardianship was under scrutiny and being implemented in many states. The numbers of states with some form of public guardianship have risen as have new methods of service delivery. Thanks to computer technology, it is now possible to aggregate information on wards, whereas years earlier it was 
only possible to get a snapshot of these persons, how they entered the system, and what was done for them.

Another possible study would be to examine the stresses of serving as a public guardian over time, and what it means to be a ward of the state for virtually one's entire life. More efforts could be placed in research that indicates how persons are tracked in the system as well as how they enter the guardianship system at all, how many guardianships are overturned in a period of years, and why. Finally, another study could examine the relationship developed between public guardians and wards. Volunteer guardians could be studied to determine who becomes volunteers, what their relationships are with wards both prior to guardianship and as a result of guardianship, activities performed by volunteer guardians, and the longevity of volunteers in an established program.

Public guardianship is a complex area that is ripe for future study. It is confounded by various service delivery models, reporting requirements, and capacities in which public guardians serve. It is confounded by the interests of various service providers, and it is confounded by the very persons it should be serving. Foremost, public guardianship must emphasize the needs of wards over the needs of others. At the heart of guardianship is the ward. His or her life and freedoms must be protected, and all other concerns radiate from that pulse. To make decisions for another, to live the decisional life of another person, to become another person: this is what guardians said about their position. The most awesome power of the state rests in the hands of persons who are often overworked. The assumption by the state of such a power over virtually helpless individuals deserves much more attention than the courts, the programs, and the professionals currently allow. 


\section{GLOSSARY OF TERMS}

Alternatives to Guardianship- legal tools, social services, and government programs that may delay or prevent the appointment of a guardian for persons who are incapable of making decisions for themselves. These include powers of attorney, advance directives, trusts, representative payeeship, protective services, and limited guardianship.

Autonomy- an ethical principle, associated with Immanuel Kant, that includes a person's right to create, change, and pursue life plans.

Beneficence- an ethical principle that seeks to prevent harm and do good. Right action is established by a collective, objective standard with which its recipient may disagree.

Paternalism, or acting in an individual's best interests in such a way that may discount his or her preferences, has been pejoratively linked with beneficence.

Best Interests- action which, in the absence of reliable evidence of an individual's views prior to appointing a surrogate decision maker, is the least intrusive and restrictive possible, given the needs of the individual. In considering an individual's needs, appropriate emphasis should be placed on his or her wishes and objectives.

Guardian Ad Litem- an individual, usually an attorney, who is the appointed fact-finder for the court and determines whether the establishment of a guardianship is in the prospective ward's best interests.

Limited Guardianship- a type of guardianship that may be granted when an individual is only partially incapacitated; it is tailored to an individual ward's needs and allows no more power by the guardian than the ward needs. The guardian manages whatever matters that the individual lacks capacity to manage. A problem with limited guardianship is that return appearances in court may be necessary to revise the powers of the guardian.

Least Restrictive Alterative- a course of action, determination, or habilitation that places as few limits as possible on the ward's liberty and meets the ward's needs.

Parens Patriae- deriving from English common law, a duty of the state to protect an individual citizen's well-being.

Public Guardian- an official appointed by a state or local government or court whose duty is to serve those incompetent persons who do not have relatives or friends appropriate to serve as a guardian (Schmidt et al., 1981). Public guardians may serve as guardians of the person, property, or both.

Substituted Judgment- a principle of decision making that requires implementation of a course of action synonymous with an individual's known wishes expressed prior to incompetence, provided that the individual could at one time develop views relevant to the issue under 
consideration and that reliable evidence of these views exists. Current opinions and wishes of the individual are also germane.

Ward- a person for whom a guardian has been appointed. 


\section{REFERENCES}

Alexander, G.J. (1985). Legal perspectives: Issues of competency. In G. LesnoffCaravaglia (Ed.), Values, ethics, and aging (pp.62-78). NY: Human Sciences Press.

Alexander, G. J. (1990). Avoiding guardianship: In E. Dejowski (Ed.), Protecting judgment-impaired adults: Issues, interventions and policies (pp.163-175). NY: Haworth Press.

Alexander, G., \& Lewin, T. (1972). The aged and the need for surrogate management. Syracuse, NY: Syracuse University Press.

Allen, R., Ferster, C., \& Zinoff, E., Weihofen, H. (1968). Mental impairment and legal incompetency. Englewood Cliffs, NJ: Prentice-Hall.

Allen, K.R., \& Walker, A.J. (1992). A feminist analysis of interviews with elderly mothers and their daughters. In J.F. Gilgun, K. Daly, \& G. Handel (Eds.), Qualitative methods in family research (pp.198-214). Newbury Park: Sage.

American Bar Association. (1988). Guardianship: An Agenda for Reform. Commission on the Mentally Disabled and Commission on Legal Problems of the Elderly.

Apolloni, T., \& Vincent, N. (1984). Guardianship reconsidered. In T. Apolloni and T.P. Cooke (Eds.), A new look at guardianship (pp.3-11). Baltimore: Paul H. Brookes Publishing Co.

Annas, G.J., \& Glantz, L.H. (1986). The right of elderly patients to refuse life-sustaining treatment. The Milbank Quarterly, 64 Suppl. 2, 95-162.

Aristotle. (1976). The Nichomachean ethics. (J.A.K. Thomson, Trans.). Harmondsworth, UK: Penguin.

Axilbund, M. T. (1979). Exercising judgment for the disabled: Report of an inquiry into limited guardianship, public guardianship, \& adult protective services in six states (executive summary). Washington, DC: American Bar Association Commission on the Mentally Disabled.

Barber, B. (1984). Strong democracy. Berkeley, CA: University of California Press.

Barnes, A. (1992). Beyond guardianship reform: A reevaluation of autonomy and beneficence for a system of principled decision-making in long-term care. Emory Law Journal, $41,635-760$.

Barnes, A.P. (1996). The more things change: Principles and practices of reformed guardianship. In M. Smyer, K.W. Schaie, \& M.B. Kapp (Eds.), Older adults' decision-making and the law (pp. 162-174). New York: Springer Publishing Company. 
Beauchamp, T., \& Childress, J. (1983). Principles of biomedical ethics, (2nd Ed.). New York: Oxford University Press, p. 65.

Bellah, R., Madsen, R., Sullivan, W.M., Swidler, A., \& Tipton, S.M. (1985). Habits of the heart: Individualism and commitment in American life. Berkeley: University of California Press.

Berger, P., \& Luckmann, T. (1967). The social construction of reality. Garden City, NJ: Anchor.

Berger, R., \& Piliavin, I. (1976). The effects of casework: A research note, Social Work, 21, 205-207.

Blenkner, M. Bloom, M., \& Nelson, M. (1971). A research and demonstration project of protective services, Social Casework, 52, 483-499.

Brock, D.W. (1994). Good decision making for incompetent patients. Hastings Center Report, 24 Suppl., 6, S8-S11.

Buchanan, A. \& Brock, D.W. (1986). Deciding for others. Milbank Quarterly, 64 Suppl.,(2):17-94.

Bulcroft, K., Kielkopf, M., \& Tripp, K. (1991). Elderly wards and their legal guardians: Analysis of county probate records in Ohio and Washington. The Gerontologist, 31, 156-164.

Callahan, D. (1984). Autonomy: A moral good, not a moral obsession. Hastings Center Report, October, 40-42. Schuster.

Callahan, D. (1987). Setting limits: Medical goals in an aging society. NY: Simon and

Childress, J.F. (1990). The place of autonomy in bioethics. Hastings Center Report, January/February, 12-17.

Christie, J. (1984). Guardianship in Alberta, Canada. In T. Apolloni \& T. Cooke (Eds.), A new look at guardianship (pp. 183-226). Baltimore: Paul H. Brookes.

Cicirelli, V. (1992). Family caregiving: Autonomous and paternalistic decision making. Newbury Park, CA: Sage.

Cohen, E. (1978). Editorial: Law and aging, lawyers and gerontologists. The Gerontologist, 18, 229. 
Cohen, E. (1988). The elderly mystique: Constraints on the autonomy of the elderly with disabilities. The Gerontologist, Suppl., 28, 24-31.

Cohen, E. (1996). Resolving ethical dilemmas arising from diminished decision-making capacity of the elderly. In M. Smyer, K.W. Schaie, \& M.B. Kapp (Eds.), Older adults' decisionmaking and the law (pp. 162-174). New York: Springer Publishing Company.

Cohen, M. (1983). An analysis of the dynamics of the adult guardianship process. Unpublished master's thesis, Pennsylvania State University, University Park, Pennsylvania.

Coleman, N., \& Dooley, J. (1990). Making the guardianship system work. Generations, Suppl., 47-50.

Collopy, B J. (1988). Autonomy in long term care: Some crucial distinctions. The Gerontologist, Suppl., 28, 10-17.

Cooper, T. (1991). An ethic of citizenship for public administration. Englewood Cliffs, NJ: Prentice-Hall.

Coward, R.T., \& Smith, W.M. (1982). Families in rural society. In D. Dillman \& D. Hobbs (Eds.), Rural society in the U.S.: Issues for the 1980's (pp. 77-84). Boulder, CO: Westview Press.

Coulton, C.J., Dunkle, R.E, Haug, M., Chow, J., \& Vielhaber, D.P. (1989). Locus of control and decisions making for posthospital care. The Gerontologist, 29, 627-633.

Creyke, R. (1989). Guardianship: Protection and autonomy-has the right balance been achieved? In J. M. Eekelaar \& D. Pearl (Eds.), An aging world: Dilemmas and challenges for law and social policy (pp. 545-570). Oxford: Clarendon Press.

Cruzan v. Director, Missouri Department of Health, 497 U.S. 261 (1990).

Culver, C.M., \& B. Gert. (1990). The inadequacy of incompetence. The Milbank Quarterly, 68, 619-643.

Dade County Grand Jury. (1982). Final report of the Grand Jury. Miami, FL: Office of the State Attorney.

Daniels, N. (1985) Just health care. New York: Cambridge University Press.

Denhardt. R.B, \& Perkins, J. (1976). The coming death of administrative man. Public Administration Review, 36, 379-384. 
Dennard, L.F. (1994). Negative democracy and the distortion of the American character. International Journal of Public Administration, 17, 2297-2342.

Denzin, N.K. (1978). The research act: A theoretical introduction to sociological methods. New York: McGraw-Hill.

Diamond, E., Jernigan, J.A., Mosely, R.A., Messina, V., \& McKeown, R.A. (1989). Decision-making ability and advance directive preferences in nursing home patients and proxies. The Gerontologist, 29, 622-626.

Dickens, B. (1989). Medico-legal issues concerning the elderly-an overview. In J. Eekelaar \& D. Pearl (Eds.), An aging world: Dilemmas and challenges for law and social policy (487-514). Oxford: Clarendon Press.

Doty, P. (1986). Family care of the elderly: The role of public policy. Milbank Memorial Fund Quarterly, 64, 34-75.

Dresser, R.S. (1992). Autonomy revisited: The limits of anticipatory choices. In R.H. Binstock, S.G. Post, \& P.G. Whitehouse (Eds.), Dementia and aging: Ethics, values, and policy choices (pp. 71-85). Baltimore, MD: Johns Hopkins Press.

Dubler, N.M. (1987). The dependent elderly: Legal rights and responsibilities in agent custody. In S.F. Spicker, S.R. Ingman, \& I.R. Lawson (Eds.), Ethical dimensions of geriatric care (pp.137-159). Boston: D. Reidel Publishing Co.

Dubler, N. M. (1988). Improving the discharge planning process: Distinguishing between coercion and choice. The Gerontologist, Suppl., 28, 76-81.

Dudovitz, N. (1985). The least restrictive alternative. Generations, Fall, 39-41.

Dworkin, G. (1982). Autonomy and informed consent. In President's Commission for the Study of Ethical Problems in Medicine and Biomedical and Behavioral Research. Making Health Care Decisions, Vol. 3. (pp. 63-81). Washington, D.C., U.S. Government Printing Office.

Dworkin, G. (1986). Moral autonomy and the demented self. Milbank Quarterly, 64 (Suppl., (2): 4-15.

Dwyer, J., \& Coward, R. (1992). Gender, family, and long-term care of the elderly. In J. Dwyer \& R. Coward (Eds.), Gender, families, and eldercare (pp. 3-17). Newbury Park, CA: Sage.

Evans, K.G., \& Wamsley, G.L. (1996). Public management and governance: A difference with an institutional distinction. Manuscript submitted for publication. 
Ferguson, K.E. (1984). The feminist case against bureaucracy. Philadelphia: Temple University Press.

Fisher, L.R. (1994). Qualitative research as art and science. In J.F. Gubrium \& A. Sankar (Eds.), Qualitative methods in aging research (pp. 3-14). Thousand Oaks, CA: Sage.

Follett, M.P. (1918/1965). The new state. New York: Longman, Green.

Frederickson, H.G., \& Hart, D.K. (1985). The public service and the patriotism of benevolence. Public Administration Review, 45, 547-554.

Friedman, L., \& Savage, M. (1988). Taking care: The Law of Conservatorship in California. Southern California Law Review, 61, 273-291.

Frolik, L.A. (1981). Plenary guardianship: An analysis, a critique, and a proposal for reform. Arizona Law Review, 23, 599-660.

Ganski, S. (1994). Public guardianship for adults: The rhetoric of reform and the realities of implementation. Unpublished doctoral dissertation, Northwestern University, Chicago, Illinois.

Gibson, J.M., \& Nathanson, P.S. (1990) Medical treatment guardians: When someone else must decide. Generations, Suppl., 43-46.

Gilligan, C. (1982). In a different voice. Cambridge, MA: Harvard University Press.

Glasser, I. (1978). Prisoners of benevolence: Power versus liberty in the welfare state. In W. Gaylen, I. Glasser, S. Marcus, \& D.J. Rothman (Eds.), Doing good: The limits of benevolence (pp. 97-168). New York: Pantheon Books.

Graversen, J., \& Pedersen, I.M. (1989). Loss of power of speech-does it mean loss of civil rights? The law in Denmark. In J. M. Eekelaar \& D. Pearl (Eds.), An aging world: Dilemmas and challenges for law and social policy (pp. 531-543). Oxford: Clarendon Press.

Grossberg, G. Zimny, G., \& Scallet, L. (1989). Guardianship of cognitively impaired elderly: Directions for research. In E. Light \& B. Lebowitz (Eds.), Alzheimer's disease treatment and family stress: Directions for research (155-173). Washington, DC: U.S. Government Printing Office.

Guardianship, An Agenda for Reform (1988). Recommendations of the National Guardianship Symposium and Policy of the American Bar Association. Commission on Legal Problems of the Elderly. Washington DC: American Bar Association. 
Harmon, M.M. (1995). Responsibility as paradox: A critique of rational discourse on government. Thousand Oaks: Sage.

Held, V. (1993). Feminist morality: Transforming culture, society, and politics. Chicago, IL: The University of Chicago Press.

Herr, S. S., \& Hopkins, B. L. (1994). Health care decision making for persons with disabilities. Journal of the American Medical Association, 271, 1017-1022.

High, D. (1988). All in the family: Extended Autonomy and expectations in surrogate health care decision-making. The Gerontologist, 28, 46-51.

High, D. (1994). Families' roles in advance directives. Hastings Center Report, Suppl., 26:6, S16-S18.

Hightower, D., Heckert, A., Schmidt, W. (1990). Elderly nursing home resident's need for public guardianship services in Tennessee. In E. F. Dejowski (Ed.), Protecting Judgement-Impaired Elders: Issues, Interventions and Policies (pp. 105-122). Binghamton, NY: The Haworth Press.

Hofland, B. (1988). Autonomy in long term care: Background issues and a programmatic response. The Gerontologist, Suppl. 28, 3-9.

Hommel, P.A. (1996). Guardianship reform in the 1980s: A decade of substantive and procedural changes. In M. Smyer, K.W. Schaie, \& M.B. Kapp (Eds.). Older adults' decisionmaking and the law (pp. 225-253). New York: Springer.

Hommel, P., Wang, L., \& Bergman (1990). Trends in guardianship reform: Implications for the medical and legal professions. Law, Medicine and Health Care, 18, 213-226.

Hommel, P., \& Wood, E. (1990). Guardianship-There are alternatives. Aging, 360, 6-12.

Horstman, P. (1975). Protective services for the elderly: The limits of parens patriae. Missouri Law Review, 40, 215-234.

Hull, L., Holmes, G., \& Karst, R. (1990). Managing guardianships of the elderly: Protection and advocacy as public policy. In E. Dejowski (Ed.), Protecting judgment-impaired adults: Issues, interventions and policies (145-162). New York: Haworth Press.

Hurme, S.B. (1994). Limited guardianship: Its implementation is long overdue. Clearinghouse Review, 28, 660-670.

In re Josiah Oakes, 8 Law Reporter 122, (Mass 1845). 
In re Quinlan, 70 N.J. 10, 355 A.2d 647 (1976).

Iris, M. (1988). Guardianship and the elderly: A multi-perspective view of the decisionmaking process. The Gerontologist, Suppl., 28, 39-45.

Iris, M. (1990). Threats to autonomy in guardianship decision-making. Generations, Suppl., 39-41.

Jaffe, D.J., \& Miller, E.M. (1994). Problematizing meaning. In J.F. Gubrium \& A. Sankar (Eds.) Qualitative methods in aging research (pp. 51-64). Thousand Oaks, CA: Sage.

Janesick, V. J. (1994). The dance of qualitative research design: Metaphor, methodolatry, and meaning. In N.K. Denzin \& Y.S. Lincoln (Eds.), Handbook of qualitative research. Thousand Oaks, CA: Sage.

Jecker, N. (1990). The role of intimate others in medical decision-making. The Gerontologist, 30, 65-71.

Jorgensen, D.L. (1989). Participant observation: A methodology for human studies. Newbury Park: Sage.

Kane, R., \& Caplan, A. L. (Eds.). (1990). Everyday ethics: Resolving dilemmas in nursing home life, New York: Springer Publishing.

Kapp, M.B. (1991). Health care decision making by the elderly: I get by with a little help from my friends, The Gerontologist, 31, 619-623.

Kapp, M.B. (1996). Alternatives to guardianship: Enhanced autonomy for diminished capacity. In M. Smyer, K.W. Schaie, \& M.B. Kapp (Eds.), Older adults' decision-making and the law (pp. 182-201). New York: Springer.

Kapp, M.B. (1996, November). Long term care for the "unbefriended": Legal risks and repercussions. In F. Ejaz (Chair), The ethics of decision making in long-term care. Symposium conducted at the meeting of the Gerontological Society of America, Washington, D.C.

Kapp, M.B., \& Lo, B. (1986). Legal perceptions and medical decision making. The Milbank Quarterly, 64, Suppl. 2, 163-200.

Kaufman, S.R., and Becker, G. (1996). Frailty, risk, and choice: cultural discourses and the question of responsibility. In M. Smyer, K.W. Schaie, \& M.B. Kapp (Eds.), Older adults' decision-making and the law (pp. 48-70). New York: Springer.

Keith, P.M., \& Wacker, R.R. (1994). Older wards and their guardians. Westport, CT: Praeger. 
Kittrie, N. (1971). The right to be different: Deviance and enforced therapy. Baltimore, MD: Johns Hopkins Press.

Kuhn, T.S. (1970). The structure of scientific revolutions (2nd ed.). Chicago: University of Chicago Press.

Lake v. Cameron, 364 F.2d. 622 (1966).

Lehmann, V., \& Mathiasen, G. (1963). Guardianship and protective services for older people. New York: NCOA Press.

Lessard v. Schmidt, 349 F. Supp. 1078 (E. D. Wisc. 1972).

Lincoln, Y.S., \& Guba, E. G. (1985). Naturalistic inquiry. Beverly Hills, CA: Sage.

Lipsky, M. (1980). Street-level bureaucracy. New York: Russell Sage Foundation.

Lisi, L.B, \& Baranaga-Burch, S. (1995). National study of guardianship systems: Summary of findings and recommendations. Clearinghouse Review, 29, pp. 643-653.

Lisi, L., \& Hommel, P. (1992). National study of guardianship system and feasibility of implementing expert systems project. Ann Arbor, MI: Center for Social Gerontology, University of Michigan.

Loewy, E. H. (1990). Social contract, communities, and guardians. In E. Dejowski (Ed.), Protecting judgment-impaired adults: Issues, interventions and policies (pp. 123-143). New York: Haworth Press.

Lord, S. (1992). Volunteers as guardians. Unpublished manuscript.

Lord, S. (1995). Annual Report FY 1995. Office of the Public Guardian. Rockville, MD.

Luborsky, M.R (1994). The identification and analysis of themes and patterns. In J.F. Gubrium \& A. Sankar (Eds.), Qualitative methods in aging research (pp.189-210). Thousand Oaks, CA: Sage.

March, J.G., \& Olsen, J.P. (1995). Democratic governance. New York: The Free Press.

Mason, D. (1991). On behalf of the patient. In Special Supplement of The Hastings Center Report, 21(5), S9-S10. $360,13$.

Maynard, C. (1990). Avoiding guardianship: Linking courts to service agencies. Aging, 
Miles, M.B. \& Huberman, A.M. (1994). Qualitative data analysis: A sourcebook of new methods (2nd ed.). Newbury Park, CA: Sage.

Miller, S., \& Hurme, S.B. (1991). Guardianship monitoring: An advocate's role. Clearinghouse Review, 25, 654-661.

Mitchell, A. (1978). Involuntary guardianship for incompetents: A strategy for legal services advocates. Clearinghouse Review, 12, 451-468.

Molumphy, J. T., \& Shivers, H. H. (1994). Virginia Guardianship Handbook. Virginia Guardianship Association.

Moody, H.R. (1988). From informed consent to negotiated consent. The Gerontologist, Suppl. 28, 46-70.

Moody, H.R. (1992). A critical view of ethical dilemmas in dementia. In R.H. Binstock, S.G. Post, \& P.J. Whitehouse (Eds.), Dementia and Aging: Ethics, values, and policy choices (pp.86-100). Baltimore: The Johns Hopkins University Press.

Morgan, D.F., \& Kass, H.D. (1991). Constitutional stewardship, phronesis and the American administrative ethos. Dialogue: The Public Administration Theory Network, 12(1), 17-60.

Morrissey, M. (1982). Guardians ad litem: An educational program in Virginia. The Gerontologist, 22, 301-304.

National Guardianship Association (1994). Ethics and standards for guardians. Elmhurst, IL: National Guardianship Association.

Noddings, N. (1984). Caring: A feminine approach to ethics and moral education. Los Angeles: University of California Press.

Osborne, D., \& Gaebler, T. (1992). Reinventing government: How the entrepreneurial spirit is transforming the public sector. New York: Plume.

Parry, J. (1985). Incompetency, guardianship, and restoration. In S.J. Brakel, J. Parry, and B.A. Weiner, (Eds.), The mentally disabled and the law. (3rd ed.), (pp. 369-434). Chicago: American Bar Foundation.

Patton, M.Q. (1990) Qualitative evaluation and research methods. (2nd ed.). Newbury Park, CA: Sage.

Peters, R., Schmidt, W. C., \& Miller, K. S. (1985). Guardianship of the elderly in Tallahassee, Florida. The Gerontologist, 25, 532-538. 
Regan, J. (1972). Protective services for the elderly: Commitment, guardianship, and alternatives. William and Mary Law Review, 13, 569-622.

Regan, J., \& Springer, G. (1977). Protective services for the elderly. A working paper prepared for the Special Committee on Aging, U.S. Senate. Washington, D.C.: U.S. Government Printing Office.

Regan, J. (1978). Intervention through adult protective services programs. The Gerontologist, 18, 250-254. 1111-1132.

Regan, J. (1981). Protecting the elderly: The new paternalism, Hastings Law Journal, $\underline{32}$,

Regan, J. (1990). The aged client and the law. New York: Columbia University Press.

Richmond-Times Dispatch. (Sept. 20-25, 1987). Guardians of the elderly: An ailing system. Associated Press. Publications.

Rothe, J.P. (1994). Qualitative research: A practical guide. Toronto, Ontario: RCI/PDE

Rothman, D.J. (1978). The state as parent: Social policy in the Progressive Era. In W. Gaylen, I. Glasser, S. Marcus, \& D.J. Rothman (Eds.), Doing good: The limits of benevolence (pp. 67-96). New York: Pantheon Books.

Sabatino, C.P. (1996). Competency: Refining our legal fictions. In M. Smyer, K.W. Schaie, \& M.B. Kapp (Eds.), Older adults' decision-making and the law (pp. 1-28). New York: Springer Publishing.

Sankar, A., \& Gubrium, J.F. (1994). Introduction. In J.F. Gubrium \& A. Sankar (Eds.), Qualitative methods in aging research (pp. vii-xvii). Thousand Oaks, CA: Sage.

Schafer, A. (1988). Civil liberties and the elderly patient. In J. Thornton \& E. Winkler (Eds.), Ethics and aging: The right to live, the right to die (208-214). Vancouver: University of British Columbia Press.

Schmidt, W.C. (1984). The evolution of a public guardianship program. The Journal of Psychiatry and Law, 12, 349-372.

Schmidt, W.C. (1990). Quantitative information about the quality of the guardianship system: Toward the next generation of guardianship research. Probate Law Journal, 10, 61-80. 
Schmidt, W.C. (1995a). Guardianship of the elderly in Florida: Social bankruptcy and the need for reform. In W.C. Schmidt (Ed.), Guardianship: The court of last resort for the elderly and disabled (pp. 3-16). Durham, NC: Carolina Academic Press.

Schmidt, W. C. (1995b). Guardianship: Court of last resort for the elderly and disabled. Durham, NC: Carolina Academic Press.

Schmidt, W.C. (1995c). Adult protective services and the therapeutic state. In W.C. Schmidt (Ed.), Guardianship: The court of last resort for the elderly and disabled (pp. 217-236). Durham, NC: Carolina Academic Press.

Schmidt, W.C. (1996, March). Guardianship issues and problems. Paper presented at the meeting of the Virginia Guardianship Association, Richmond, VA.

Schmidt, W. C., Miller, K. S., Bell, W. G., \& New, B. E. (1981). Public guardianship and the elderly. Cambridge, MA: Ballinger Publishing Co.

Schmidt, W.C., Miller, K.S., Peters, R., \& Lowenstein, D. (1988). A descriptive analysis of professional and volunteer programs for the delivery of public guardianship services. Probate Law Journal, 8(2), 125-156.

Schmidt, W.C., \& Peters, R. (1995). Legal incompetents' needs for guardianship in Florida. In W.C. Schmidt (Ed.), Guardianship: The court of last resort for the elderly and disabled (pp. 19-36). Durham, NC: Carolina Academic Press.

Select Committee on Aging. (1989). Surrogate decisionmaking for adults: Model standards to ensure quality guardianship and representative payeeship services. Washington, D.C.: U.S. Government Printing Office.

Selznick, P. (1992). The moral commonwealth: Social theory and the promise of community. Los Angeles: University of California Press.

Selznick, P. (1995). Personhood and moral obligation. In A. Etzioni (Ed.), New communitarian thinking: Persons, virtues, institutions, and communities. (pp. 110-125). Charlottesville, VA: University Press of Virginia.

Sherman, R.B. (1980). Guardianship: Time for a reassessment. Fordham Law Review, 49, 350-378.

Sherwin, S. (1993). No longer patient: Feminist ethics and health care. Philadelphia: Temple University Press.

Siemon, D., Hurme, S. B., \& Sabatino, C. P. (1993). Public guardianship: Where is it and what does it need? Clearinghouse Review, 27, 588-599. 
Simon, H.A. (1966). Administrative behavior (2nd ed.). New York: The Free Press.

Sproger, S.R. (1984). Public guardianship in California. In T. Apolloni and T.P. Cooke (Eds.), A new look at guardianship (pp.165-181). Baltimore: Paul H. Brookes Publishing Co.

Stake, R.E. (1994). Case studies. In N.K. Denzin \& Y.S. Lincoln (Eds.), Handbook of qualitative research (pp. 236-247). Thousand Oaks, CA: Sage.

Steinberg, R.M. (1985). Alternative approaches to conservatorship and protection of older adults referred to public guardian. Los Angeles: University of Southern California, Andrus Gerontology Center.

Stiegel, L. (1992). Alternatives to guardianship: Substantive training materials and module for professionals working with the elderly and persons with disabilities. Part I-II. Washington, DC: American Bar Association, Commission on Legal Problems of the Elderly and Commission on Mental and Physical Disability Law.

Stiegel, L.A. (1996). Commentary: Barriers to the development and use of alternatives to guardianship. In M. Smyer, K.W. Schaie, \& M.B. Kapp (Eds.), Older adults' decision-making and the law. (pp. 202-212). New York: Springer Publishing.

Stivers, C. (1990). Toward a feminist perspective in public administration theory. Women \& Politics, 10(4): 49-65.

Stivers, C. (1993). Gender images in public administration: Legitimacy and the administrative state. Newbury Park, CA: Sage.

Stivers, C. (1994). The listening bureaucrat: Responsiveness in public administration. Public Administration Review, 54, 364-369.

Strauss, A. (1987). Qualitative analysis for social scientists. New York: Cambridge University Press.

Strauss, A., \& Corbin, J. (1990). Basics of qualitative research: Grounded theory procedures and techniques. Newbury Park, CA: Sage. Brothers.

Taylor, F. (1915). The principles of scientific management. New York: Harper and

Tesch, R. (1992). Qualitative research: Analysis types and software tools. Philadelphia: The Falmer Press.

Thomasma, D. (1984). Freedom, dependency, and the care of the very old. Journal of the American Geriatrics Society, 32, 906-914. 
Topolnicki, D. (1989). The gulag of guardianship. Money Magazine, March, 140-152. $38-40$.

Veatch, R. (1984). Autonomy's temporary triumph. Hastings Center Report, October,

Vittoria, A. (1992). The elderly guardianship hearing: A socio-legal encounter. Journal of Aging Studies, 6, 165-190.

Wamsley, G.L. (1990). The agency perspective: Public administrators as agential leaders. In G.L Wamsley, R.N. Backer, C.T. Goodsell, P.S. Kronenberg, J.A. Rohr, C.M. Stivers, O.F. White, \& J.F. Wolf (Eds.), Refounding public administration (pp. 114-62). Newbury Park, CA: Sage. Sage.

Wamsley, G.L., et al. (1990). Refounding public administration. Newbury Park, CA:

Wetle, T., Levkoff, S., Cwikel, J., \& Rosen, A. (1988). Nursing home resident participation in medical decision: Perceptions and preferences. The Gerontologist, Suppl., 28, 32-38.

White, O.F., \& McSwain, C.J. (1990). The phoenix project: Raising a new image of public administration from the ashes of the past. In H.D. Kass \& B.L. Catron (Eds.), Images and identities in public administration (pp. 23-59). Newbury Park: Sage.

Wilber, K. (1990). Material abuse of the elderly: When is guardianship a solution? In E.F. Dejowski (Ed.), Protecting judgment-impaired adults: Issues, interventions and policies (pp. 89-104). New York: Haworth.

Wilber, K. (1991). Alternatives to conservatorship: The role of daily money management services. The Gerontologist, 31, 150-155.

Wilber, K.H. (1995). The search for effective alternative to conservatorship: Lessons from a daily money management diversion study. Journal of Aging and Social Policy, 7(1), 3956.

Wilber, K.H. (1996). Commentary: Alternatives to guardianship revisited: What's risk got to do with it? In M. Smyer, K.W. Schaie, \& M.B. Kapp (Eds.), Older adults' decisionmaking and the law. (pp. 213-224). New York: Springer Publishing.

Wilber, K.H., \& Buturain, L. (1992). Developing a daily money management service model: Navigating the uncharted waters of liability and viability. The Gerontologist, 33, 687691. 
Wilber, K. H., \& Reynolds, S. L. (1995). Rethinking alternatives to guardianship. The Gerontologist, 35, 248-257.

Williams, R. (1995). Annual report. Office of the Public Guardian. Wilmington, DE.

Wood, E.F. (1986). Statement of recommended judicial practices. Washington, D.C.: Commission on Legal Problems of the Elderly.

Wood, E.F. (1995). State guardianship legislation: Directions for reform. Clearinghouse Review, 29, 654-657. 


\section{APPENDIX A \\ RESEARCH PROTOCOLS AND INFORMED CONSENT DOCUMENTS}

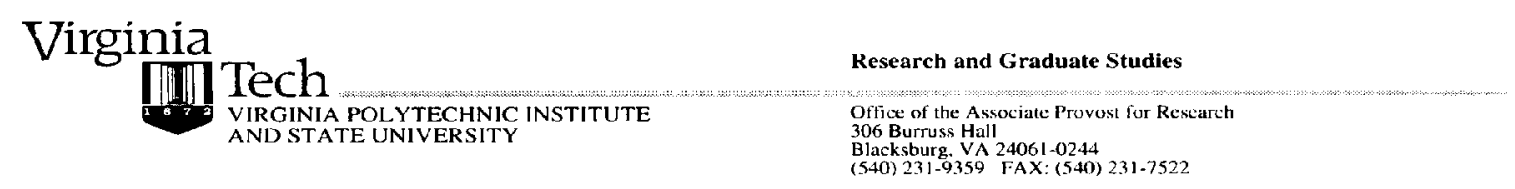

\section{MEMORANDUM}

TO: $\quad$ Pamela B. Teaster

Public Administration and Policy

FROM: $\quad$ Ernest R. Stout

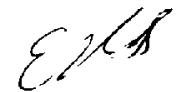

Associate Provost for Research

DATE: $\quad$ February 26, 1996

SUBJECT: IRB APPROVAL/"Living the Life of Another: The Role of the State as Guardian of Last Resort"

Ref. 96-064

The Institutional Review Board has reviewed your request for the above referenced project. We concur with Dr. Goodsell that the experiments are of minimal risk to the human subjects who will participate and that appropriate safeguards have been taken. Therefore, the Institutional Review Board for Research Involving Human Subjects approves your request. The IRB has determined that each subject should receive a complete copy of the signed Informed Consent.

This approval is valid for 12 months. If the involvement with human subjects is not complete within 12 months, the project must be resubmitted for re-approval. We will prompt you about 10 months from now. If there are significant changes in the protocol involving human subjects, those changes must be approved before proceeding.

Best wishes.

ERS/php

c: Dr. Goodsell 
B. Teaster, C.A.G,S Deparment Pub. Admin \& Policy

Invesigatonsl:_Pamela B. Teaster, C.A.G,S

Project Title: Iiving the Life of Another: The Role of the State as Guardian of Last Resort

Source of Support: Deparmental Research 1 Sponsored Research. J Proposal No

1. The criteria for "expedited review" by the Institutional Revew Board for a prolect involving the use of human sublect

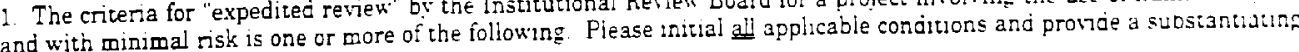
statement of protocol.

a. Collection of:

1) hair or nail clipping in a non-disfiguring manner:

2) deciduous teeth;

3) permanent teeth if patient care indicates need of extraction

b. Collection of excreta and external secretions: sweat, uncanulated saliva, placenta removed at deliver: amnotic Iluic obtained at time of rupture of the membrane.

7 . Recording of data from subjects 18 years or older. using non-invasive procedures routinely emploved in clinica! practice. Exemption does not include exposure to electromagnetic radiation outside the visible range.

1 d Collection of biood samples by venipuncture (not exceeding $150 \mathrm{~m} / 8$ week period, and no more thar twice a week! from subjects 18 years or older, in good health and not pregnant.

$\square$ e. Collection of supra- and subgingival dental plaque and calculus, provided the proceciure is no more invasive than routine sealing of the teeth.

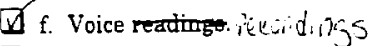

$\square$ g. Moderate exercise by healthy volunteers.

h. Study of existing data, documents, records, pathological specimens or diagnostic specimens.

$\square$ i. Research on drugs or devices for which an investigational exemption is not required.

2. If the project involves human subjects who are exposed to "more than minimal risk" and are not covered by the criteria above (a to i), the IRB review must involve the full IRB board. Pleage check if the research involves more than minimal risk** _ and provide a substantiating statement of protocol.

3. Human subjects would be involved in the proposed activity as eithey Minors and/or Children* Abortuses__., Pregnant Women_, Prisoners__, Mentally Retard___, Mentaliy Disabled $\_$. Note that if children are involved in the research as human subjects, they may have to provide conght as well as their parents.

Whether or not the project may undergo "expedited review" or must be reviewed by the full Institutional Review Board, it is neressary that the required informed consent forms also be reviewed. These should be submitted with the proposal. However, if there is insufficient time to meet the sponsor's deadline, submittal can be delayed up to thirty days after submittal of the proposal without jeopardizing the IRB certification to the prospective sponsor.

* Minimal risk means that the risks of harm anticipated in the proposed research are not greater, considering the probability and magnitude, than those encountered in daily life or during performance of routine physical or psychological examinations or tests.

* Subject at risk is an individual who may be exposed to the possibility of injury as a consequence of participation as a subject in any research. development or related activity which depars from the application of those established and accepted methods necessary to meet his needs, or which increases the ardinary nsks of daily life. including the recognized risks inherent in a chosen occupation or field of science.

This is to certify that the project identified above will be carried out as approved by the Human Subject Review Board and will neither be modified nor carried out beyond the period approved below without express review and approval by the Board.

Investgators/Date

The Human Subjects Revieu. Board has reviewed the protocol identified above, as it involves human subjects, and hereby approves the conduct of the project for 2 months, at which time the protocot hus be resybmitted for approval to conginue.

ก 


\title{
VIRGINIA POLYTECHNIC INSTITUTE AND STATE UNIVERSITY
}

\author{
Informed Consent for Participants of Investigative Projects
}

Wards

Title of Project: Living the Life of Another: The Role of the State as Guardian Investigator: Pamela B. Teaster, C.A.G.S, Public Administration and Policy Analysis

\section{THE PURPOSE OF THE PROJECT}

The purpose of this project is to answer the research question, "How do public guardians meet the needs of their wards?" This research should illuminate the perspectives of the ward, his or her primary guardian, and the program supervisor. Ultimately, it should reveal how decisions are made on behalf of the ward and how public guardianship is carried out. This research has the potential to benefit wards and public guardians by revealing ways that needs are met and by making suggestions for improvement from the interviews, notes, and observations.

Maximum number of subjects $=38$. $\quad$ (Figured on 20 wards, 4 supervisors, 1 primary public guardian (DE), 1 primary public guardian (TN), 4 maximum primary public guardians (MD), 4 maximum primary public guardians (Personal Support Network), and 4 maximum caregiving public guardians (Chesapeake Volunteer Guardianship Program).

\section{PROCEDURES}

Human participants are used in order to interview them regarding guardianship (lucid wards) and to observe the interactions of public guardians and their wards (lucid and non-lucid). Also, in order to understand how public guardians meet the needs of their wards and the rationale behind the arrangement of services and client advocacy, it is necessary to review lucid and non-lucid wards' case files so that the researcher may understand his or her unique problems and needs. All interviews, participant observations, and review of case files will be conducted by Pamela B. Teaster, the researcher.

Wards who are lucid, in absence of the public guardian, will be asked questions regarding their background, their needs, how the public guardian meets their needs, how well the ward knows them, and how they feel about being a ward. Also, wards who are lucid and nonlucid will be observed interacting with their primary public guardian. The ward's case file will also be reviewed for pertinent information. Wards will be interviewed and observed for a maximum of 2 hours. The interviews will be audio taped, and notes will be taken during the observation, the interview, and from both lucid and non-lucid wards' case files. It is estimated that research at the agency will require no more than four working days. 
Transcripts of the interviews will be produced by Pamela B. Teaster and secretarial assistants who will have no knowledge of the ward. Transcription by secretarial assistants will be terminated should the secretary know the ward.

\section{RISKS}

There are minimal risks to participants in this research project. Should the presence of the investigator or the questions posed by the investigator proved unduly upsetting, or should the

ward would wish to stop the interview or observation, the investigator will terminate the study of the ward immediately.

\section{BENEFITS}

The benefit to the ward, the primary public guardian, and the public guardian's supervisor is to have an forum to present their unique perspectives on public guardianship by documenting how public guardians meet the needs of their wards. This research has the potential to help improve policies that will affect the lives of persons who are in need of guardianship or guardianship services. Copies of the study are available for participants upon their request.

\section{EXTENT OF ANONYMITY AND CONFIDENTIALITY}

The confidentiality of each subject will be preserved by the use of a code for identification. The key to the code, notes, tapes and their transcripts will be held under lock and key within the researcher's house and will be destroyed upon completion of the dissertation and graduation of the student.

Should abuse of any kind be reported to the researcher in the course of the interview, the researcher will report it to the administrator directly over the program supervisor.

\section{COMPENSATION}

There is no compensation for participation as research subjects.

\section{FREEDOM TO WITHDRAW}

Research participants are free to withdraw from the study at any time without penalty. Wards may refuse to answer any questions posed by the researcher, Pamela B. Teaster. 


\section{APPROVAL OF RESEARCH}

This research project has been approved by the Institutional Review Board for Research Involving Human Subjects at Virginia Polytechnic Institute and State University, the Department of Public Administration and Policy Analysis, and the Center for Gerontology, Graduate Certificate in Gerontology. Research sites are the following: the Maryland Office of the Public Guardian, the Delaware Department of Social Services, the Tennessee Public Guardian, the Personal Support Services, and the Chesapeake Volunteer Guardian Program.

\section{SUBJECT'S RESPONSIBILITY}

I voluntarily agree to participate in this study and answer questions about guardianship, allow the researcher to observe me, and review and make notes on the ward's case file.

\section{SUBJECT'S PERMISSION}

I have read or been read to and understand the Informed Consent document and conditions of this project. I have had all my questions answered. I hereby acknowledge the above and give my voluntary consent for participation in this project.

If I participate, I may withdraw at any time without penalty. I agree to be observed, interviewed, and have Pamela B. Teaster read and take notes on my case file.

Signature

\section{Date}

On behalf of or guardian of

Should I have any questions about this research or its conduct, I may contact:

Pamela B. Teaster $540 / 345-0451$

Investigator

Charles T. Goodsell, Ph.D.

$540 / 231-5133$

Faculty Advisor

Center for Public Administration and Policy

E. R. Stout

$540 / 231-9359$

Chair, Institutional Review Board

Research Division 


\section{VIRGINIA POLYTECHNIC INSTITUTE AND STATE UNIVERSITY}

Informed Consent for Participants of Investigative Projects

(Ward's Assent)

Title of Project: $\quad$ Living the Life of Another:

The Role of the State as Guardian

INVESTIGATOR: Pamela B. Teaster

The purpose of this study is to see how guardians (like give name) meet your needs.

I agree to let Ms. Teaster talk to me about my life and the way I feel (if I am clear as to time and place). I agree to let Ms. Teaster watch me with my guardian (for both clear and non-clear wards),

I agree to let Ms. Teaster make an audiotape of our talk together, if I am clear. I understand that she will make notes on my files. She will not use my name in anything that she writes.

I may stop at any time if I choose. Ms. Teaster will send me a copy of what she has learned, if I request it. 


\title{
VIRGINIA POLYTECHNIC INSTITUTE AND STATE UNIVERSITY
}

\author{
Informed Consent for Participants of Investigative Projects
}

\author{
Primary Public Guardian
}

Title of Project: Living the Life of Another: The Role of the State as Guardian Investigator: Pamela B. Teaster, C.A.G.S, Public Administration and Policy Analysis

\section{THE PURPOSE OF THE PROJECT}

The purpose of this project is to answer the research question, "How do public guardians meet the needs of their wards?" This research should illuminate the perspectives of the ward, his or her primary guardian, and the program supervisor. Ultimately, it should reveal how decisions are made on behalf of the ward and how public guardianship is carried out. This research has the potential to benefit wards and public guardians by revealing ways that needs are met and by making suggestions for improvement from the interviews, notes, and observations.

Maximum number of subjects $=38$. (Figured on 20 wards, 4 supervisors, 1 primary public guardian (DE), 1 primary public guardian (TN), 4 maximum primary public guardians (MD), 4 maximum primary public guardians (Personal Support Network), and 4 maximum caregiving public guardians (Chesapeake Volunteer Guardianship Program).

\section{PROCEDURES}

Human participants are used in order to interview them regarding guardianship (lucid wards) and to observe the interactions of public guardians and their wards (lucid and non-lucid). Also, in order to understand how public guardians meet the needs of their wards and the rationale behind the arrangement of services and client advocacy, it is necessary to review both lucid and non-lucid wards' case files so that the researcher may understand his or her unique problems and needs. All interviews, participant observations, and review of case files will be conducted by Pamela B. Teaster, the researcher.

The primary public guardian (guardian closest to the ward) will be observed interacting with his or her wards (both lucid and non-lucid), and the primary guardian will be asked questions regarding the nature of being a public guardian, the time spent in care provision, the adequacy of service provision, and decision making. The interview of the primary guardian should require approximately 3 hours. Follow-up phone calls will be required to validate the data and clear up any questions regarding the interview. 
Transcripts of the interviews will be produced by Pamela B. Teaster and secretarial assistants who will have no knowledge of the primary guardian. Should the secretarial assistant know the primary guardian, transcription by that person will cease, and other secretarial assistance will be sought.

\section{RISKS}

There are minimal risks to participants in this research project. Should the presence of the investigator or the questions posed by the investigator proved unduly upsetting, the investigator will terminate the study of the primary guardian immediately.

\section{BENEFITS}

The benefit to the ward, the primary public guardian, and the public guardian's supervisor is to have an forum to present their unique perspectives on public guardianship by documenting how public guardians meet the needs of their wards. This research has the potential to help improve policies that will affect the lives of persons who are in need of guardianship or guardianship services. Copies of the study are available for participants upon their request.

\section{EXTENT OF ANONYMITY AND CONFIDENTIALITY}

The confidentiality of each subject will be preserved by the use of a code for identification. The key to the code, notes, tapes and their transcripts will be held under lock and key within the researcher's house and will be destroyed upon completion of the dissertation and graduation of the student.

Should abuse of any kind be reported to the researcher in the course of the interview, the researcher will report it to the administrator directly over the program supervisor.

\section{COMPENSATION}

There is no compensation for participation as research subjects.

\section{FREEDOM TO WITHDRAW}

Research participants are free to withdraw from the study at any time without penalty. The primary public guardian may decline to answer any question that the researcher asks. 


\section{APPROVAL OF RESEARCH}

This research project has been approved by the Institutional Review Board for Research Involving Human Subjects at Virginia Polytechnic Institute and State University, the Department of Public Administration and Policy Analysis, and the Center for Gerontology, Graduate Certificate in Gerontology. Research sites are the following: the Maryland Office of the Public Guardian, the Delaware Department of Social Services, the Tennessee Public Guardian, the Personal Support Services, and the Chesapeake Volunteer Guardian Program.

\section{SUBJECT'S RESPONSIBILITY}

I voluntarily agree to participate in this study and answer questions about guardianship, allow the researcher to observe me, and review and make notes on the ward's case file.

\section{SUBJECT'S PERMISSION}

I have read or been read to and understand the Informed Consent document and conditions of this project. I have had all my questions answered. I hereby acknowledge the above and give my voluntary consent for participation in this project.

If I participate, I may withdraw at any time without penalty. I agree to be observed, interviewed, and have Pamela B. Teaster read and take notes on my case file.

Signature

Date

On behalf of or guardian of

Should I have any questions about this research or its conduct, I may contact:

Pamela B. Teaster

540/345-0451

Investigator

Charles T. Goodsell Ph.D.

$540 / 231-5133$

Faculty Advisor

Center for Public Administration and Policy

E. R. Stout

$540 / 231-9359$

Chair, Institutional Review Board

Research Division 


\title{
VIRGINIA POLYTECHNIC INSTITUTE AND STATE UNIVERSITY
}

\author{
Informed Consent for Participants of Investigative Projects
}

Program Supervisor

Title of Project: Living the Life of Another: The Role of the State as Guardian

Investigator: Pamela B. Teaster, C.A.G.S, Public Administration and Policy Analysis

\section{THE PURPOSE OF THE PROJECT}

The purpose of this project is to answer the research question, "How do public guardians meet the needs of their wards?" This research should illuminate the perspectives of the ward, his or her primary guardian, and the program supervisor. Ultimately, it should reveal how decisions are made on behalf of the ward and how public guardianship is carried out. This research has the potential to benefit wards and public guardians by revealing ways that needs are met and by making suggestions for improvement from the interviews, notes, and observations.

Maximum number of subjects $=38$. (Figured on 20 wards, 4 supervisors, 1 primary public guardian (DE), 1 primary public guardian (TN), 4 maximum primary public guardians (MD), 4 maximum primary public guardians (Personal Support Network), and 4 maximum caregiving public guardians (Chesapeake Volunteer Guardianship Program).

\section{PROCEDURES}

Human participants are used in order to interview them regarding guardianship (lucid wards) and to observe the interactions of public guardians and their wards (lucid and non-lucid). Also, in order to understand how public guardians meet the needs of their wards and the rationale behind the arrangement of services and client advocacy, it is necessary to review both lucid and non-lucid wards' case files so that the researcher may understand his or her unique problems and needs. All interviews, participant observations, and review of case files will be conducted by Pamela B. Teaster, the researcher.

The program supervisor of the primary public guardian will also be interviewed. Interview questions will include perceptions regarding the ward, the primary guardian, and the guardianship process. Supervisors will also be asked questions regarding funding, administrative support, accountability, client advocacy, and public guardianship in general. The interview of the program supervisor should require approximately 3 hours. Follow-up phone calls will be required to validate the data and clear up any questions regarding the interview. 
Transcripts of the interviews will be produced by Pamela B. Teaster and secretarial assistants who will have no knowledge of the program supervisor. Should the secretarial assistant know the program supervisor, transcription by that person will cease, and other secretarial assistance will be sought.

\section{RISKS}

There are minimal risks to participants in this research project. Should the presence of the investigator or the questions posed by the investigator proved unduly upsetting, the investigator will terminate the study immediately.

\section{BENEFITS}

The benefit to the ward, the primary public guardian, and the public guardian's supervisor is to have an forum to present their unique perspectives on public guardianship by documenting how public guardians meet the needs of their wards. This research has the potential to help improve policies that will affect the lives of persons who are in need of guardianship or guardianship services. Copies of the study are available for participants upon their request.

\section{EXTENT OF ANONYMITY AND CONFIDENTIALITY}

The confidentiality of each subject will be preserved by the use of a code for identification. The key to the code, notes, tapes and their transcripts will be held under lock and key within the researcher's house and will be destroyed upon completion of the dissertation and graduation of the student.

Should abuse of any kind be reported to the researcher in the course of the interview, the researcher will report it to the administrator directly over the program supervisor.

\section{COMPENSATION}

There is no compensation for participation as research subjects.

\section{FREEDOM TO WITHDRAW}

Research participants are free to withdraw from the study at any time without penalty. Program supervisors may decline to answer any question posed by Pamela B. Teaster. 


\section{APPROVAL OF RESEARCH}

This research project has been approved by the Institutional Review Board for Research Involving Human Subjects at Virginia Polytechnic Institute and State University, the Department of Public Administration and Policy Analysis, and the Center for Gerontology, Graduate Certificate in Gerontology. Research sites are the following: the Maryland Office of the Public Guardian, the Delaware Department of Social Services, the Tennessee Public Guardian, the Personal Support Services, and the Chesapeake Volunteer Guardian Program.

\section{SUBJECT'S RESPONSIBILITY}

I voluntarily agree to participate in this study and answer questions about guardianship, allow the researcher to interview me and review the ward's case file.

\section{SUBJECT'S PERMISSION}

I have read or been read to and understand the Informed Consent document and conditions of this project. I have had all my questions answered. I hereby acknowledge the above and give my voluntary consent for participation in this project.

If I participate, I may withdraw at any time without penalty. I agree to be observed, interviewed, and have Pamela B. Teaster read and take notes on my case file.

Signature

Date

Should I have any questions about this research or its conduct, I may contact:

Pamela B. Teaster

$540 / 345-0451$

Investigator

Charles T. Goodsell, Ph.D.

$540 / 231-5133$

Faculty Advisor

Center for Public Administration and Policy

E. R. Stout

$540 / 231-9359$

Chair, Institutional Review Board

Research Division 


\section{APPENDIX B \\ INTERVIEW QUESTIONS}

\section{SEMI-STRUCTURED INTERVIEW QUESTIONS FOR THE WARD}

1. Tell me about yourself.

2. How did (you become a ward) or (come under the primary guardian's [use name] care)?

3. How do you feel about your health and health care? What are your day to day wishes? What did you/do you like to do? What would you like to be doing that you can't do now?

4. Do you feel that your public guardian meets your needs? How so or how not?

5. How do you feel about being a ward?

6. What experiences have you had being a ward that you have liked/disliked?

7. How well do you think that your guardian knows you?

8. What would you like your guardian to know about you that you think he or she doesn't know?

9. In making decisions for you, do you think that the guardian respects your wishes when possible?

10. What decisions do you think you could make that you aren't making now?

11. Do you think that guardianship has been good for you? How so or how not?

12. What else would you like to talk about? Is there anything that you would like to discuss about which I haven't asked you?

*Questions for the ward may be rephrased so that the ward can better understand and respond to them. 


\section{SEMI-STRUCTURED INTERVIEW QUESTIONS FOR THE PRIMARY PUBLIC GUARDIAN}

1. Tell me about yourself. What is your background?

2. What is your case load? Are you a full-time public guardian?

3. How long have your been a public guardian?

4. How do you feel about being a public guardian?

5. In what stage is this ward? (i.e., return of functioning, end of life)

6. What amount of time do you spend on this ward per month? How is that time broken down?

7. How well do think that you know the ward?

8. How do you know about the needs of the ward? How well do you think that you know the ward's needs?

9. How did you discover the ward's needs?

10. Tell me about your relationship with this ward.

11. In what ways have you met the needs of this ward? (Socially, health, empowerment, caregiving, restoration of function, respect for wishes)

12. Have you ever been constrained in attempting to meet the needs of this ward?

13. Was your interaction that I observed between you and the ward typical? How so, or how not?

14. How effective do you believe that you are in meeting the needs of the ward?

15. What would you like to change about public guardianship if you could?

16. Have you had any experiences with this ward that you would want to discuss?

17. What sorts of decisions have you made for this ward? What affects the decisions that you make? How long do you expect to be associated with this ward? What do you perceive to be the future prognosis for this ward? What are your care goals for this ward? 
18. How do you cope with the responsibilities of being a direct care providing public guardian?

19. Discuss how you must account for the work you do for this ward.

20. What other issues would you like to discuss? Is there anything that you would like to discuss about which I haven't asked you? 


\section{SEMI-STRUCTURED INTERVIEW QUESTIONS FOR THE PROGRAM SUPERVISOR}

1. Tell me about yourself. What is your background?

2. Who has ultimate authority for the wards?

3. How do you hold the primary guardian (or guardian's agent) accountable for her work with a ward?

4. How are you held accountable for work done on behalf of a ward?

5. What is your knowledge of the wards?

6. How do public guardians meet the needs of their wards?

7. What do you look for in a primary care providing guardian or guardian's agent?

8. What sorts of supervision do you provide for the care providing guardian?

9. What chief concerns do you have concerning guardians and their wards?

10. What sort of support do you receive for your program?

11. What would you like to change about your program?

12. What would you like to change about public guardianship?

13. How much do you interact with other state public guardianship programs? How much do you interact with other AAA's?

14. What advice do you have for persons who would be interested in serving as public guardians?

15. What are official qualifications for direct care providing public guardians? What are your personal qualifications for direct care providing public guardians?

16. How do you support your guardians' mental and emotional health?

17. What other issues would you like to discuss? Is there anything that you would like to discuss about which I haven't asked you? 


\section{APPENDIX C \\ VALUES HISTORY FORM}

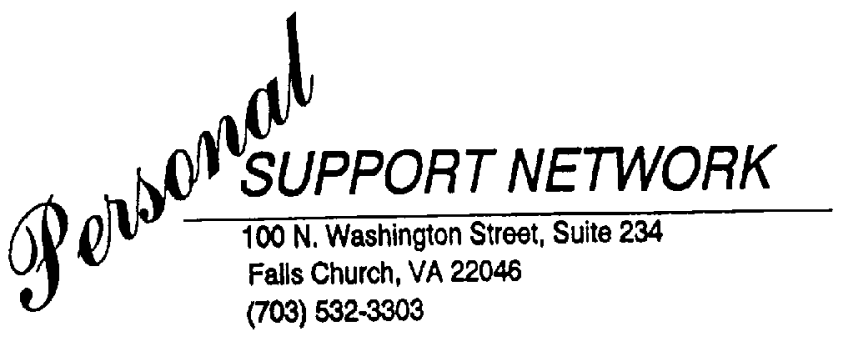

VALUES HISTORY FORM

Background and Suggestions for Use

The Values History Form, developed at the Center for Health Law and Ethics of the Institute of Public Law (University of New Mexico), provides a way for people to discuss and document their values, wishes, and preferences in the area of medical treatment decisions.

While it is not a formal legal document, the Values History Form may complement and significantly elaborate on traditional advance directives such as Living Wills and Durable Powers of Attorney. Discussing and answering the Form's questions with family and friends over time can help both in the present as well as in the future when a surrogate decision maker might be making decisions on your behalf.

What is most important is that each of us spend time thinking about our own values, wishes, and preferences, and communicate these with others. As you complete the Values History Form, you might wish to provide copies to members of your family, your friends, your doctors and your attorney, as appropriate.

If you have a Living will or a Durable Power of Attorney for Health Care Decisions, You may wish to attach a copy of the Values History Form to those documents.

Most important, start discussing these issues early, and encourage family and friends of all ages to do the same. After all, it is the thorough discussion of these issues over time that eases the difficulty of such decisions in times of crisis.

The purpose of this form is to assist you in thinking about and writing down what is important to you about your health. If you should at some time become unable to make health care decisions for yourself, you thoughts as expressed on this form may help others make a decision for you in accordance with what you would have chosen.

The first section of this form provides an opportunity for you to discuss your values, wishes, and preferences in a number of different areas, such as your personal relationships, your overall attitude toward life, and your thoughts about illness. The second section of this form asks whether you have already expressed you wishes concerning medical treatment through either written or oral communications and if not, whether you would like to do so now. 


\section{VALUES HISTORY}

NAME:

DATE:

COMPLETED BY:

OR INFORMATION OBTAINED FROM:

RELATIONSHIP TO CLIENT:

PSN CLIENT REPRESENTATIVE:

\section{SECTION I}

\section{A. YOUR LIVING ENVIRONMENT}

What has been your living situation over the last ten years (e.g., lived alone, lived with others, etc.). Is this living situation your preference?

How difficult is it for you to maintain the kind of environment for yourself that you find comfortable? Does any illness or medical problem you now have mean that it will be harder in the future?

Comments:

Client Initial

Date Completed 


\section{B. YOUR OVERALL ATTITUDE TOWARD HEALTH}

What is your overall current health status? Please list current medical problems.

If you have current medical problems, in what ways, if any, do they affect your ability to function?

How do you feel about your current health status?

How well are you able to meet the basic necessities of life- eating, meal preparation, personal care, etc.?

Client Initial

Date Completed 
Is pain a factor in your life? How do you feel about pain?

Comments:

C. YOUR PERCEPTION OF THE ROLE OF PHYSICIANS AND OTHER HEALTH CARE PROFESSIONALS

Do you trust physicians in general?

Do you like your physicians?

Do you view the physician as the ultimate decision maker?

Client Initial

Date Completed 
How do you relate to caregivers including nurses, therapists, social workers, etc.?

\section{Comments:}

D. YOUR THOUGHTS CONCERNING INDEPENDENCE AND CONTROL How important is independence and self-sufficiency in your life?

If you were to experience decreased physical and mental capabilities, how would that affect your attitude toward independence and self-sufficiency? Would you want to maintain your independence at risk to your health and safety?

\section{Comments:}

Client Initial

Date Completed 


\section{E. YOUR PERSONAL RELATIONSHIPS}

What role do friends and/or family play in your life?

Are there individuals whom you want involved in your life if you are mentally incapacitated and/or dying? (Names, phone numbers, and addresses).

Do you trust and believe in friends, family, and others supporting your wishes concerning medical treatment?

Comments:

\section{F. YOUR RELIGIOUS BACKGROUND AND BELIEFS}

What is your religious background?

Client Initial

Date Completed 
How do your religious beliefs affect your attitude toward serious or terminal illness?

How does your faith community, church, or synagogue view the role of prayer or religious sacraments in any illness?

\section{Comments:}

\section{G. YOUR OVERALL ATTITUDE TOWARD LIFE, ILLNESS, AND DEATH}

What activities do you enjoy?

Are you happy to be alive?

Client Initial

Date Completed 
Do you feel that your life is worth living?

Are you satisfied with what you have achieved in life?

What makes you laugh/cry?

What do you fear most? What frightens or upsets you?

Do you have goals for the future?

List those goals:

\section{Client Initial}

Date Completed 
What will be important to you when you are dying (e.g., physical comfort, no pain, family/friends present, etc.)?

Where would you prefer to die (e.g., home, hospital, hospice, etc.)?

What is your attitude toward death?

How do you feel about the use of life sustaining measures in the face of terminal illness?

Irreversible coma?

\section{Client Initial}

Date Completed 
Chronic, debilitating illness (e.g., Alzheimer's)

\section{Comments:}

\section{H. YOUR ATTITUDE CONCERNING FINANCES}

Do you worry about having enough money to provide for your care?

Would you prefer to spend less money on your care so that more money can be saved for the benefit of your beneficiaries? How do your beneficiaries feel about this issue?

Comments:

Client Initial

Date Completed 


\section{YOUR WISHES CONCERNING YOUR FUNERAL}

What are your wishes concerning funeral and burial or cremation?

Do you want a religious service?

Have you made funeral arrangements? If so, with whom?

\section{Comments:}

\section{SECTION II}

\section{A. WRITTEN LEGAL DOCUMENTS}

\section{LIVING WILL}

Yes No

Date Written:

Document Location:

Client Initial

Date Completed 
DURABLE POWER OF ATTORNEY

Yes__ No_

Date Written:

Document Location:

Name of Attorney-in-Fact:

County where recorded:

Comments:

DURABLE POWER OF ATTORNEY FOR HEALTH CARE (MEDICAL POA)

Yes__ No_

Date Written:___ Document Location:

Comments:

\section{ORGAN DONATIONS DOCUMENT}

Yes__ No_

Date Written:____ Document Location:

Comments:

\section{B. WISHES CONCERNING SPECIFIC MEDICAL PROCEDURES}

\section{ORGAN DONATIONS}

Do you want to donate any organs?

Client Initial

Date Completed 
What organ(s) do you wish to donate?

\section{Comments:}

\section{KIDNEY DIALYSIS}

If necessary for survival, do you want to be on long-term dialysis?

If you become decisionally incapacitated, do you want to be on long-term dialysis?

If you choose to be on long-term dialysis, do you want to: (Check one)

(a) Stay on it permanently?

\section{Client Initial}

Date Completed 
(b) Stay on it as long as it improves substantially your quality of life?

Comments:

\section{LIFE SUSTAINING PROCEDURES}

Which of the following means to resuscitate and sustain life do you want performed on you?

(Check those desired)

None

Mouth-to-Mouth and use of pharmacological and mechanical devices (e.g., respirator)

Comments:

\section{ARTIFICIAL NUTRITION/HYDRATION}

If sustaining life requires medical assistance for nutritional and/or fluid intake, which of the following do you want? (Check and initial those desired)

Nasal/Gastric Tube (Internal)

Parenteral Nutrition (IV)

Gastrostomy Tube (Surgically implanted

tube through stomach wall)

IV Hydration with Vitamins

IV Hydration without Vitamins

None of the Above

Client Initial

Date Completed 
Comments:

\section{ORGAN TRANSPLANT}

If you need an organ transplant to sustain your life, do you want it?

Comments (are there any organs you don't want?)

\section{BLOOD TRANSFUSION}

If medically necessary, do you want a blood transfusion?

Comments:

\section{EXPERIMENTAL TREATMENTS}

If you have a life threatening illness where normally accepted medical procedures have been unsuccessful, would you choose to use experimental treatments?

(Check one and initial)

(a) Under any circumstance

(b) Only if it would not compromise

my quality of life at that time

\section{WISHES CONCERNING MONEY \& HEALTH CARE COSTS}

Do you want to spend your assets on life-sustaining medical care?

Client Initial

Date Completed 
Given the choice between home care and institution care, on which would you prefer to spend your assets?

Is it important to you to preserve your assets for your beneficiaries?

\section{Comments:}

Client Initial 


\section{ACKNOWLEDGMENT FOR NATURAL PERSONS}

The preceding document (Values History) expresses my wishes and desires should I become decisionally incapacitated. This information may be relied upon by my surrogate decisionmaker or attorney-in-fact.

IN WITNESS WHEREOF, I have hereunto set my hand and seal this ___ day of , 199

Signed, Sealed, and Delivered in the Presence of:

WITNESS

WITNESS

COMMONWEALTH OF VIRGINIA ）

COUNTY OF

The foregoing instrument was acknowledged before me on this day of

$\longrightarrow, 199$

\section{DATE}

\section{DATE}

\section{NOTARY PUBLIC}

My commission expires: 


\section{The 6 page vita has been removed from the scanned document}




\section{The 6 page vita has been removed from the scanned document}




\section{The 6 page vita has been removed from the scanned document}




\section{The 6 page vita has been removed from the scanned document}




\section{The 6 page vita has been removed from the scanned document}




\section{The 6 page vita has been removed from the scanned document}




\section{DISSERTATION COMMITTEE MEMBERS}

Charles T. Goodsell, Ph.D., Chair, Center for Public Administration, Virginia Polytechnic Institute and State University.

William J. McAuley, Ph.D., University of Oklahoma Health Sciences Center, University of Oklahoma.

Larkin S. Dudley, Ph.D., Center for Public Administration, Virginia Polytechnic Institute and State University.

Gary L. Wamsley, Ph.D., Center for Public Administration, Virginia Polytechnic Institute and State University.

Doris T. Zallen, Ph.D., Center for Programs in the Humanities, Virginia Polytechnic Institute and State University.

REFERENCES - Upon Request

$02 / 97$ 